\title{
The Enculturation of New Faculty in Higher Education: A Comparative Investigation of Three Academic Departments
}

\author{
Teryl Ann Rosch \\ Loyola University Chicago
}

Follow this and additional works at: https://ecommons.luc.edu/luc_diss

Part of the Education Commons

\section{Recommended Citation}

Rosch, Teryl Ann, "The Enculturation of New Faculty in Higher Education: A Comparative Investigation of Three Academic Departments" (1994). Dissertations. 3482.

https://ecommons.luc.edu/luc_diss/3482

This Dissertation is brought to you for free and open access by the Theses and Dissertations at Loyola eCommons. It has been accepted for inclusion in Dissertations by an authorized administrator of Loyola eCommons. For more information, please contact ecommons@luc.edu. (c) (i) $\Theta \Theta$

This work is licensed under a Creative Commons Attribution-Noncommercial-No Derivative Works 3.0 License. Copyright @ 1994 Teryl Ann Rosch 
LOYOLA UNIVERSITY OF CHICAGO

THE ENCULTURATION OF NEW FACULTY IN HIGHER EDUCATION:

A COMPARATIVE INVESTIGATION

OF THREE ACADEMIC DEPARTMENTS

\author{
A DISSERTATION SUBMITTED TO \\ THE FACULTY OF THE GRADUATE SCHOOL \\ IN CANDIDACY FOR THE DEGREE OF \\ DOCTOR OF PHILOSOPHY
}

DEPARTMENT OF EDUCATIONAL LEADERSHIP AND POLICY STUDIES

BY
TERYL ANN ROSCH

CHICAGO, ILLINOIS

MAY 1994 
Copyright by Teryl ann Rosch, 1994.

All rights reserved. 


\section{ACKNOWLEDGMENTS}

Five people are essentially responsible for gently prodding me to complete this dissertation when personal and professional obstacles made the task seem overwhelming.

Principally, the members of my dissertation committee served as socializing agents, shaping my educational thinking throughout my graduate studies. I am especially indebted to Dr. Jill Reich who, as an exemplary chairperson, offered scholarly insight whenever needed in guiding this study to completion; and who, as a friend, extended constant personal support. I am indebted also to Dr. Frank Catania who provided both the intellectual challenges of my graduate training, and the administrator-scholar characteristics that will guide my professional career. I thank also, my professor, Dr. Terry Williams, who is responsible for the underpinnings of my graduate education, and who provided the professorial model I hope to emulate in the years ahead.

My husband, Lee, was my partner in this endeavor. His continual encouragement gave me the stamina needed during difficult moments; his sense of humor lightened the load; and his editorial support allowed precious time to be devoted to the complex challenges of this task.

This dissertation could not have been completed without the understanding, support and kindness of Dr. George Olson, my professional colleague.

Finally, I am especially grateful to the new faculty who graciously permitted me to track the experiences of their first academic appointment year. In many ways, their personal accounts are the most meaningful aspect of this study. 


\section{TABLE OF CONTENTS}

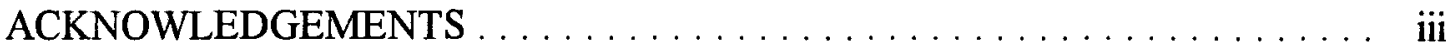

LIST OF ILLUSTRATIONS $\ldots \ldots \ldots \ldots \ldots \ldots \ldots \ldots \ldots \ldots \ldots \ldots$

LIST OF TABLES $\ldots \ldots \ldots \ldots \ldots \ldots \ldots \ldots \ldots \ldots \ldots \ldots \ldots$

Chapter

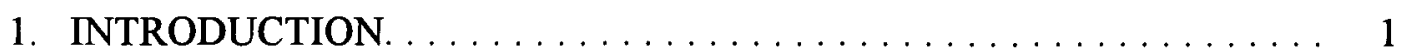

Purpose of the Study

The Conceptual Model

Significance of the Study

Organization of the Study

2. REVIEW OF THE LITERATURE $\ldots \ldots \ldots \ldots \ldots \ldots \ldots \ldots \ldots \ldots$

Institutional Culture

Subcultures

The Enculturation Model of Organizational Entry

Stage One: Pre-Arrival

Stage Two: Encounter

Stage Three: Adaptation

Stage Four: Commitment

Summary

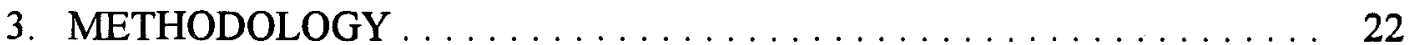

Research Design

Subjects 
Data Collection

Data Analysis

Summary

4. IDEATIONAL (CONTENT) DATA RESULTS $\ldots \ldots \ldots \ldots \ldots \ldots \ldots$

Introduction

Analysis of Ideational (Content) Data

Institutional Culture

Theme One: An Institution in Transition

Theme Two: Religious Traditions in an Increasingly Pluralistic Evironment

Theme Three: Shifting Role Expectations

Theme Four: The Changing Nature of the Department and Discipline

Departmental Subcultures

Perceptions Regarding the Environment and Faculty Morale

The Work Climate and Faculty Attitudes Toward Work

The Role Orientation of Current Group Members

Summary of Data Analysis

5. SOCIO-CULTURAL (PROCESS) DATA RESULTS

Introduction

Analysis of Socio-Cultural (Process) Data

Stage One: Pre-Arrival

Stage Two: Encounter 
Stage Three: Adaptation

Stage Four: Commitment

6. SUMMARY AND CONCLUSIONS

Context of the Study

Research Design

Data Collection

Data Analysis

Major Findings: Ideational (Content) Data

Major Findings: Socio-Cultural (Process) Data

Discussion and Interpretation of Findings

Stage One: Pre-arrival

Stage Two: Encounter

Stage Three: Adaptation

Stage Four: Commitment

Conclusions: The Enculturation Model

Limitations of the Study

Implications for Practice

Implications for Further Research

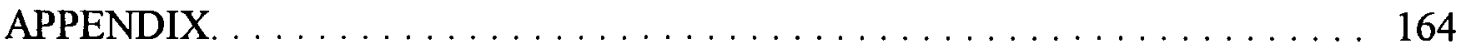

1. DEFINITION OF TERMS

2. CONSENT FORM FOR PARTICIPANTS

3. CURRENT FACULTY QUESTIONNAIRE 


\section{NEW FACULTY LOG FORMAT}

REFERENCES. . . . . . . . . . . . . . . . . . . . . . . 178

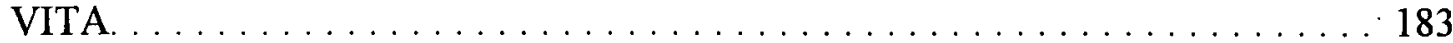




\section{LIST OF ILLUSTRATIONS}

$\begin{array}{ll}\text { Figure } & \text { Page }\end{array}$

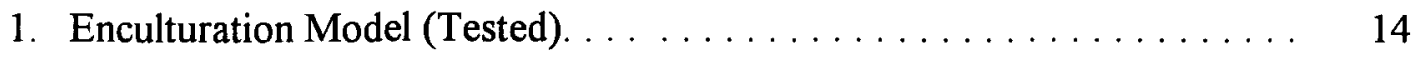

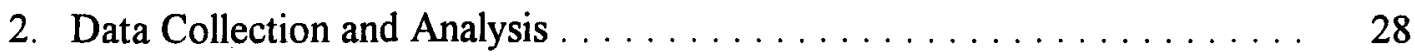

3. Theoretical and Process Dimensions of the Enculturation Model . . . . . . 147

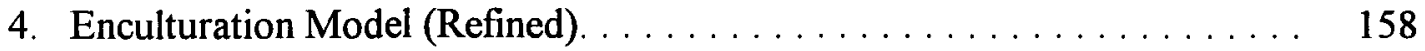




\section{LIST OF TABLES}

Table Page

1. Pressure to Perform Research $\ldots \ldots \ldots \ldots \ldots \ldots \ldots \ldots \ldots \ldots \ldots$

2. Pressure to Increase Research Performance . . . . . . . . . . . . . . . . . . . . . 42

3. Difficulty Balancing Teaching and Research . . . . . . . . . . . . . 44

4. Changes in the Institutional Work Environment . . . . . . . . . . . . . . . 49

5. Changes in the Department Work Environment. . . . . . . . . . . . . . . 49

6. Changes in Insitutional Faculty Morale $\ldots \ldots \ldots \ldots \ldots \ldots \ldots \ldots \ldots \ldots$

7. Changes in Departmental Faculty Morale . . . . . . . . . . . . . 51

8. Characteristic Ratings for Climate I / Social Isolation. . . . . . . . . 60

9. Characteristic Ratings for Climate II / Attitudes Toward Work . . . . . . . . . . . . . . . . . . . . . . . . . 62

10. Characteristic Ratings for Climate III / Attitudes Toward Performance. . . . . . . . . . . . . . . . . . . . . . . . . . 62

11. ACTUAL Hours Per Week / ALL TASKS . . . . . . . . . . . . . . 66

12. ACTUAL Percentage of Time TEACHING . . . . . . . . . . . . . 67

13. IDEAL Percentage of Time TEACHING . . . . . . . . . . . . . . . . . . . . 69

14. ACTUAL Percentage of Time RESEARCH. . . . . . . . . . . . . 71

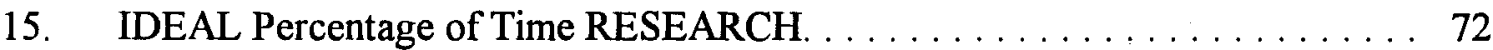

16. ACTUAL Percentage of Time DEPARTMENT ADMINISTRATION . . . . . . . . . . . . . . . . . . . . . . 73 
17. IDEAL Percentage of Time DEPARTMENT ADMINISTRATION.

18. ACTUAL Percentage Time UNIVERSITY ADMINISTRATION.

19. IDEAL Percentage Time UNIVERSITY ADMINISTRATION.

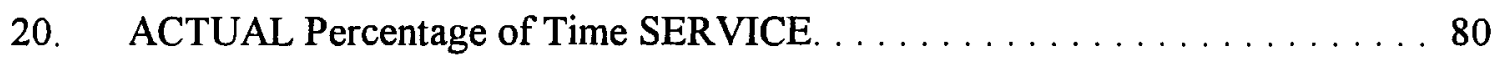

21. IDEAL Percentage of Time SERVICE $\ldots \ldots \ldots \ldots \ldots \ldots$

22. Comparison of Actual Time / Importance of All Tasks. . . . . . . . . . . 83

23. Comparison of the Importance of All Tasks /

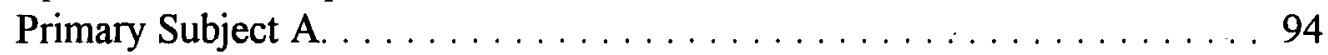

24. Comparison of the Importance of All Tasks / Primary Subject B. . . . . . . . . . . . . . . . . 95

25. Comparison of the Importance of All Tasks /

Primary Subject C. . . . . . . . . . . . . . . . . 95

26. \% of Current Faculty Rating Formalized Hiring Procedures / By Department. . . . . . . . . . . . . . . . . . . . . . . 100

27. $\%$ of Faculty Rating Formalized Orientation Procedures / By Department. 109 


\section{CHAPTER I}

\section{INTRODUCTION}

The professional identity, or role orientation, of faculty in higher education is assumed to be acquired during the period in which an individual studies for and receives a doctorate (Gotlieb, 1961). Studies focusing on training in graduate school use the term socialization to describe the process by which individuals acquire role orientation, or professional identity. The end product of successful professional socialization is seen to be the internalization of the norms of the profession into the individual's self-image or identity (Bragg, 1976). Thus, the traditional view of socialization in higher education has been that professional identity is acquired through extensive and intensive formal education during graduate school and that role orientation remains relatively stable over time (Cornwall \& Grimes, 1987).

Socialization may be conceptualized as such given a normative view that the transmission of values of the academic profession should occur during graduate training (Bragg, 1976) and with the internalization of particular values, professional identity will be to one academic profession. This normative view fails to address four major perspectives which can be found in studies of professional identity in higher education, in the sociological literature on organizational entry, and in recent research on faculty development. First, higher education studies offer conflicting viewpoints about professional identity. While some studies assert that professional identity is to a singular academic profession (Becher, 1987; Bowen \& Schuster, 1986; Freedman, 1979; Mix, 1971); others hold the view that because role orientation varies, professional identity also varies, and thus, several academic professions exist (Bess, 1982; Light, 1974; Ruscio, 1987). Of the classification systems which have been developed to study the academic 
profession (Becher, 1987; Biglan, 1973; Clark, 1963, 1980) only Clark's typology considers professional identity in terms of variations in faculty role orientation. Given the debate, it is surprising that relatively few studies compare professional identity by examining role orientation acquired during graduate training, within and among disciplines.

A second problem is that, while the literature on professional socialization of faculty does describe graduate training as an "anticipatory socialization" period (Freedman, 1979), few studies examine socialization beyond the prospective faculty stage. In considering socialization primarily as a transmission or "changing to" process, most studies have not examined the "changing from" process of leaving graduate school behind (Louis, 1980). Only recently have studies on faculty development traced how new faculty cope during the initial period of career entry (Baldwin \& Blackburn, 1981; Boice, 1991; Fink, 1984; Sorcinelli, 1985). These studies suggest that individuals continually adapt and are responsive to the socializing efforts of an organization. Based on a situational change perspective, an assumption could be made that role orientation, although influenced by training, is malleable and changes in response to organizational opportunities and pressures (Cornwell \& Grimes, 1987). Yet, in higher education, little attention has been paid to the process of continual adaptation. Continual adaptation or the degree to which professional identity is carried over, or adjusted, during the initial period of career entry should also be examined.

A third problem with the traditional view of socialization in higher education is that while the academic profession provides general identity for faculty, an individual's general value structure and the reciprocal nature of the socialization process have been largely ignored (Van Maanen, 1976). While studies on organizational entry have, for several decades, examined how individuals choose organizations and how organizations choose individuals (Lawler, 1973; Vroom, 1966; Wanous 1977), most have focused on 
the employee recruitment and selection processes primarily from the organization's standpoint. If individuals continue to be responsive to the socializing efforts of an organization, then the manner in which a newcomer moves from outside to inside the organization must be further considered -- from the individual's standpoint.

Finally, because there is little disagreement that the academic profession provides general identity for all faculty, the concept of one academic profession has obscured the cultural differences of higher education institutions, the subcultural variations within and among disciplines, and the internalized normative pressures to meet organizational interests which arise as faculty enter new settings. Just as internalized normative pressures will operate to move individuals to act in ways which meet organizational interests (Weiner, 1982), newcomers will also shape, to some degree, the institutional culture (Van Maanen \& Barley, 1985). Only recently has socialization been conceived as "cultural learning" in which the values, knowledge, attitudes, skills, and expectations of a particular culture are acquired by initiates (Corcoran \& Clark, 1984). At the same time, culture is seen to evolve as it is shaped by the interaction of newcomers and culture bearers (Kuh \& Whitt, 1988). While newcomers will integrate, to some extent, their own needs and values with what they perceive to be the institution's norms and values (Bess, 1978), the reciprocal nature of this "cultural learning" process is only now being recognized ( Boice \& Thomas, 1989; Tierney, 1988).

\section{Purpose of the Study}

The general purpose of this study is to examine the enculturation processes as new faculty become members of three separate academic departments within an institution of higher education. The study was undertaken to complement and extend research on organizational entry and socialization within the context of an academic setting. In order to fully examine each dimension, the study incorporated recent concepts of cultural learning to address the reciprocal nature of the processes that extend beyond initial entry. 
Implicit in the study is an analysis of the ways in which different academic disciplinary subcultures selected, socialized, and expressed institutional culture to new faculty, and the degree to which professional identity and role orientation were carried over, or adjusted, during the entry period. Initial questions raised to guide the purpose of the study included:

What professional identity and role orientation do newcomers bring into a new setting as a result of their anticipatory socialization experience?

To what extent does role orientation of new faculty vary, in comparison to current faculty, within and across disciplines?

Through what processes are newcomers able to detect, diagnose and interpret expectations of an institution and the work environment?

In what manner are cultural nuances transmitted to new members and to what extent are they adopted?

To what degree are professional values and role orientation adjusted as one is enculturated?

Within the context of these initial questions, the overall purpose of the study was to analyze the enculturation processes by which new faculty adjusted and responded to a particular academic institution and to various disciplinary subcultures within this university setting. This inductive study tested a four stage model of organizational entry as data were collected and analyzed.

\section{The Conceptual Model}

The conceptual model was drawn from theoretical constructs described in research on faculty development during organizational entry, from sociological studies on socialization and organizational commitment, and from sociological, anthropological and higher education literature on organizational culture.

The conceptual framework, or enculturation model, attempts to meet the criteria of theoretical integration, definitional precision, and predictive power required for useful 
theoretical models (Weiner, 1982).

To meet the criterion of theoretical integration, an inductive research approach was chosen to test theoretical propositions against critical process variables as new faculty became members of various disciplinary subcultures within an academic setting.

To meet the criterion of definitional precision, three dimensions of the reciprocal nature of culture in the socialization of new faculty need to be distinguished. These include: 1) socialization: the overt or deliberate, formal or informal, structure by which an individual comes to understand the values, abilities, expected behaviors, and social knowledge essential for assuming an organizational role and for appropriate participation as an organizational member; 2) enculturation: the reciprocal learning process by which the culture's normative-value system is diagnosed by new members and the dynamic response to that normative-value system; and 3) acculturation: the extent to which the norms and values of the local culture are assimilated by new organization members (acculturation). Other definitional constructs related to the study are presented in Appendix A.

Finally, to meet the criterion of predictive power, the model assumes that the conceptual framework will be similar across the disciplines in which the faculty entered. While the study traced the entry of three new faculty into one institution, one might also expect the findings to have applicability for new faculty as a whole. The model addresses the organizational entry period as a complex, continuous enculturation process.

\section{Significance of the Study}

Faculty development studies rarely speak of the first real transition in an academic career -- the move from being a graduate student to that of a professor. The skills and abilities needed to successfully depart from the graduate experience are significantly different than those required for the march toward tenure (Lincoln, 1986). How do faculty adapt to a new learning environment, what strategies do they adopt to cope with this 
transition, and how does the new learning environment differ from the environment to which they were accustomed?

Each institution has an organizational culture that establishes the social reality to which those entering must adjust. During this adjustment period, it has been suggested that faculty select or attend to information on the norms or expectations of the organization, process this information, and based on their own past experiences and accomplishments attach meaning to the information accumulated (Braskamp, Fowler \& Ory, 1984). Aside from the subtle disciplinary cultural differences in each setting, faculty have different concerns at each phase of their career and may vary in their career development depending upon the type of institution they have joined (Smart, 1978). Yet, in the search for generalizations, research has too often glossed over socialization process differences, and as a result, may have missed the most revealing and relevant data: new members' personal points of view about the experiences encountered. Subtle differences abound because innumerable faculty subcultures are arrayed across different disciplines and types of institutions. So, also, new faculty in different disciplines, at the same institution, tend to enact their roles in different ways. What might account for this intrainstitutional diversity? While available evidence is meager, the literature does suggest that both selection and professional socialization factors are at work and that broad generalizations about faculty as a group "may be neither intellectually defensible nor operationally useful" (Finklestein, 1984, p. 226).

The present study complements sociological literature on socialization, and extends recent research on faculty development during organizational entry. The study also incorporates recent concepts of cultural learning to address the reciprocal nature of the processes that extend beyond the initial entry and socialization stages of an academic career. Lacking a strong theoretical foundation, research in these areas has been fragmented. Thus, the study employed and investigated the explanatory power of a 
conceptual model by which the enculturation of new faculty to various disciplines could be described.

The manner in which an organization recruits, selects, socializes, places, develops, and evaluates faculty strongly reflects its culture. Often the initial entry experiences of new faculty are negative rather than positive (Boice, 1992). To prevent a negative outcome, strategies which effectively address the needs of academic professionals during career entry should be considered, given that the quality of higher education is inextricably linked to the productivity and commitment of faculty.

\section{Organization of the Study}

Chapter II contains a review of the related literature and an overview of the conceptual framework adopted from studies on organizational entry, socialization and organizational culture. The conceptual model provides a systematic framework by which aspects of organizational entry (anticipatory socialization, socialization, enculturation and acculturation) can be examined.

Chapter III provides a description of the procedures and instruments used in the collection of quantitative and qualitative data.

The analysis and presentation of qualitative and quantitative data describing institutional ideology, academic subcultures and role orientation of current group members in the three subcultures studied are the foci of Chapter IV.

Chapter $\mathrm{V}$ presents qualitative and quantitative data describing new members' affective reaction to experiences in the new setting and socialization structure, and analyzes the reciprocal learning (enculturation) process.

A summary of the dynamic response to the normative-value system, and a discussion of the findings (the extent to which professional values were carried over, or adjusted, by new members studied) is presented in Chapter VI. Recommendations for further study and refinement of the conceptual model are also addressed. 


\section{CHAPTER II}

\section{REVIEW OF THE LITERATURE}

This chapter presents a review of the literature as it relates to institutional culture and academic subcultures to provide a basis for understanding the organizational entry process. Following the review of the literature related to culture, a survey of the literature is presented from which theoretical constructs were drawn to formulate the conceptual, enculturation model used in the study.

\section{Institutional Culture}

Only recently has socialization been conceived as "cultural learning" in which the values, knowledge, attitudes, skills, and expectations of a particular culture are acquired by initiates (Corcoran \& Clark, 1984). In order to examine the reciprocal learning process by which the culture's normative-value system is diagnosed by new members and their dynamic response to that normative-value system (enculturation), it is important first to understand institutional culture.

The concept of institutional culture has been described by various authors who provide a number of perspectives from which institutional culture can be defined (Clark, 1975; Gamst \& Norbeck, 1976; Louis, 1980; Masland, 1985; Tierney, 1987). These divergent perspectives can be organized into either ideational or the socio-cultural schools of thought. The ideational school (e.g., Goodenough, 1971) proposes that culture is located in the minds of the culture bearers, while the socio-cultural school (e.g., Geertz, 1973) describes culture as the product of shared meanings and symbols. While there are well-demarcated schools of thought, the critical issue in studying culture seems to be that 
the researcher adopt a particular definition that takes into consideration, or incorporates, common constructs related to culture. This study will adopt a mediating approach to the ideational and socio-cultural system views by defining institutional culture as norms, values, practices, beliefs, and assumptions rooted partially in history, which guide the behavior of individuals and groups and are continually reshaped as organizational members learn to cope with problems of external adaptation or the internal integration of collective understandings.

The strength of such a definition is that it is a multi-dimensional concept of culture encompassing both the ideational and socio-cultural systems and it explicitly acknowledges the influence culture has on the behavior of faculty (Kuh \& Whitt, 1988). The assumption is that "organizational members develop interpretations about the nature of the organization's culture based on historical institutional traditions, current situational contexts, and individual perceptions" (Tierney, 1987, p. 63). What is meant, then, by a mediating approach is that both the observed acts within the context of the institution's social system (socio-cultural) and culture as it is interpreted by culture bearers (ideational) will be described. By comparing the perspectives of current institutional members and new faculty, the assumptions, understandings, and meanings shared by group members, as well as the manner in which institutional culture is transmitted, should surface.

A final point regarding institutional culture must be made. Most research on culture assumes that cultural properties detected in an environment are usually the determining forces in the development of a unitary (institutional) culture. Research focusing on unitary (institutional) culture regards the overall organization as a setting that fosters the development of local shared meaning. The concept of institutions as "culture bearing milieux" (Louis, 1980) was derived from studies of this nature. In studies on unitary culture, culture is seen to evolve when all members of an organization face roughly the same problems, and when they adopt a common set of understandings for enacting 
proper and consensually approved behavior (Van Maanen \& Barley, 1985). Yet, by viewing institutions as unitary cultures, the variations or patterns of subcultures within the institution are ignored. "Frequently investigators will fail to account for the existence of subcultures or neglect to explain how subcultures relate to the concept of 'a culture' for the entire organization" (Hossler, et.al., 1988, p. 64). This is especially symptomatic in higher education where the variations or patterns of disciplinary subcultures within an academic setting are often ignored.

Central to this study, then, is an analysis of the ways in which different academic disciplinary subcultures select and transmit organizational culture to new faculty, and the degree to which professional values and prior experience are carried over, or adjusted, during the entry period. To support such analysis it is important to understand the concept of sub-culture.

\section{Subcultures}

By focusing on subcultures as units for analysis, this study recognizes cultural multiplicity. The concept of multiplicity suggests that culture is "always evolving, continually created and recreated by ongoing patterns of interactions between individuals and groups" (Kuh \& Whitt, 1988, p.12). While both institutional and disciplinary subcultures have been perceived as objective reality deeply seated in the unconscious processes of individuals and groups, the assimilation of initiates is seen to be facilitated primarily by work group cultures (Berger \& Luckmann, 1966). That is, while institutional culture may reduce ambiguity and facilitate social interaction, an understanding of the entry experience of newcomers would be incomplete without analyzing the subculture an individual has joined.

The notion of subcultures is predominately sociological, drawing from research into behavior systems. A behavior system includes the following characteristics: 1) a group of specialists recognized by society, as well as by themselves, as possessing an 
identifiable complex of common culture values, communication devices, techniques, and appropriate behavior patterns; (2) the acquisition by initiates of a body of esoteric knowledge and appropriate behavior patterns before the novices are accepted by the initiated; and (3) appropriate sanctions applied by the membership to control members in their relations with one another and with the larger society (Arnold, 1970, p. 22). While the concept of subculture evolved from research into behavior systems, three additional perspectives on the study of subculture can be noted as applied to higher education.

First, subcultures have been defined as a subset of an organization's members who interact regularly with one another, identify themselves as a distinct group within the organization, share a set of problems commonly defined to be the problems of all, and routinely take action on the basis of collective understandings unique to the group" (Van Maanen \& Barley, 1985, p.38). By this definition, research should seek to explore the multiplicity of subcultures which may arise through sustained interaction with others who share similar problems. So, too, individuals can participate simultaneously in several subcultures and the degree of participation in each subculture can vary. This variation can occur with time, intensity, and extensiveness. For example, a person may manifest a high level of affiliation toward one subculture, but a much lower level toward another to which she/he also belongs (Shibutani, 1961).

Second, in the academic organization, subcultures are often defined by variations in intellectual tasks that link faculty among disciplines. Becher (1987) and Light (1974) subscribe to the notion of discipline-based subcultures. In stating that "scholarly activities center on each discipline" (cited in Becher, 1987, p.272), Light suggests that faculty are more likely to have commonalities with individuals in their own discipline than with other faculty at their institution. In addition, in order for groups to be considered subcultures, persistent interactions or the means for socialization/social control should be evident (Van Maanen \& Barley, 1985). Given that patterns of interactions and social control can extend 
into the larger institutional context, even if one subscribes to the notion of discipline-based subcultures, there is value in simultaneously analyzing institutional culture. That is, while the pervasiveness of the unitary institutional culture concept is tempered by focusing on the array of disciplines which permeate the academic organization, subcultures must be examined in the context of the institution in which they reside (Tierney, 1987). Tierney proposes an alternative approach to research on culture by suggesting that what takes place within a discipline is a discourse constituted by both the discipline and other aspects of the institution. Thus, "even in institutions where clearly delineated institutional culture is not apparent, the strength of what the institutional mission says, or does not say, helps define the parameters for action and discourse within each discipline" (Tierney, 1987, p. 16).

Finally, while there are few means agreed upon for operationalizing common constructs related to culture or subcultures, by examining subcultures in relation to the institutional culture, the pervasiveness, homogeneity, and stability of shared meaning between academic departments studied can be compared and the uniqueness of the discipline can be maintained. To support such analysis it is important that a framework be employed which permits comparison of findings across studies.

\section{The Enculturation Model of Organizational Entry}

While career stages conceptualized by faculty development and occupational theorists (Baldwin \& Blackburn, 1981; Boice, 1991; and Braskamp, Fowler \& Ory, 1984) generally include an initial entry period as the primary career establishment stage, studies of new faculty experiences during this entry period are limited. Thus, this study focuses less on the publicly inspectable, and often studied, aspects of career development and more on the "invisible transition" suggested by Lincoln (1986) -- one that is intensely individual and marked with significant change. 
Theoretical constructs described in research on faculty development during organization entry and from sociological studies on socialization and organizational commitment are presented in four stages related to the conceptual model presented in Figure 1.

A review of the literature, relevant to an analysis of organizational entry, is organized into the four-stage sequence of the model. These are: (1) the pre-arrival stage, dealing primarily with an individual's predispositions prior to entering a new setting; (2) the encounter stage, dealing with an individual's preconceptions formed during recruitment and selection; (3) the adaptation stage, dealing with the external socialization processes and the initiate's identification with the organization; and (4) the commitment stage, dealing with the extent to which the norms and values of the local culture are assimilated by new organization members.

\section{Stage One: Pre-Arrival}

What professional identity and role orientation do newcomers bring into a new setting as a result of their anticipatory socialization experience?

To what extent does role orientation of new faculty vary within and across disciplines?

The first stage of the model considers the predisposition of individuals prior to organizational entry. An individual's predisposition includes the professional identity and role orientation acquired during graduate training. The higher education view of professional socialization is that professional identity is acquired through extensive and intensive formal education and that, once acquired, role orientation remains relatively stable over time (Cornwall \& Grimes, 1987). In higher education, professionals are seen to subscribe to "the absolute value of a rationalized set of norms" to which they have been socialized during their educational training (Satow, 1975, p. 235). This suggests that while professionals may be socialized to new roles, in new settings, they bring with them a 


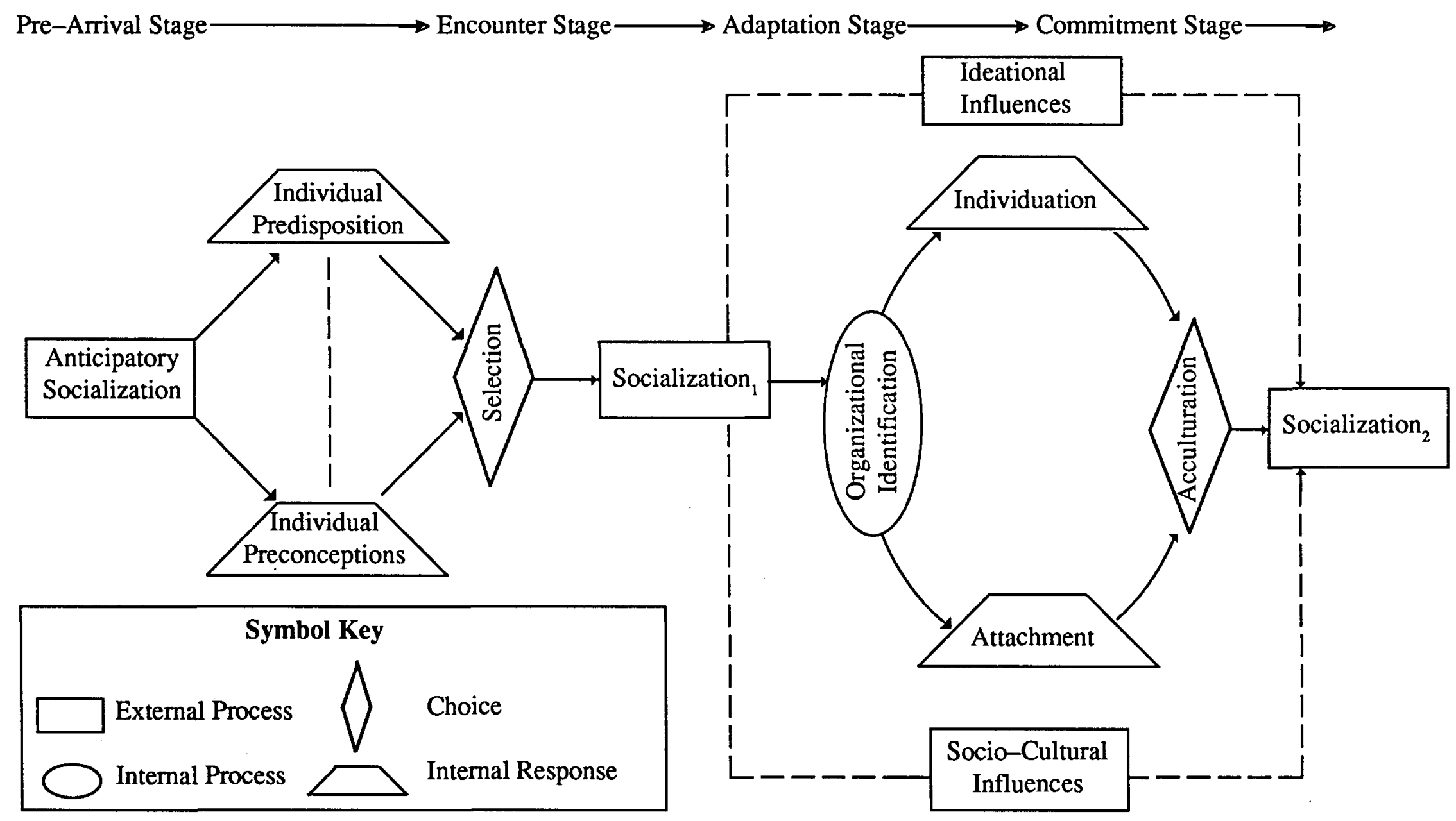

Figure 1: Enculturation Model (Tested) 
particular reality in which they expect to function. In the model, the pre-arrival stage considers the professional identity and role orientation newcomers bring into a new setting as a result of their anticipatory socialization experience.

The professional identity perspective flows from the concept that academics make up a "single homogeneous" group (Becher, 1987). While there is little disagreement that the academic profession provides general identity for all faculty, this perspective can obscure the subcultural differences that exist in terms of disciplinary affiliation. That is, while the academic profession provides general identity for all faculty, an individual's underlying motivation and general value structure also contribute to the underlying development of professional identity (Van Maanen, 1976). So, too, variations in role orientation or professional identity, by discipline, have not been fully examined (Van Maanen, 1976).

Clark's typology of disciplinary culture $(1963,1980)$ can be used to describe a faculty member's role orientation to the discipline. In his typology, Clark identifies three dimensions of faculty orientation: local-cosmopolitan (orientation to the institution and to the discipline); pure-applied (orientation to the use of knowledge); and humanisticscientific (commitment to personal interpretation or public verification of knowledge). It has been suggested that four groups of faculty members are produced from these dimensions: the teacher (high identification to institution/high commitment to pure study); the scholar-researcher (low identification to institutional/high commitment to pure study); the demonstrator (high identification with institution/low commitment to pure study); and the consultant (low identification to institution/low commitment to pure study) (Clark, 1963). Differences in professional identity or the role orientation a newcomer brings into a new setting, as a result of his/her anticipatory socialization experience, can be described according to Clark's typology. The extent to which an individual's role orientation varies within and across disciplines upon entry, and the degree to which professional values are 
adjusted as one is enculturated within a new setting, can also be compared. For example, if professional values or role orientation change over time, research should consider if professional identity were actually acquired during graduate training, and if acquired, whether a re-socialization process has occurred.

Thus, while the enculturation model presented incorporates the theoretical proposition that values acquired during "anticipatory socialization" provide a perspective for interpreting the experiences encountered in a new setting (Freedman, 1979), it also draws attention to the likelihood of re-socialization; the notion that an individual is responsive to the socializing efforts of an organization.

\section{Stage Two: Encounter}

\section{Through what processes are newcomers able to detect, diagnose and interpret expectations of an institution and the work environment?}

The encounter stage of the model highlights how individual predispositions intermingle with the ideas and goals a faculty candidate has formulated as a result of the recruitment and selection process. During the hiring process, candidates "select or attend to information in the form of norms or expectations, process this information, and attach meaning to it using their past experience and accomplishments as a frame of reference" (Braskamp, Fowler \& Ory, 1984, p. 210). The subtle differences in the move from being a "dependent and vaguely precarious graduate student to being a relatively independent and more secure professional" (Lincoln, 1986) are also considered. During organizational entry, as individuals are faced with new value commitments, they begin to reappraise existing disposition structures and question whether the mere transportation of skills and abilities learned in graduate school will be sufficient for successful transition (Braskamp, Fowler, \& Ory, 1984).

This period of questioning and reappraisal culminates when newcomers have 
formulated a set of individual preconceptions regarding the reality in which they expect to function. In this perspective, a transitional learning process has already begun which can either support or confuse individuals in their new role as faculty members (Louis, 1980). Just as any person entering unfamiliar settings will look for cues about how to proceed (Van Maanen, 1978), cognitive scripts may be formed to support transitional learning. Cognitive scripts have been defined as "a coherent sequence of events expected by individuals" (Abelson, 1967, p. 37). Such expectations support, or come in contrast with, the experiences which later unfold in the new setting. So, also, as they are selected to become part of the community, they cannot stay independent of their cognitive scripts, but rather, they are forced to adapt. Regardless of previous socialization experiences, as individuals enter new organizations, they are in effect resocialized to the various roles of the academic profession (Glazer \& Strauss, 1971).

\section{Stage Three: Adaptation}

\section{In what manner are cultural nuances transmitted to new members and to what extent are they adopted?}

Given that the transmission and internalization of values of the academic profession are believed to occur during graduate training, little attention has been paid to the process of continual adaptation; the notion that an individual will also be responsive to the socializing efforts of an organization. While the sociological literature on socialization focuses extensively on the adaptation process (Becker, 1964; Brim, 1966; Louis, 1980; Moore, 1969; Van Maanen, 1976, 1978), the literature on the socialization of academic professionals neglects adaptation beyond the prospective faculty stage (Bess, 1978; Bragg, 1976; Gotlieb, 1961). Socialization has been described as the process by which an individual comes to understand the values, attitudes, and social knowledge essential for assuming an organizational role and for participating as an organization member (Bragg, 
1976; Brim, 1966). There are four important and distinct elements that this definition of socialization does not delineate.

First, a process of continual adaptation occurs as new faculty enter into an organizational setting. For example, while a graduate student may become accustomed to being assessed, rewarded, or penalized by external evaluation in a highly individualized learning environment, as a new faculty member, one must quickly learn to apply selfevaluative strategies as external approbation or disapproval are perceived (Browns, Collins, \& Duguid, 1989). The subtle differences between graduate school and the workplace setting must be considered if one is to understand how an individual adapts during organizational entry. Generally, a variety of adaptation, defense, or denial mechanisms may be triggered as prior experiences are recalled and as contrasts are generated. As individuals adjust to new situations, cognitive elements which accompany transitional learning can be affected by emotional aspects of the process. That is, during socialization, as contrasts are generated, newcomers may experience a sense of disorientation or foreignness, and a kind of sensory overload described by Hughes (1958) as "reality shock". In this perspective, socialization as an adaptive process can either support or confuse the individual learning a new role (Louis, 1980).

The second element that this definition neglects is that socialization is a learning process. As such, socialization must include formal or planned, non-formal or opportunistic, and informal or accidental learning opportunities (Honey \& Mumford, 1989; Simpkins, 1977). Formal or planned learning during socialization would include orientation programs, formal meetings with department chairpersons or other faculty, opportunities to present one's research or to hear colleague presentations, or visits to the classroom of new faculty. Non-formal, or opportunistic, learning would include those occasions where new faculty either work alongside or under the tutelage of a more experienced faculty member, or seek specific information as needed. Finally, there is the 
varied, informal, or accidental occasions for learning, including: conversations with colleagues; reading departmental publications, reports, or institutional newsletters; and sharing research ideas with those inside or external to the organization.

Third, because sociological literature conceives of socialization primarily as a transmission process, i.e., how an initiate's behavior is shaped to a particular group, the reciprocal nature of the process has been largely ignored. Yet, socialization is a social process; it does not occur in a vacuum (Bragg, 1976). As a social process, reciprocity can be considered at two levels. At the first level, different relationships play a critical role in providing various cues to newcomers about how to proceed. Thus, colleagues, superiors, subordinates, clients, and other work associates can, and most often do, affect the individual who is adapting. These relationships cause an individual to interpret, or misinterpret the events experienced, and to formulate appropriate, or inappropriate, actions to be taken. Yet, to date, only the overt structures supporting such relationships have been a traditional focus of studies on socialization.

Finally, while overt structures deal with deliberate, formal or informal actions orienting new members, enculturated factors can also play a part in socialization. Only recently has socialization been conceived as "cultural learning" in which the values, knowledge, attitudes, skills, and expectations of a particular culture are acquired by initiates (Corcoran \& Clark, 1984). Enculturated factors (norms and values of the local culture) might include organizational philosophy, or distinct values permeating the organization (Enz, 1986, p.7); climate, or work setting perceptions (Enz, 1986, p. 3); and social contracts, an implicit set of shared assumptions that constitute the particular work setting (Wilkins, 1983). When newcomers are assimilating these important assumptions, or norms governing membership, values, activities and aims of the organization they are, in part, learning culture (Gamst $\&$ Norbeck, 1976). If socialization, beyond the prospective faculty stage is a cultural learning process, then how newcomers are able to detect, 
diagnose, and interpret the cultural features of an institution are important considerations in research on professionals who are beyond the anticipatory socialization stage.

\section{Stage Four: Commitment}

To what degree are professional identity and role orientation adjusted as one is enculturated?

The last stage of the model considers how an individual's level of commitment to the organization is influenced by both personal predispositions and organizational interventions. Organizational commitment can be defined as the affective attachment to the goals and values of an organization, to one's role in relation to these goals and values, and to the relative strength of an individual's identification with and involvement in the organization (Mowady, Porter, \& Steers, 1982). An understanding of organizational goals and values coupled with the level of integration of organizational goals with personal goals and values is viewed by researchers as organizational identification (Hall \& Schneider, 1972; Lee, 1971). Organizational identification is seen to be affected by practices of selection and socialization. The notion that selection is a helpful determinant in level of organizational identification suggests that some people are more likely to develop commitment to an organization than other people and that the assessment of values and beliefs should be a part of the recruitment process. With an inappropriate personorganization fit, it would also be logical to assume that socialization efforts would need to be directed not only to the installation of beliefs, but to the eradication of conflicting values. While job satisfaction could help to accomplish a shift in a person's professional identity, or role orientation, the change would be very difficult to accomplish in noncoercive organizations. Thus, the enculturation model assumes that varying levels of identification will occur.

Finally, the model considers two response levels to the re-socialization process: individuation and attachment. These are organizational identification levels which 
represent the dynamic (enculturation) response to socialization efforts. Individuation and attachment can be defined as affective and developmental responses to the goals and values of an organization, and to one's role in relation to these goals and values. When individuation occurs, an individual's response is aimed at questioning the organization's attempt to alter self-image, or work role identification. When attachment occurs, an individual's efforts are focused on acquiring new self-images, or roles. While both responses address the relative strength of an individual's identification with and involvement in the organization, when individuation occurs, an individual may also contribute, to some degree, in shaping new aspects of the institutional culture (Van Maanen \& Barley, 1985).

\section{Summary}

This chapter briefly reviewed sociological, anthropological and higher education literature on institutional culture and academic subcultures. This literature provides a basis for understanding organizational entry as an enculturation process. Theoretical constructs described in research on faculty development during organization entry and from sociological studies on socialization and organizational commitment were presented in four stages related to the conceptual model in Figure 1.

In summary, the stages relevant to an analysis of organizational entry include prearrival, encounter, adaptation, and commitment. This sequential framework will be used to describe and test the enculturation model as new faculty become members of three separate academic departments within an institution of higher education. 


\section{CHAPTER III \\ METHODOLOGY}

\section{Research Design}

In order to describe the enculturation processes as new faculty became members of three separate academic departments within an institution of higher education, a holisticinductive research design was selected. This approach was selected for two reasons: first, inductive, rather than deductive, analysis is more likely to accurately represent the multiple realities that are found in the data collected (Lincoln \& Guba, 1985); and, second, a holistic-inductive design allowed the researcher to test theoretical propositions against critical process variables as the study progressed.

The study began by developing a conceptual model to specify process components related to organizational entry. The conceptual model was drawn from theoretical constructs described in research on faculty development during organizational entry, and from sociological studies on socialization and organizational commitment. Organizational entry process components were defined to include: 1) the overt or deliberate, formal or informal, structure by which new faculty came to understand the values, abilities, expected behaviors, and social knowledge essential for assuming an organizational role and for appropriate participation as an organizational member (socialization); 2) the reciprocal learning process by which the culture's normative-value system was diagnosed by new members and the dynamic response to that normative-value system (enculturation); and 3) the extent to which the norms and values of the local culture were assimilated by new organization members (acculturation). 
These process dimensions were further delineated within four sequential stages of organizational entry: pre-arrival, encounter, adaptation, and commitment. The primary theoretical propositions within each stage of the model included:

$\square$ during the pre-arrival stage, the values acquired during graduate training provide a perspective for interpreting experiences which are encountered in the new setting;

$\square$ during the encounter stage, as individuals are faced with new value commitments, existing disposition structures are questioned and a coherent sequence of expected events are formulated to support transitional learning;

$\square$ during the adaptation stage, a variety of adaptation, defense, or denial mechanisms are triggered as prior experiences are recalled, and as contrasts are generated, a "cultural learning" process begins; and

$\square$ during the commitment stage, the dynamic (enculturation) response to socialization efforts occurs.

The research design utilized both quantitative and qualitative techniques to test the explanatory power of this conceptual model. First, quantitative techniques were employed to gather initial data to explain the "cultural web of meaning of the organization" (Tierney, 1988)--specifically, the institutional ideology of the organization and its members, the degree of similarity or differences of institutional ideology between subcultures, and the role orientation of current group members in each subculture.

Second, given that the study focused upon new members and how they were affected by the social stimuli and work environment of the academic department they joined -- i.e., the study did not focus on current faculty members in departments -qualitative methods were also employed to capture the new members' personal points of view about the experiences encountered. 
Using the constant comparative method of naturalistic inquiry first documented by Glaser and Strauss (1967) and later extended by Lincoln and Guba (1985), such simultaneous data collection and analysis permitted the model of the enculturation of new faculty to be inductively generated, to be tested as data were collected, and to be refined accordingly .

\section{Subjects}

In order to describe the reciprocal nature of culture in the socialization of new faculty, two sets of subjects participated in the study: those termed secondary subjects (culture-bearers/current faculty) and those termed primary subjects (new faculty initiates). All secondary subjects were either institutional administrators or faculty within three academic departments of a Doctoral Granting I institution (Carnegie Classification, 1990). Three academic departments, out of seven involved in the process of recruiting and selecting new faculty for the upcoming academic year, were invited to participate. The three departments were selected because the individuals hired were assuming their first full-time, tenure track position (this was not the case for the remaining four departments). Two of the participating academic departments represented disciplines within the Humanities and one represented a discipline within the Social Sciences.

The three newly hired faculty members, one from each department, agreed to serve as primary subjects. These faculty were provided a statement about the research purposes, confidentiality provisions, and the voluntary nature of the study. Written consent was obtained prior to tracking individual experiences (Appendix B). No penalty was associated with refusal to participate and individuals were free to withdraw their participation at any point during the study. The potential vulnerability of tracking individual faculty as they assimilated to a new position was recognized. Thus, neither the institution, nor the names of faculty participants, have been identified in any reports of this study -- the names of the primary and secondary subjects who participated are known only 
to the investigator. Uncoded transcript material was not shared with the department or institution.

\section{Data Collection}

In order to analyze the factors involved in the enculturation of new faculty, a survey originally developed by DeVries (1970) was adopted and initially employed to explore the institutional ideology of the organization and its members, the degree of similarity or differences of institutional ideology among subcultures, and the role orientation of current group members in each subculture (Appendix B).

Prior to the first primary subject interviews, the survey was distributed to all current faculty of the three study departments. During their first week in the department, primary subjects were also asked to complete the survey in order to analyze anticipatory socialization experiences. Survey questions were organized into items relating to the role orientation of current members, those relating to the climate and to changes in this work environment, and those relating to formal department procedures. Questions concerning the role orientation of current members ranged from items rating the relative importance of various academic tasks, to those estimating the amount of time spent working on these tasks. Questions concerning the institution and work climate, as well as formal procedures within each department, were also included.

Since the study focused upon the manner in which cultural nuances were transmitted to new members and the extent to which they were adopted, qualitative methods were employed to capture the personal experiences of primary subjects. Because these experiences are best described from both an etic (observer) and an emic (personal) point of view, a log format was employed to gather ongoing personal perceptions of the primary subjects during the entry period. Other qualitative methods used in this study included the three basic techniques developed to explore culture (Masland, 1985): document analysis, observations, and interviews. 
Document analysis consisted of a review of archival department materials. Such analysis provided the formal view, or consensually agreed upon context, within which the institution and departments operated. Documents examined included college catalogues, the mission statement of the institution, annual reports, self studies for accreditation, and minutes of departmental meetings. Documents analyzed were similar for each department studied.

Observation encompassed a wide range of department activities including a subset of job interviews of all candidates in the three departments studied, formal and informal events, and departmental meetings. The objective of collecting observational data was to discern the social reality in which organizational members operated. By assessing the interaction of members in the work environment, the researcher was able to compare observational data to survey data as the study progressed.

A variety of interviews (structured and open-ended) were used throughout the study to gather new information and to confirm observations. With the individual's prior permission, all interviews were taped in order to verify the researcher's written notes. Interviews ranged from forty-five to seventy-five minutes each. For chairpersons and university administrators, topics included questions about formal structures, strategies, policies and management processes; the formal goals, objectives, authority, control mechanisms of the organization; and the process of recruitment, selection and formal socialization processes for new faculty.

Over a twelve month entry period, one interview per month was conducted with each primary subject. Although the first two interviews were structured, as the new academic year began and the opportunity for observations unfolded, open-ended interviews more often occurred.

Finally, a log format was employed to provide a written structure for primary subjects to record their affective and cognitive reactions to perceived, important elements 
of their socialization. Primary subjects were asked to concentrate on recording those experiences which met general expectations about personal-institution fit; those experiences which met general expectations about department operations; those experiences which did not meet their expectations; and those experiences which they had not expected to encounter (Appendix C). Although the log format was not intended as a daily journal, the primary subjects tended to record events daily, while extended comments regarding cognitive and affective reactions to particular experiences appeared sporadically.

\section{Data Analysis}

Data collected were initially categorized according to either content or process dimensions of the enculturation model, and then analyzed in accordance with the four proposed sequential stages of organizational entry. Figure 2 illustrates the manner in which sources and types of data were structured to support the underlying questions investigated in each stage of the study. To delineate content (cultural) from process (enculturation) dimensions of the study, the following distinction was made:

content areas relate to the institutional ideology of the organization and its members. Content areas provide the basis for analyzing the degree of similarity or differences of institutional ideology between subcultures and the role orientation of current, compared to incoming, members of the subculture; and

$\square$ process areas relate to the manner in which the academic subcultures selected and transmitted culture to new faculty. Process areas provide the basis for analyzing the degree to which professional values and role orientation of new faculty were adjusted during the entry period.

Through comparative analysis of the content (cultural) data collected from secondary and primary subjects, the researcher was able to examine two of the original questions underlying the study: what professional identity and role orientation do 


\section{Data Category:}

CONTENT/IDEATIONAL

Source of Data: Secondary Subjects

Data Type: $\quad$ Interviews \&

Document Analysis

Survey

Stages:

Pre-Arrival

Underlying

Questions:

\section{What are the assumptions, \\ understandings and meanin} shared by group members?

What is the role orientation of current organization members?
Primary Subjects

Initial Interviews

Survey Comparison

Monthly Interviews

Observations

Encounter

Primary Subjects

Primary Subjects

Primary Subjects

Monthly Interviews Final Interview

Personal Logs

Observations

Adaptation

What anticipatory socialization experiences does the newcomer bring into the new setting?

\section{What role orientation do newcomers bring to the organization? (predisposition)}

\section{Commitment}

\section{What learning opportunities are} provided?

What relationships are formed?

As prior experiences

are recalled \& contrasts are generated a cultural learning process begins.
Are new roles acquired? (attachment)

Are new roles questioned? (individuation)

\author{
Existing disposition \\ structures are questioned \\ \& cognitive scripts \\ are formed.
}

The dynamic (enculturation)

response occurs.

Figure 2: Data Collection and Analysis 
newcomers bring into a new setting; and to what extent does role orientation of new faculty vary, in comparison to current faculty, within and across disciplines?

By employing both quantitative and qualitative techniques in the initial data collection stage, culture was examined from both the ideational (content) and the sociocultural (process) perspectives. Because the ideational school proposes that culture is located in the minds of culture bearers, content data were collected via a survey administered to current faculty and later analyzed in comparison to interview data collected from a subset of the same faculty.

In order to address the socio-cultural dimension i.e., the shared meanings within subcultures, the researcher focused on new organization members as they learned, adapted and integrated collective understandings. By analyzing data collected from the personal logs and interviews of primary subjects, the dynamic enculturation process eventually surfaced. Process questions underlying this portion of the study included: through what process are newcomers able to detect, diagnose and interpret expectations of an institution and the work environment; in what manner are cultural nuances transmitted to new members and to what extent are they adopted; and to what degree are professional values and role orientation adjusted as one is enculturated?

When all interviews were transcribed, initial notations were made in the margins to distinguish data related to content elements from data related to process aspects of the study. After all transcripts were coded, using the constant comparative method, content interview data was compared to survey results and process interview data was compared to primary subject logs. Next, data were categorized data according to the questions within the larger content and process framework. As the analysis of data became more select and focused, if incidents did not add new information to the content or process categories, they were no longer considered.

Finally, as data were scrutinized according to these questions, theoretical 
properties of the content and process dimensions began to emerge and the enculturation model was refined accordingly.

\section{Summary}

In summary, a holistic-inductive research design was selected to describe the enculturation process of new faculty as they became members of three separate academic departments within an institution of higher education.

Data were collected from both culture-bearers/current faculty, those termed secondary subjects, and new faculty initiates, those termed primary subjects, in order to describe the reciprocal nature of the enculturation process.

The research design included both quantitative and qualitative techniques and data collected were categorized according to either content or process dimensions of organizational entry. Figure 2 illustrates the constant comparative method by which sources and types of data were analyzed to investigate the underlying questions of the study.

The analyses of content (ideological) data are presented in Chapter IV; and analyses of process (socio-cultural) data are presented in Chapter V. 


\section{CHAPTER IV}

\section{IDEATIONAL (CONTENT) DATA RESULTS}

\section{Introduction}

Two sets of subjects participated in the study: culture bearers/current faculty, those termed secondary subjects and new faculty initiates, those termed primary subjects. This chapter summarizes the results of the data analyses for secondary subjects. The chapter is divided into four sections: an overview of the categorization and analysis of ideational (content) data; an analysis of data measuring institutional culture; an analysis of data measuring academic subcultures; and an analysis of data measuring the role orientation of current members. Following the analyses of data sections, a summary of overall findings is presented.

\section{Analysis of Ideational (Content) Data}

To understand the culture of the institution, and of the three participating academic departments, secondary subject data were analyzed to describe the ideational realm of the organization and its members. Specifically, an analysis of interview and survey data determined the degree of similarity and differences of institutional ideology and of the role orientation of current group members within and among subcultures; document analysis shed light on the formal view, or context, within which the departments were expected to operate; and observational data helped the researcher to discern the social reality in which organizational members actually operated.

In this chapter, the culture of the organization and the subcultures of the three participating departments are examined from the ideational (content) perspective of 
current culture bearers. Prior to the first primary subject interviews, a questionnaire (Appendix B) was distributed to faculty within the three study departments: two departments represented disciplines within the Humanities and one represented a discipline within the Social Sciences. Accompanying the questionnaire was a cover letter asking the cooperation of the faculty member, explaining the purposes of the study, and assuring confidentiality of the faculty member's responses. Departmental return rates of the questionnaire varied: eleven faculty out of a total of 22 faculty in Department A returned surveys: 3 full professors, 6 associate professors, and 2 assistant professors. Ten faculty out of a total of 24 faculty in Department B returned surveys: 3 full professors, 5 associate professors, and 2 assistant professors. Eleven faculty out of a total of 18 faculty in Department $\mathrm{C}$ returned surveys: 4 full professors, 4 associate professors, and 3 assistant professors.

After repeated coding of transcripts, survey data were interwoven with secondary subject interview data and a composite view of the institutional culture and subcultures emerged. All categorized secondary subject interview data and survey data were analyzed as follows:

First, survey and interview data were coded as relating to the institutional ideology; to perceptions regarding the environment and faculty morale; or to the work climate or attitudes toward work in the three study departments. These data addressed the question: what are the assumptions, understandings and meanings shared by current group members?

In a similar manner, survey data which were coded as relating to the relative importance of various academic tasks, and to the amount of time spent working on the same academic tasks, addressed the question: what is the role orientation of current organization members? 
To understand the culture of the institution, particular attention was devoted to issues of greatest consensus in interpretation or perceptions of members. To understand the subculture of each department, particular attention was devoted to issues around which there was the greatest variation across departments.

The analyses of interview, survey, document and observational data of secondary subjects seek to explain the "cultural web of meaning of the organization" (Tierney, 1988).

QUESTION 1: What are the assumptions, understandings, and meanings shared by current group members?

\section{Institutional Culture}

A composite view of the institutional culture was drawn from content (ideational data) describing factors around which the greatest consensus across departments was demonstrated. While overall issues regarding the institution were complex and varied, within the range of issues expressed, patterns did emerge to permit further grouping of comments around single topics. These over-arching ideational topics are best characterized in terms of four broad and interrelated themes: perceptions regarding the current transitory state of the institutional mission; perceptions regarding the diminishing Catholic nature of the institution; perceptions regarding shifting role expectations for faculty performance; and perceptions regarding the changing nature of the departments and disciplines. While in some instances it was difficult to distinguish the discrete beginning of one theme from the completion of another, the four themes will be separately described, but are not presented in any hierarchical order.

Following this section on institutional culture, the manner in which the assumptions, understandings and meanings shared by group members are enacted in each subculture (the homogeneity of interpretation) will be discussed. 


\section{Theme One: An Institution in Transition}

Approximately 10 interview hours with a diverse cross-section of administrators and faculty concerning the nature of the institution-- its mission, goals, history, traditions and values-- produced many interesting statements. A review of 65 coded transcript references related to institutional mission, in one manner or another, all pointed to an institution in transition theme. Some respondents strongly supported the changing nature of the institution, some were less supportive of a shift in mission, and a few were openly resistant toward any perceived change in mission. A sampling of the remarks made during the interviews indicate the range of such perspectives and the uncertainty expressed regarding the eventual outcome of this transition.

The overall mission of the university was most often described in terms similar to the over-arching mission of any university: to foster, promote, and to extend learning. The message of student learning as a primary goal was clearly stated in university publications, often repeated by faculty, and reinforced in the comments of administrators interviewed. A senior administrator described the learning mission of the university as follows:

The nature of the university, because of its founding tradition and history, must focus its future direction not just on teaching or on research, but on learning. Where do teaching and research fit in? Obviously they are two aspects or dimensions of learning. If a university delivers health care, it does so in the context of learning. If this university assists young people to mature and grow, it does so in the context of learning. It may not be easy to relate every activity to that ultimate purpose, but $I$ think if in the last analysis that it can't be related to that purpose, then it doesn't belong here.

When asked to describe the mission of the university, faculty would typically respond, "we are historically a teaching institution." As each interview would progress, the notion of learning as a distinct description of the institutional mission would emerge. As faculty were asked to describe what set the institution apart from other institutions, in most cases they stated clearly that the university "reflects a genuine concern that students learn while 
they are here" and that "while the mission rhetoric might be similar, other institutions wouldn't demonstrate this as their primary goal."

Beyond this common sentiment, that learning was a distinct aspect of the mission, faculty generally indicated that the future mission of the university was unclear. The university was described as "being forced to change to a research-orientation given the current academic marketplace"-- or, as an institution which was "striving to become more prestigious." While there was agreement that the university was "in the middle of a significant change away from its founding teaching mission," most concluded that the "character and direction of the change won't fully be understood until it's all over."

Administrators described the transitory state of the mission as "an expected uncertainty" given the "broad and varied constituencies" which comprise the institution. In explaining the contradictory viewpoints on the matter of mission, another senior administrator used the following analogy:

I like the analogy of Interstate 94 . If you ask five people in which direction the Interstate highway runs, you may get five different answers. You see, if you look at a map, its an east-west road. But, obviously, within the city for a certain period of time of time it goes north. I think the university is like that. There may not be one overall agreed-to mission, because, for this particular period, we may be placing more emphasis on research credentials than we did when the road was not yet running through the city.

When asked to account for the perceptual shift away from teaching, some faculty were less nonchalant in their remarks and less convinced of the necessity for this change. One long-term faculty member described his strong conviction in this regard:

The administration wants the university to become more prestigious. They view the institution as second-rate, and nationally, they want it to be taken more seriously. That's not a bad aspiration, but there is also nothing wrong with being second-rate. Somebody has to be.

Most faculty attributed changes in perception of the mission to two documents, commonly referred to as "white papers", which were promulgated within the institution a 
few years prior to this study. The papers were referred to as "typically institutional, bureaucratic kinds of documents that didn't say very much, " and at the same time," tried to make a statement of what the mission of the institution was going to be". Some faculty believed that the research document was a "positive statement regarding the place toward which the institution might develop", but that the institution, realistically, "does not have the kind of resources to fully take us in that direction." One chairperson attributed the ambiguity in mission, in part, to these documents:

The white paper on research was talked about in lots of places. I'm not sure how valuable it was in the long run. I mean, the paper was a way of examining the institutional mission and the current thinking on the place of research in our institution. But we've found that it wasn't written in stone. The outcome may have been a renewed mission statement, but the paper was too broad to have particular meaning for any given unit.

After the document on research was released, a second "white paper" on the mission of teaching was distributed. A number of faculty cited the development of this paper as "a response to the strong and negative reaction to the research document among faculty." Faculty also claimed that there were "obviously a lot of faculty who felt that teaching should be paramount to the mission, and these sentiments could not be overlooked." While the second paper "recognized the crucial importance of teaching," a number of faculty suggested that the document was simply a "necessary statement which had to be made in order not to marginalize older faculty and our students." One department chairperson concluded:

The emphasis on research created real tension because people argued that we couldn't be a major research institution and still value teaching as we have in the past. I think that one of the reasons that teaching was made to be so important (in the second document) is because the senior administration understood that it was important to recognize the teaching faculty. They've been a very important faculty for many years, and many of them are still here, and will be for a decade or more. So, you know, they simply couldn't say research is everything, forget everything else. 
An associate professor also addressed the effect that a transition away from teaching would have on the institution:

In the past, people coming into the institution, at an entry level, would be assimilated over time. They would have to pay their dues in order to get tenure. If you start bringing in more experienced types, that practice would break the culture of the department. The trade-off for moving in that direction may be too costly.

Another associate professor suggested that although the university was emphasizing research more, the institution was intentionally moving slowly toward that goal:

For the moment, the university is stressing a balance between research and teaching, that both roles are equally important. Perhaps the university is trying to avoid making the change too quickly. There are too many culture barriers keeping the institution from becoming a first-rate university. The university may be trying to avoid taking on all of these changes too quickly-or, perhaps they are sitting back for a while because people say there is going to be a dearth of Ph.D's in the late 1990's. In a market like that, salaries and research supports wouldn't become the sole bargaining chips.

\section{Theme Two: Religious Traditions in an Increasingly Pluralistic Environment}

Faculty also cited the religious nature of the institution as the primary force through which the tradition of learning had historically been reinforced. If administrators or faculty referred to the religious character of the institution during the interview, an immediate follow-up question was asked: what does this nature mean to you and what makes this nature real for you in the present time? The obvious examples of a religious presence included symbolic expressions such as the university logo, an annual alluniversity opening Mass of the Holy Spirit, religious artifacts displayed in various buildings, and the presence of clergy within the faculty ranks. Within the context of comparisons to the past, older faculty pointed to symbolic expressions that continued to reinforce a religious presence:

The religious influence was more pronounced when I first joined the institution. I remember having to open my classes with a prayer. That 
to reside in the institution. But even today, when we interview prospective faculty, the religious nature is addressed. The dean will ask each candidate if they have any reservations in teaching within this sort of environment. It comes up in the department as well; in the literature we send to candidates about the institution. We assume on the basis of our literature, a candidate will better understand the (denominational) vision of higher education.

Another senior administrator described how the Board of Trustees had approved of two actions, during the study period, which "portend to strengthen the (denominational) tradition" --the revision of the mission statement and the adoption of a new university logo. Both the statement and the logo contain unmistakable religious language ingredients. The logo repeated the founders' principal for his early followers: "Ad majorem Dei gloriam," which translates "for the greater glory of God." The mission statement was revised in sections to include a number of phrases rooted in this tradition: "a capacity for critical and ethical judgment; living for others; the conviction that learning is the way of seeking and finding God; and respect for the human person."

While most faculty were able to describe obvious indicators of a religious presence, or ways in which this presence had diminished over time, other faculty pointed to less obvious examples in which the traditions, to them, were still present and influential. They spoke of the religious nature as "being exhibited in the retirement policy of the institution", in attempts to "provide faculty with appropriate support to conduct research," and in an ongoing concern with equity... "that everyone is treated fairly."

While the nature of this religious tradition was seen as a continuing positive presence, faculty tended to make strong distinctions between this tradition and the diminishing importance of the Catholic nature of the institution:

There are occasion when the university becomes very Catholic-- very Catholic meaning when they exercise their doctrine with a capital $\mathrm{C}$. Certain issues like abortion immediately cause the flag to be raised. I doubt that you would get good, concrete, open discussions on an issue like abortion. On the other hand, the university bends backwards to make sure that academic freedom is taken very seriously. And yet, there is tension in being in an increasingly pluralistic community. A lot of non-Catholics come through 
here, and that causes even more problems with a Catholic identity.

During the period of the study, an issue arose which demonstrated differences in opinions about what academic freedom means in a Catholic university. The issue entailed the Women's Center and its right to distribute birth control information on campus. In this situation, faculty perceived that the institution had tried to "dispose of the issue on a technicality by arguing that the Women's Center had not gone through the formality of having their constitution approved." Faculty perceived this decision as "a knee-jerk reaction on the part of the administration," an attempt on the part of the university to find an easy way around the issue "by finding refuge in a technicality." After the issue continued for a short period of time, a senior administrator lamented that the university had spent "undue time working on ways to address the issues in an appropriate setting" but that "nothing materialized because few students and faculty expressed interest in a public forum." Faculty, on the other hand, tended to take a more observational approach to the matter. Although the incident created a stir among the faculty in luncheon discussions and in other informal gatherings, in the end, faculty seemed content with the way the issue had been handled:

If you are an official of the university, an officer of the organization, you are supposed to take the university point of view-- and that point of view would reflect a certain protectiveness about Catholic doctrine, regardless of what your individual view might be in a case like that. And it seems to me that the university responded in a way that most universities should. A university holds a disputation or discussion, or it holds a forum, seminar, or workshop. That's what a university does when it confronts an issue of some significance.

Few faculty felt strongly about whether or not a table should be allowed for the distribution of condoms. The majority "waited to see if the institution would allow the merits of the case to be explored. It did; and the issue died."

Potential collisions such as this, between academic freedom and Catholic doctrine, highlighted the difficulty the university seemed to be experiencing in keeping religious 
values alive in an institution that is no longer a church enclave.

\section{Theme Three: Shifting Role Expectations for Faculty Performance}

Despite the continuing controversy around the distribution of documents on research and teaching, over a fifteen year span, scholarship had gradually increased in importance within the institution. A faculty member discussed this changing emphasis over time:

When I came to the university in the mid-1970's, scholarship was less important than it is today. There were scholars in the department, several very famous scholars actually, but by and large you were tenured on the basis of your quality of teaching, with only some evidence of research. Today that is not the case at all. It is very difficult to obtain tenure in the department, as it is in many departments of the college. Because scholarship has become very important in the scheme of things, either you prove yourself able to be promoted to associate professor by virtue of your publications, or you don't get tenure. This was not at all the case fifteen years ago.

Within a 10 to 12 year span, the institution also began to hire a different kind of academic-- individuals were brought in to give greater focus to publications in a particular field. One chairperson described the hiring process as follows:

There was a sense of building and developing the department at that time. We were also hiring in response to people retiring or leaving. Now we are hiring to strengthen particular fields and to replace positions in which there were tenure denials. Many more students were coming to the university from the immediate metropolitan area than they are today. As our reach for expanded student markets increased, so did our interest increase in developing a national focus. In order to do that, to reach beyond our immediate walls, we needed to establish and gain a national reputation through an increasing research faculty track.

Another chairperson speculated about the impact an increased recruitment effort for attracting more seasoned academics would have on the institution:

If you want a national reputation, you may need to begin playing the salary and incentive game. Our faculty has already been raided by other institutions. If you try to recruit or retain someone of national merit, either the salary level will immediately jump up or the travel and research supports will be increased. Suddenly you've upset the department's apple cart. Other faculty 
begin to ask-- how do they get that and I don't? If you threaten the balance of a carefully preserved, equitable system the whole thing can snowball.

Finally, one assistant professor summarized the impact the shift in role expectations was already having on the department:

The department is already split culturally over the issue. The people who have been in the institution for a long time, those who have operated out of a teaching mode, are suddenly becoming outnumbered. If you hire only two new people in a year, within five years you will have a core of faculty who operate with a completely different attitude. The bad thing about that is it could create a caste system where some people have heavier teaching loads. The institution could, however, choose to keep the faculty workload the same for everyone. In that case, the pressure for those of us who are heading toward tenure would only further increase.

While the qualitative data presented above indicate that faculty perceived a shift in performance expectations away from teaching and increasingly toward research, survey questions related to the issue can also be examined. Table 1 describes the number and percentage of faculty, per department, who responded to the first question: In your department, are faculty under pressure to participate in research?

Table 1.-- Pressure to Perform Research.

\begin{tabular}{lccc}
\hline \hline & YES & NO & \% Yes \\
\hline DEPARTMENT A & & & \\
Professor (n=3) & 3 & 1 & 83 \\
Associate (n=6) & 5 & & 100 \\
Assistant (n=2) & 2 & & \\
& & & 100 \\
DEPARTMENT B & & & 100 \\
Professor (n=3) & 3 & & 100 \\
Associate (n=5) & 5 & & \\
Assistant (n=2) & 2 & & 75 \\
& & & 100 \\
DEPARTMENT C & & & 100 \\
Professor (n=4) & 3 & & \\
Associate (n=4) & 4 & & \\
Assistant (n=3) & 3 & & \\
& & & \\
\hline
\end{tabular}


In Department A,10 of 11 faculty responded positively to the question. Only one associate professor responded that there was no perceived pressure to perform research. In Department B, all 10 responded yes when asked if faculty were under pressure to perform research. In Department C, 10 of 11 faculty responded positively when asked if department faculty were under pressure to perform research. Only one full professor responded that there was no perceived pressure to perform research. The data suggest a shared assumption among faculty: pressure to perform research is generally perceived, regardless of department or rank.

In the survey, faculty were also asked if they had perceived any pressure to increase involvement in research during the past five years. Table 2 describes the number and percentage of faculty, per department, who responded to the second question: In the last five years, have you perceived any pressure to increase involvement in research?

Table 2.-- Pressure to Increase Research Performance.

\begin{tabular}{lccc}
\hline & YES & NO & \% Yes \\
\hline DEPARTMENT A & & 1 & 67 \\
Professor $(\mathrm{n}=3)$ & 2 & 4 & 33 \\
Associate $(\mathrm{n}=6)$ & 2 & & 100 \\
Assistant $(\mathrm{n}=2)$ & 2 & & \\
& & 1 & 67 \\
DEPARTMENT B & 2 & & 100 \\
Professor (n=3) & 5 & & 100 \\
Associate (n=5) & 2 & & \\
Assistant (n=2) & & 1 & 75 \\
DEPARTMENT C & & & 100 \\
Professor (n=4) & 3 & & 0 \\
Associate $(\mathrm{n}=4)$ & 4 & & \\
Assistant $(\mathrm{n}=3)$ & 0 & & \\
& & & \\
\hline
\end{tabular}

In Department A, all 11 responded when asked if department faculty perceived increased pressure to perform research, and the results changed somewhat. Two-thirds 
of the full professors (67\%) said yes, only one-third of the associates (33\%) said yes, while the assistant professors both said yes. In Department B, all 10 responded when asked if they perceived increased pressure to perform research. Two thirds of the full professors (67\%) said yes, while all associates and assistant professors (100\%) said yes. In Department C, 8 of the 11 faculty responded when asked if they perceived increased pressure to perform research. Three-fourths of the full professors $(75 \%)$ said yes, all associate professors $(100 \%)$ said yes, while none of the assistant professors elected to respond (given they had been in the department less than five years).

Spanning the departments, except for four of the six associate professors in Department A, faculty generally agreed that pressure to perform research had increased in the last five years. A possible explanation for the variation in response in Department A was provided during an interview with one of the associate professors: "I really don't perceive any more pressure than when I first joined the department. We were expected to balance teaching and research from the start."

In the survey, faculty were also asked if they found it difficult to teach and do research at the same time. Table 3 describes the number and percentage of faculty, per department, who responded to the third question.

In Department A, all 11 faculty responded when asked if it was difficult to teach and do research at the same time. Both assistant professors (100\%) said yes, two of the three full professors (67\%) said yes, while none of the associate professors $(0 \%)$ said yes. In Department B, all 10 faculty responded when asked if it was difficult to teach and do research at the same time. Both assistant professors (100\%) said yes, all five associate professors $(100 \%)$ said yes, and two of the three full professors $(67 \%)$ said yes. In Department $\mathrm{C}$, all 11 faculty responded when asked if it was difficult to teach and do research at the same time. All three assistant professors (100\%) said yes, all 4 full professors (100\%) said yes, while 2 of the 4 full professors (50\%) said yes. 
It is interesting to note that $100 \%$ of the associate professors in Department $\mathrm{A}$ said that it was not difficult to balance teaching and research, while $85 \%$ of the remaining respondents reported difficulty in balancing the two roles.

Table 3.-- Difficulty Balancing Teaching and Research.

\begin{tabular}{lccc}
\hline & YES & NO & \% Yes \\
\hline DEPARTMENT A & 2 & 1 & 67 \\
Professor $(n=3)$ & 2 & 6 & 0 \\
Associate $(n=6)$ & & & 100 \\
Assistant $(n=2)$ & 2 & 1 & 67 \\
DEPARTMENT B & 5 & & 100 \\
Professor $(n=3)$ & 2 & 100 \\
Associate $(n=5)$ & & & \\
Assistant $(n=2)$ & & 2 & 50 \\
& 2 & 100 \\
DEPARTMENT C & 4 & & 100 \\
Professor $(n=4)$ & 3 & & \\
Associate $(n=4)$ & & & \\
Assistant $(n=3)$ & & & \\
& & & \\
\hline
\end{tabular}

In summary, among departments, 30 of the 32 faculty responding (94\%) reported perceived pressure to participate in research; 22 of the 29 faculty responding (76\%) reported pressure to increase involvement in research during the past 5 years; and 22 out of 32 faculty responding (69\%) reported difficulty teaching and doing research at the same time.

\section{Theme Four: The Changing Nature of the Department and Discipline}

Faculty saw the departments as having "historically evolved" though a process of "selecting and supporting structures and academic programs which best met departmental goals at particular points in time." Across departments, the faculty described changes that had dramatically altered the nature of the department structure, personnel and operating supports. In the documents reviewed, key indicators of expansion over a ten year span were reflected in the following data: the number of academic chairs increased from seven 
to twenty-four, the number of full-time faculty rose from 658 to 806 , and the number of faculty with the Ph.D., or other terminal degree, rose from $85 \%$ to $94 \%$. During this ten year span, the university's annual operating budget also increased from $\$ 120$ million to $\$ 408$ million. Five major buildings were constructed during the ten year period, one of which was dedicated solely to the humanities.

While interview data did not point to these quantifiable comparisons, faculty in all three departments described significant changes that occurred as a result of having become $\mathrm{Ph} . \mathrm{D}$. granting units. A long-term professor briefly described the shift in focus for the department as this change occurred:

Once we became a Ph.D. granting department, our overall goals changed. We became more concerned with having faculty with well developed specializations. Prior to that point, our faculty consisted of many generalists who had masters degrees and could be considered more versatile. The objective of the department was to provide general courses at the undergraduate level. We now emphasize training graduate students while at the same time providing appropriate advance courses for our majors and minors, and providing support staff for the core program of our college.

Other faculty referred to departmental practices which had "continually added faculty in specialized areas the department had agreed to emphasize." There was no doubt among those interviewed that the content and structure of the department changed as additional disciplinary subfields were introduced. Becoming a Ph.D. granting department, and "a developmental tendency to build upon particular strengths" in departments, were seen as the two primary contributing forces behind the evolving nature of the departments:

These two forces led to the transformation of the humanities as well as the social sciences. Scholarship as a whole has become divided into numerous separate, independent, and distinct branches of learning. Through specialization, by achieving mastery of one of the subdivisions of the discipline, all scholarly activity became directed and confined. The departments in response became more rigid and bureaucratized.

For some faculty, another price had been paid for the achievement of this progress-- as 
subfields were introduced, the social fabric became increasingly strained and the interactions among faculty were reorganized. One faculty member suggested that:

In developing the strengths of our department, and in emphasizing scholarship in teaching and research, we have fragmented our older and newer faculty. Older faculty see the junior faculty as overly ambitious. And the junior faculty have expectations that older faculty never had before. They expect leaves, financial supports for travel, certain kinds of classes, and the opportunity to teach graduate courses. You used to have to be almost ancient before you could get a graduate course. Today, new faculty get the graduate course often in their second semester. It puts them in the prestigious program right at the beginning.

As specialization increased, faculty maintained that "individual subfields were allowed to govern separate spheres of expertise." As a result, one chairperson suggested that some older faculty members learned not to encroach in another's field "because that could invite criticism for not being sufficiently familiar with the latest scholarship: the most prudent course of wisdom for older faculty has been to stick to teaching and their own specialties."

Describing any of the departments studied as having simply become more specialized would belie the complexity of the individual discipline. With an increasingly specialized faculty, changes in disciplinary styles of inquiry became more pronounced. Although faculty could easily describe the present contour of their department and its particular subfields, most believed that such descriptions were "an historically convenient way to describe the organization of the department", rather than "an accurate description of the intellectual work of the discipline." When asked if there were significant differences of opinion among disciplines about what was considered intellectual work, an eloquent and reflective response was offered:

What happened in this discipline only reflects what has happened in every other branch of scholarship. We have always debated the extent to which we should widen our nets. Do we allow interpretive analyses to penetrate our practices-- or, do we maintain objective, neutral practices? The need to answer problems provides some catalyst for migration across practices. Each 
discipline also shares a commitment to accuracy and to procedures of verification and documentation. More recently, we have begun to admit that the knowledge we produce is contextual, relative, open to revision and debate, and never absolute.

New lines of investigation open precisely through these moments of intense debate.

While the terrains of the disciplines were described differently in each department, the integrative effect of these methodological standards was detectable.

Finally, not all faculty believed that the professionalization of the disciplines had resulted in a corresponding increase in supports. Rather, through a process of emphasizing particular subfields over others, resources were perceived as having been gradually increased in specialized areas:

In one sense, the institution has placed a great deal more emphasis on resource distribution. When I first came here, research leaves and summer grants were not abundant. In another sense, the university only recently established an office for research support services. If you were new to the campus, it also would look like the Humanities have been wonderfully supported. After all, we reside in a lovely building devoted to the Humanities. But, these things are a matter of perception and history. You had to be here fifteen years ago to remember the hole the department had to crawl out of in order to get to that building.

While faculty were aware of significant strides in resources over time, they were also concerned about "the absence of a systematic program of released time, and the lack of regularized leave policy along the lines of the traditional sabbaticals found in research oriented institutions." This was especially problematic to junior faculty who felt that they "needed to be assured of research and writing blocks of time free from teaching and other departmental obligations."

In summary, the qualitative and quantitative data presented in this section presented commonalities, across departments; commonalities instrumental in describing the institutional culture. Thematic descriptions of the culture included: the evolving nature of the institutional mission; an accompanying change in faculty performance expectations; a gradual shift towards specialization as departments became Ph.D. granting entities; increasingly divided relationships between older and newer faculty; and marked concerns 
regarding limited resources extended to support developmental changes. Despite these concerns, most faculty felt that the various changes in the institution and departments were positive.

\section{Departmental Subcultures}

The previous section addressed the assumptions, understandings, and meanings shared by current group members regarding the institutional mission and ideology of the organization. Of primary importance to this section is how these beliefs and assumptions are rooted, or enacted, within the three subcultures. Two steps were taken to analyze the content data related to the subcultures. First, survey and interview data across disciplines were coded in relation to perceptions regarding either of two dimensions: the overall environment and faculty morale, and the work climate and faculty attitudes toward work. Approximately 10 interview hours were conducted with a subset of faculty respondents as a follow-up to the survey. The purpose of these interviews was to clarify survey responses and to collect additional data related to the environment and faculty morale, and to the work climate. (The survey was also designed to include questions related to these areas.) Second, a total of 82 coded transcript references were analyzed in relation to the two subcultural dimensions. While the homogeneity of interpretation was instrumental in describing institutional culture, in order to understand the three subcultures, particular attention needed to be devoted to issues around which there were significant variation across disciplines in interpretations or perceptions of members. The analyses of data will be presented in the two dimensions noted above.

\section{Perceptions Regarding the Environment and Faculty Morale}

Survey questions related to the overall environment and to general faculty morale will initially be examined. Following the description of survey data, corresponding interview data were examined. Table 4 describes the number of faculty, per department, who believed the institution's work environment had greatly improved, improved, 
remained the same, worsened, or greatly worsened.

Table 4.-- Changes in the Institutional Work Environment.

\begin{tabular}{|c|c|c|c|c|c|}
\hline & $\begin{array}{l}\text { Greatly } \\
\text { Improved }\end{array}$ & Improved & $\begin{array}{l}\text { Remained } \\
\text { Unchanged }\end{array}$ & Worsened & $\begin{array}{l}\text { Greatly } \\
\text { Worsened }\end{array}$ \\
\hline Department $A_{(n=11)}$ & & 6 & 1 & 1 & \\
\hline Department B $(n=10)$ & & 6 & 2 & 2 & \\
\hline Department $C_{(n=11)}$ & & 4 & 3 & 3 & \\
\hline
\end{tabular}

When asked how changes in the work environment were perceived in the institution during the past five years, Departments A and B were positive, and Department $\mathrm{C}$ was slightly positive. The percentages denoting improved institutional environment changes were $75 \%, 60 \%$, and $40 \%$ respectively.

Table 5 describes the number of faculty, per department, who believed the department's work environment had greatly improved, improved, remained the same, worsened, or greatly worsened.

Table 5.-- Changes in the Department Work Environment.

\begin{tabular}{|c|c|c|c|c|c|}
\hline & $\begin{array}{l}\text { Greatly } \\
\text { Improved } \\
\end{array}$ & Improved & $\begin{array}{l}\text { Remained } \\
\text { Unchanged }\end{array}$ & Worsened & $\begin{array}{c}\text { Greatly } \\
\text { Worsened }\end{array}$ \\
\hline Department A (n=11) & & 7 & 1 & & \\
\hline Department B $(\mathrm{n}=10)$ & 1 & 5 & 3 & 1 & \\
\hline Department $C_{(n=11)}$ & 1 & 3 & 2 & 3 & 1 \\
\hline
\end{tabular}

When asked how changes in the department work environment were perceived during the past five years, the results were positive for Departments A and B, and mixed for Department C. The percentages denoting improvements in the department work environment were $87.5 \%, 60 \%$, and $40 \%$ respectively. 
When comparing changes noted in the institutional and department work environments (Tables 5 and 6), a close relationship exists. For both questions, Department A indicated overall improvements, Department B also indicated improvements, but to a lesser extent; and Department $\mathrm{C}$ was mixed. Approximately the same number of Department $\mathrm{C}$ respondents cited improvements as did worsen.

Table 6 describes the number of faculty, per department, who believed faculty morale within the institution had greatly improved, improved, remained the same, worsened, or greatly worsened.

Table 6.-- Changes in Institutional Faculty Morale.

\begin{tabular}{lccccc}
\hline \hline & $\begin{array}{c}\text { Greatly } \\
\text { Improved }\end{array}$ & Improved & $\begin{array}{c}\text { Remain } \\
\text { Unchanged }\end{array}$ & Worsened & $\begin{array}{c}\text { Greatly } \\
\text { Worsened }\end{array}$ \\
\hline Department A $_{(\mathrm{n}=11)}$ & 1 & 5 & 1 & 1 & \\
Department B $_{(\mathrm{n}=10)}$ & & 4 & 3 & 3 & \\
Department $_{(\mathrm{n}=11)}$ & 2 & 3 & 5 \\
\hline
\end{tabular}

When asked how changes were perceived in the institution within the past five years, with respect to faculty morale, responses were positive for Department $\mathrm{A}$, mixed for Department B, and negative for Department C. The percentages denoting improved faculty morale were $75 \%, 40 \%$, and $20 \%$ respectively. One-half of the faculty in Department $\mathrm{C}$ indicated that morale had worsened.

Table 7 describes the number of faculty, per department, who believed faculty morale within the department had greatly improved, improved, remained the same, worsened, or greatly worsened. 
Table 7.-- Changes in Departmental Faculty Morale.

\begin{tabular}{llccccc}
\hline \hline & $\begin{array}{c}\text { Greatly } \\
\text { Improved }\end{array}$ & Improved & $\begin{array}{c}\text { Remain } \\
\text { Unchanged }\end{array}$ & Worsened & $\begin{array}{c}\text { Greatly } \\
\text { Worsened }\end{array}$ \\
\hline Department A & $(n=11)$ & 7 & 1 & & \\
Department B & $(n=10)$ & & 3 & 5 & 2 & \\
Department C & $(n=11)$ & 1 & 2 & 2 & 4 & 1 \\
\hline
\end{tabular}

When asked how changes were perceived in the department during the past five years, with respect to faculty morale, Department A was positive, Department B was slightly positive, and Department $\mathrm{C}$ was slightly negative. The percentages denoting improvements were $87.5 \%, 30 \%$, and $30 \%$ respectively. The percentages denoting worsening in faculty morale were $0 \%, 20 \%$, and $50 \%$ respectively.

When comparing changes noted in faculty morale in the institution and departments (Tables 6 and 7), a close relationship exists. For both questions, 75\% or more of Department A's respondents indicated improvement, Department B indicated slight improvement, while Department $\mathrm{C}$ indicated that faculty morale had somewhat worsened.

In comparing Tables 4 through 7 , more positive changes are indicated than negative. While the responses related to improvements in the work environment (Tables 4 and 5) evoked roughly three times as many positive changes as negative changes, responses related to faculty morale (Tables 6 and 7) evoked about 1.5 as many positive changes as negative changes. Thus, faculty felt that the various changes in the institution and departments were somewhat positive. This is especially true in the work environment, where both institution and department questions evoked a positive response from the majority of respondents.

Comparing the departments among questions of work environment and faculty 
morale (Tables 4 through 7), Department A was very positive, compared to positive for work environment and mixed for faculty morale for Department B; and mixed for work environment and negative for faculty morale for Department $\mathrm{C}$. One might expect to find a degree of uniformity across departments for questions of institutional work environment and institutional faculty morale; however, that is not the case. Variation is especially pronounced for faculty morale: $75 \%$ of Department A respondents indicated positive changes, compared to Department B 40\%, and Department C 20\%. However, there was consistency within each department: Department A answered highly positively overall; Department B answered both work environment questions positively, and both faculty morale questions mixed (only one more answered positively than negatively); and Department $\mathrm{C}$ answers were mixed for work environment and negative for faculty morale.

While positive changes are indicated for both improvements in the institution and department, and with respect to general faculty morale, the particular ratings of each department can be further examined through the interview data.

When asked, "In general, how do you feel about this institution," only two in fifteen interviewed, claimed, "I have recently considered leaving," and "The department is fine, but the institution stinks." The remaining thirteen faculty suggested, in one manner or another, that the institution "provides an excellent working environment." As they elaborated, overall positive sentiments included "the sensitivity of the institution to the difference among departments," "favorable signs of progress in implementing a systematic program of release time," and "the development of working procedures governing academic workload."

Sometimes immediately manifest, sometimes lying just beneath the surface of comment, faculty would talk about the institution's sensitivity to departmental differences. One professor characterized the environmental context as follows: 
The institution is sensitive to the differences among disciplines. For example, while academic departments generally have the same functions, their strengths and their centrality to the priorities of the university may vary considerably. These differences may be the result of faculty strengths, or the quality and strengths of the academic program. It is important to recognize these inherent functional differences. Generally, the administration is sensitive to these issues.

In a similarily positive manner, a long-term member and the chairperson of Department $\mathrm{A}$ compared the institution to other universities. In his description of the environment, he reflects on relationships with the administration:

I characterize the university as the best of all possible worlds. Perhaps that is a kind of sentimentalizing view because I've been here seventeen years. But, my experience every year, when I go to professional association meetings, is that this is an extraordinary institution. That is evident in the way the senior administration relates to the junior administration. We don't have the political problems that most state universities have. We have a great deal more flexibility and autonomy. We don't have the same accountabilities. If I have to make a decision which requires the dean's approval, I obviously contact the dean. But those occasions are infrequent: when I have a special request which involves resources, or when something is clearly beyond my authority to decide.

The chairperson of Department B also provided insight into the contributing, positive, relationship between administrative sensitivity and the general environment. Using one particular administrator as an example, he further defined the particular style of sensitivity as a "characteristic of various administrators":

Naturally, I don't want to waste anyone's time, but if I have an issue I want to talk to them [various administrators' names] about, I call. There is truly a deliberate style that characterizes the administration-- a sincere attempt to deliberate and negotiate. I think that's one of the strengths of this institution. I particularly respect [name of dean] because he's a negotiator, and when he says no to you, you're never angry. You walk away knowing that he's given it thought, he's asked you, and he makes a decision based on all of the various factors involved. Even if you believe he should be listening more closely to some of the factors which affect your department, you still respect him. Everyone in this department does, he's a super individual. In a sense, he typifies most of the administration. If I had to characterize the administrative structure ...particular individuals...you would say that there is a tremendous 
amount of enlightenment and respect for individual disciplines.

The Chairperson of Department C, albeit in a less complimentary manner, acknowledged the willingness of the administration to consider and support departmental priorities. He was critical of the mixed messages departments received regarding priorities in the institution, but not with administrative style or sensitivities:

I don't always get along with the administration, but you rarely hear of chairpersons having to fight with them. The various deans I have worked with over the years have always been easy to talk to. And usually they try to support what you recommend, at least if they have the resources. I haven't always been successful in getting more resources for the department, but they do consider your opinion. Basically, it comes down to a tug between vested interests and between diverse perceptions of what the university should be. Too often, though, there are unclear messages from the administration about where the university is going.

Faculty cited two tangible policy development efforts as contributing to positive attitudes about the environment. Eight of the fifteen faculty interviewed referred to "favorable signs" that the university was progressing toward an "equitable policy" for release time, and that it had already begun to develop procedures for academic workload reductions. An associate professor in Department $\mathbf{C}$ further commented:

I would say that the majority of faculty in this department spend about half of their time in class, preparing for class, or advising students. The remainder is spent on administrative tasks. Whatever is left over goes toward research. If the institution is purposely shifting away from a teaching orientation to a research orientation, its not evident in our current workload. The majority of faculty are playing the game. We do what we are assigned, and frankly we feel strongly about the teaching element of our work. But, the reality is that teaching effectiveness isn't the primary criterion for achieving tenure. Looking at our workload is a long overdue move in the right direction.

Obviously concurring with this faculty member, on the importance of examining the academic workload, was an associate professor from Department B. She seemed particularly pleased that the university had completed its review and speculated about having been the first department in the college to undergo a review of this nature: 
We were the first department to be interviewed in the so called "(graduate dean's name) Task Force;" the intent of which was to determine workloads. As a consequence of the study, we implemented course reductions for the research faculty in our department. The fact that we were chosen to be examined first has to do with our size, and the quality and prestige of our faculty.

In Department C, where the Task Force had not yet convened, an associate professor commented:

The university has laid the groundwork for creating a more favorable balance between teaching and research. But an appropriate balance cannot be dictated from "the tower". Nor is it realistic to expect the change efforts to "bubble upward" from individual academic departments. It is essential that a dialogue be conducted with each unit and that clear expectations be produced.

In the survey, the responses indicated more positive than negative changes were perceived regarding the work environment. The interview data were consistent with the survey data, i.e., Departments A and B generally perceived improvements, while Department $\mathrm{C}$ had mixed views regarding the environment.

Comparing survey responses noted for improvements in faculty morale, $75 \%$ or more of Department A respondents indicated improvements, Department B indicated slight improvement, while Department $\mathrm{C}$ indicated that faculty morale had somewhat worsened. The interview data generally reflected these findings. In terms of institutional morale, eleven of the fifteen faculty interviewed rated it as "high" and strongly related to the level of faculty morale within the departments. Without hesitation, respondents explained the primary factor behind the high level of morale: "If things were fiscally unsound, if there were cutbacks, there would be horrible morale. The changes we are experiencing, the things that do cause us stress, are handled better in this rather upbeat environment."

Survey data were also analyzed to pinpoint factors cited as contributing to positive faculty morale and those factors contributing to poor morale, particularly for Department 
C. Two factors were attributed to positive morale: the overall quality of the academic program and the leadership style of the chairperson. A sampling of remarks, by department, indicate the range of perceptual variations regarding academic quality. An associate professor in Department A commented:

The fact there were a lot of good faculty who were publishing, and the fact that we had positions open and could bring in new faculty, meant we could take on the mission of increased publication. We have a pretty strong Ph.D. program which obviously feeds our interest in research, and the research agenda, in turn, feeds the Ph.D. program. I think for that reason, we probably stand as one of the most important programs in the college. I believe faculty take pride in the fact that we are an accomplished department.

In Department B, an associate professor called attention to what he perceived as the university's "vote of confidence" in his unit:

I have an example that I'd like to share which will illustrate the university's concern for building upon the quality of our program. A few years ago, we had sixty part-time faculty. It was an appalling situation-- fifty percent--.over fifty percent of our sections were being taught by part-time faculty. It was not a healthy situation--one of the biggest problems in the profession generally. And so, the university committed ten full-time positions to the department, beginning at $\$ 20,000$ each, to teach four sections of [name of program] each semester over a five-year plan. It was implemented over a couple of years, and frankly this was the last thing I ever thought would happen. The university has the money, everyone knows the university has money, its just that it's so conservatively managed.

For Department $\mathrm{C}$, faculty were divided in their own evaluation of the department's academic program. Again, an associate professor commented:

The quality of our academic program is being questioned and the department hasn't done what it takes to reform the curriculum (What would it take?) At the minimum, we need to sit down with one another and reach consensus on the essentials-- what experience, knowledge and skills do students need to succeed? Second, we need to talk about priorities for the department. Our graduate program has had difficulty producing Ph.D.'s. Productivity problems are rooted in confusion about priorities.

It is interesting to compare the position of this faculty member with the following 
administrator's statement regarding Department $\mathrm{C}$ :

The department perceives they are under rather close scrutiny, but by and large the department has a solid program. They've gone through periods in which there have been internal upheavals, but those have been in the context of a good program trying to become better, not in the context of a bad program trying to become good. I would be surprised if the faculty perceives our concern as unfounded. Ultimately the department will decide what can or cannot be improved. I have nothing substantive to say to them-- so, our business is conducted accordingly.

Joining this administrator is another who believes the ultimate responsibility for academic program quality rests with the department. Her statement does, however, reflect knowledge of the department:

The chair prefers not having the dean involved too closely in the department. So, everything will be done to resolve issues before things surface to the level of the dean. I'm sure there is a lot that I don't even hear about, or at least that I officially hear about. A lot more surfaces through informal sources than formal ones. It is not a matter of trust, it's simply a matter of how decision-making is perceived at the department level. They imagine their department to be somewhat autonomous, and indeed, certain decisions are a matter of faculty prerogative.

When asked how closely the administration monitored the quality of academic programs, the chairperson of Department $\mathrm{C}$ responded simply, "The deans have filters into what's going on. Their job is very difficult, don't get me wrong. But I think to fully understand the needs of this department, you have to be the chairperson."

Faculty also indicated the leadership style of the chairperson as closely associated with departmental morale and general well-being. During separate interviews, chairpersons were asked to describe how they perceived their role. The chairperson of Department A described his role as follows:

I handle all of the day-to-day business so that the department can operate smoothly. I think a lot of my tasks are glorified administrative assistant functions that anyone with a certain sense of detail would be able to do. In fact, I probably handle too much for the department. But the faculty have 
come to believe that is a large part of my role. In handling all of these details, I have freed them to attend to their primary responsibilities. Over the years, I would say they have come to trust me in most matters. That trust has allowed me greater responsibility for formulating the goals and long-term direction of the department.

An Assistant Professor in Department A also offered his assessment of the chairperson's administrative style, and commented on how the chairperson was perceived by other faculty in the department:

I know that people look to him for everything. He really does run the department, but not in an obviously heavy-handed way. It's kind of funny that he engenders so much trust, because when you look at him he has that deadpanned, serious tone. Some people refer to him as "poker face," but the term is more endearing than critical. It's just that while he is the one mind that really determines how things will be done, people walk away appreciative. $\mathrm{He}$ is respected for his craftsmanship in administering the department. People know he has the best interests of the faculty in mind.

When asked to describe how he perceived his role, the chairperson of Department B described his role as having two separate dimensions. The first, he saw as his primary responsibility:

I see myself as facilitating faculty development. Basically, I try to support faculty and encourage them as they conduct their teaching and research. I see myself as representing the faculty to the administration. And I see myself as the line of information between the administration and the department. I see myself in both capacities as an advocate for the faculty and as a conduit for bringing administrative decisions down to the department. When I leave the chairmanship this year, I will return to the faculty ranks. Overall, I have always tried to be their colleague.

In terms of day-to-day management, he essentially conceded that the department was exceptionally large and that he relied on others to carry out specific program concerns:

The directors run their programs on a day-to-day basis. They come to me with problems, but they make their own decisions. In fact, I won't make decisions for them. Because of the size of our department, that's the way we operate. If a student calls with a complaint about an undergraduate matter, I will usually refer the person to the director of undergraduate programs. That person needs to take the appropriate action based on policies governing that program. I don't want to usurp their authority or make a decision that conflicts 
with what the program director would do. We do meet, sometimes two or three times a week. I advise them of what I think during those meetings.

The chairperson of Department $\mathrm{C}$ was also asked to describe how he perceived his role.

He focused his comments comparatively to previous chairpersons:

As chairman I have overall responsibility for the department in a variety of matters ranging from the budget to the organization of committees. I suspect that being chair of this department, in this university, is one of the most difficult jobs in the industry. The role has changed significantly over the past twenty years. It has moved somewhat from an authoritarian system to one which decisions are made in consultation with the faculty. I think at least, [previous chairpersons' names] would admit that during their regimes there was far less demand for faculty approval. It doesn't mean that I don't have authority in certain issues, I do. It simply means that there is more group decision-making. Whatever the department vote is, which I do record, I still have an obligation to express my opinions. There is still a sense of power in this leadership role, but I would argue that it is less than it was ten years ago. I suppose I suggest that the department has become more democratic. It's not the same world as it was ten years ago. There are clearly times that I wish I didn't have to go through the faculty for as many decisions as I have to. But, I recognize that the culture is changing.

An Assistant Professor in Department $\mathrm{C}$ used an analogy in offering his assessment of the chairperson's administrative style:

It's interesting that in academic life, some departments can become their own little feifdoms. They can be their own islands of admiration or hostility depending on who's running the department. Its amazing how little immediate influence a dean has over a chairperson, or a particular faculty. some people are too difficult for the central administration to control.

\section{The Work Climate and Faculty Attitudes Toward Work}

In the survey, secondary subjects were also asked to rate the work climate of the department on eight bi-polar adjective dimensions. They were given an eight point scale for each dimension and were asked to place an " $\mathrm{X}$ " in the appropriate box to indicate their personal rating for each characteristic, e.g.,

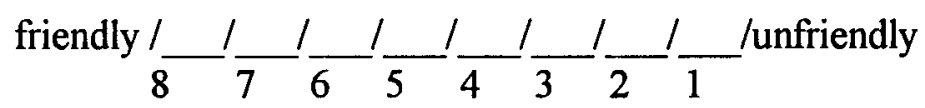

Since respondents were given a numerical scale, averages were derived to summarize 
overall responses. All faculty responded when asked to rate the department climate or atmosphere. Of the eight climate dimensions, three seemed particularly appropriate as measures of feelings of social isolation: friendly-unfriendly, rejecting-accepting, and cold-warm. In Table 8, these three dimensions are presented as Climate I.

Table 8.-- Characteristic Ratings for Climate I /Social Isolation

\begin{tabular}{lcccc}
\hline \hline $\begin{array}{l}\text { Averages for } \\
\text { Characteristics: }\end{array}$ & $\begin{array}{l}\text { Friendly (8.0)- } \\
\text { Unfriendly (1.0) }\end{array}$ & $\begin{array}{c}\text { Accepting (8.0)- } \\
\text { Rejecting (1.0) }\end{array}$ & $\begin{array}{l}\text { Warm (8.0)- } \\
\text { Cold (1.0) }\end{array}$ & $\begin{array}{l}\text { Standard } \\
\text { Deviation }\end{array}$ \\
\hline Department A & 6.3 & 5.7 & 5.8 & .262 \\
Department B & 5.6 & 5.3 & 4.9 & .287 \\
Department C & 5.7 & 5.2 & 4.7 & .408 \\
\hline
\end{tabular}

When looking at the characteristics of friendliness, acceptance, and warmth, Department A scored slightly higher than Departments B and C in all three characteristics. Although Departments B and C appear almost identical, Department B characteristic ratings have a $s d$ of .287 compared to a $s d$ of .408 for Department $\mathrm{C}$. The range of scores for all characteristics was 6.3 (Department A friendliness) to 4.7 (Department $\mathrm{C}$ warmth). As an overall picture, the social environment for Department A came to 5.93 on a 1 to 8 scale, compared to approximately 5.2 for Departments B and C. Generally, the data suggest that faculty in all three departments are friendlier than they are warm or accepting. Department $\mathrm{A}$ is rated as exhibiting the characteristics of friendliness, acceptance and warmth to a greater degree than the other two departments.

While generally supporting these ratings, the interview data were further analyzed to determine aspects of social isolation among faculty. When asked to describe relationships with colleagues, faculty members in department A spoke of "healthy tensions" which "have not caused a major split or division among faculty." One assistant professor in Department A remarked: 
It's not like people come, teach, and go. There are spontaneous occasions and more formal opportunities for intellectual discussions and socializing. A lot of it has to do with the right mix of personalities. More importantly, it has to do with the desire of most faculty to make the department a center of intellectual activity.

In Department B, faculty described relationships as "friendly...though people do not become friends." One assistant professor made the distinction that "people who have been here the longest tend to be indifferent while the younger end of the spectrum tend to be more friendly." Also commenting on how differences among faculty affect relationships, an associate professor claimed:

We avoid confrontation. When differences appear, we often ignore the issue or we try to arrive at consensus on the more superficial elements of the issue. In terms of scholarly differences, we tend to stay in our own corners. If these differences arise, people bite their tongues. Despite differences in scholarly views, people are at least civil to each other.

In Department $\mathrm{C}$, the survey rating for friendliness was notably higher than the characteristic rating for warmth, but only marginally higher than acceptance. When asked to descibe the relationships among faculty, an assistant professor quickly quipped, "We tend to congregate most closely to gossip," and then he further commented:

There is a preoccupation with, or predilection towards, controversy. People wouldn't say that they are gossiping, rather, they would say that they are keeping informed. The myth of collegiality also operates functionally in the department. There is a tendency for people who do not have the strongest liking for each other to be collegial. There has been warfare, but in general, once a meeting is over people put things aside. We are simply not as cohesive, though, as some would claim.

Both the survey and interview data point to varying degrees of social isolation among faculty, regardless of department.

On the survey, three of the eight dimensions seemed particularly appropriate for measuring attitudes toward work: satisfying-frustrating, interesting-boring, and enthusiastic-unenthusiastic. In Table 9, these three dimensions are presented as Climate II. 
Table 9.-- Characteristic Ratings for Climate II /Attitudes Toward Work

\begin{tabular}{lcccc}
\hline \hline $\begin{array}{l}\text { Averages for } \\
\text { Characteristics: }\end{array}$ & $\begin{array}{l}\text { Satisfying (8.0)-- } \\
\text { Frustrating (1.0) }\end{array}$ & $\begin{array}{l}\text { Enthusiastic (8.0)-- } \\
\text { Unenthusiastic (1.0) }\end{array}$ & $\begin{array}{l}\text { Interesting (8.0)-- Standard } \\
\text { Boring (1.0) }\end{array}$ & \begin{tabular}{c} 
Deviation \\
\hline Department A
\end{tabular} \\
\hline & 5.3 & 5.0 & 3.6 & .741 \\
Department B & 6.1 & 5.0 & 3.9 & .899 \\
Department C & 4.2 & 4.1 & 4.1 & .047 \\
\hline
\end{tabular}

Compared to Climate I, with Department A scoring higher than the other two departments in friendliness, acceptance and warmth, in Climate II the results are mixed. Department B scored highest in satisfaction, Department A and B scored approximately the same margin over Department C in enthusiasm (5.0 to 4.1), and Department C scored highest in interest. The average scores for Department $\mathrm{C}$, across all three characteristics, were highly consistent (4.1 or 4.2) with a $s d$ of .047, compared to a $s d$ of .741 for Department A and a $s d$ of 899 for Department B. As an overall picture, the work attitude characteristics for Department A averaged 4.6, Department B averaged 5.0, and Department C averaged 4.1. It should be noted that the characteristic, "interesting to boring", pulled both Department $A$ and $B$ averages down dramatically.

The last two dimensions seemed particularly appropriate for measuring attitudes toward performance: productive-unproductive and successful-unsuccessful. In Table 10, these two dimensions will be presented as Climate III.

Table 10.-- Characteristic Ratings for Climate III /Attitudes Toward Performance

\begin{tabular}{lccc}
\hline \hline $\begin{array}{l}\text { Averages for } \\
\text { Characteristics: }\end{array}$ & $\begin{array}{c}\text { Productive (8.0)-- } \\
\text { Unproductive (1.0) }\end{array}$ & $\begin{array}{c}\text { Successful (8.0)- } \\
\text { Unsuccessful (1.0) }\end{array}$ & $\begin{array}{c}\text { Standard } \\
\text { Deviation }\end{array}$ \\
\hline Department A & 5.7 & 3.2 & 1.25 \\
Department B & 5.3 & 4.1 & .6 \\
Department C & 4.7 & 3.5 & .6 \\
\hline
\end{tabular}


Every department averaged higher for productivity than for success, with the gap for Department A (2.5) more than twice the gap for Departments B and C (1.2). Department A low score of 3.2 for successfulness (lowest of the three departments) stands out compared to its 5.7 for productivity (highest of the three departments), its average of 5.93 for social environment characteristics, and its average 4.6 for work attitude characteristics. Characteristic ratings for Department A have a $s d$ of 1.25; more than double that of either Department B or C.

While the survey data related to Tables 9 and 10 indicate that faculty in Departments $\mathrm{A}$ and $\mathrm{B}$ are generally more satisfied and enthusiastic about their work than those in Department C, the lowest characteristic ratings for Climate II/Attitudes Toward Work (interesting to boring), and the lowest characteristic rating for Climate III/Attitudes Toward Performance (success) called for further examination.

In the interview data, when asked "how would you characterize your attitude toward work, and the attitude of others in your department" most faculty initially described their "deep satisfaction in getting to do what I really want to do professionally," or cited "professional freedom to explore what matters most to me" as indicators of enthusiasm for the academic life. Lower ratings for interest were attributed to the routine aspects of work. Explaining this further, an associate professor commented:

Both teaching and research become mundane. In terms of teaching, you can end up with the same courses again and again. A good teacher continually looks for new and interesting material to infuse enthusiasm. In terms of research, when you've rewritten something for the fourth time, it also becomes mundane. But, when you're satisfied that you've put down in good, solid form what you intended to, and it reads well, and it shows the roots of your research, you become energized to begin again.

A more revealing part of the interviews was related to a section asking faculty to "describe your version of an outstanding professor." The imagery of an outstanding professor changed slightly across departments. Department A had a more idealized version 
of the professor. The description was the perfect "combination of scholar and teacher, with research being front and center." The individual was described as someone who "imparts a sense of excitement, a love of learning, and who puts energy and enthusiasm into teaching." Of course, the ideal was also "someone who had national stature." For department B, the idealized type included the paragon of scholarship and teaching, but the scholar was defined as someone with "enormously high standards" and the teaching emphasis was with "brilliant books." The ideal was also someone who was "intellectually sharp" and "held a deep respect for students, and an even stronger obligation to them." For Department $\mathrm{C}$, the best idealized type was simply "a person who has a strong grasp of their discipline, but also responds to the institutional imperatives of teaching."

While the descriptions twisted and turned around general value terms, they ended in a strikingly normative posture, deifying research as the "foremost interest of the outstanding scholar." Would the expectations set forth for this idealized type help to shed light on survey differences, i.e., a high productivity rating and a low success rating, in the Climate III/Attitudes Toward Performance Scale?

When asked if their ideal type was something they could realistically achieve, faculty automatically observed that the most absorbing element of their work was teaching. A few claimed that teaching "can run down the intellectual core of a professionals' life" and that the resolution to this dilemma would be discovered in determining "how work is to be divided." Again, an associate professor commented:

A heavy teaching load is a problem for faculty who need to be engaged in scholarship. While I believe most are satisfied and enthusiastic about teaching, when scholarly work is pushed to the margin of our role, what stimulates us the most is denied to us.

Based on the interview data, it is likely that the ratings for productivity considered multiple aspects of the work role (teaching, research, administration, service) while ratings for success were predominately based on performance expectations for research. Even if 
this were the case, standards for success would not necessarily be based solely on publication, but perhaps on differing standards of excellence. An associate professor in Department A described the matter of research excellence in this way:

If research is a priority of the institution, the research produced should be of high quality and significant. How often is the frenzy related to research focused on ensuring publication rather than quality. Is the research produced the sort that intrigues and excites faculty? Does it explore new areas? Or, is it research that more easily appeals to particular sorts of journals?

\section{QUESTION 2: What is the role orientation of current group members? \\ The Role Orientation of Current Faculty}

To further understand the subcultures of the three departments under study, the survey included questions concerning the role orientation of current members. The questions ranged from items rating the relative importance of various academic tasks, to those estimating the amount of time spent working on these tasks. Results of this section of the survey are now presented. The results will also be reintroduced in Chapter $\mathrm{V}$ in order to determine the extent to which the role orientation of new faculty varies in comparison to current faculty.

Faculty were asked the average number of hours per week on all tasks related to the academic profession, including teaching, research, administration and service.

Table 11 depicts the average time per week spent on all tasks related to the academic profession, by department and rank.

In Department A, full professors all put in between 50 - 60 hours per week, associates all put in between 40 - 60 hours per week, and the two assistant professors averaged 55 hours per week. In Department B, full professors all put in between 50 - 60 hours per week, associates all put in between 45 - 65 hours per week, and the two assistant professors averaged 62.5 hours per week In Department $C$, full professors all put in between 40 - 60 hours per week, associates all put in between 45 - 70 hours per 
week, and the three assistant professors put in between 45 - 65 hours per week.

\begin{tabular}{|c|c|c|c|c|c|c|c|c|}
\hline Hours per Week & 40 & 45 & 50 & 55 & 60 & 65 & 70 & Average \\
\hline \multicolumn{9}{|l|}{ DEPARTMENT A } \\
\hline Professors $(n=3)$ & & & 2 & & 1 & & & 53 \\
\hline Associate $(n=6$ & 1 & 1 & & 1 & 3 & & & 53 \\
\hline Assistant $(n=2)$ & & 1 & & & & 1 & & 55 \\
\hline \multicolumn{9}{|l|}{ DEPARTMENT B } \\
\hline Professor (n=3) & & & 1 & & 2 & & & 57 \\
\hline Associate $(n=5)$ & & 1 & 1 & 2 & & 1 & & 54 \\
\hline Assistant $(n=2)$ & & & & 1 & & & 1 & 62 \\
\hline \multicolumn{9}{|l|}{ DEPARTMENT C } \\
\hline Professor $(n=4)$ & 1 & & & 1 & 2 & & & 54 \\
\hline Associate $(n=4)$ & & 1 & 1 & & & 1 & 1 & 57 \\
\hline Assistant $(\mathrm{n}=3)$ & & 1 & 1 & & & 1 & & 53 \\
\hline
\end{tabular}

As Table 11 shows, the average number of hours spent per week on all tasks related to the academic profession, including teaching, research, administration and service, was approximately 55 hours regardless of department or rank. The sole exception perhaps worth noting falls with the two assistant professors in Department B averaging 62.5 hours; having been upwardly skewed with one respondent denoting 70 hours per week.

The survey asked the faculty to separately estimate the percentage of their time spent in each of the following tasks: teaching, research, department administration, university administration, and service.

\section{Table12 shows the \% of time spent teaching, by department and rank.}

In Department A, the assistant professors averaged $57 \%$ of their time teaching, the associate professors $35 \%$, and the full professors $22 \%$. In Department $\mathrm{B}$, the responses showed that the assistant professors averaged $45 \%$ of their time teaching, the associate professors $50 \%$, and the full professors $50 \%$. In Department $\mathrm{C}$, the responses showed that time spent teaching for the assistant professors averaged $57 \%$, the associate professors 
Table 12.--ACTUAL Percentage of Time TEACHING

\begin{tabular}{|rrrrrrr|}
\hline $5 \%$ & $10 \%$ & $15 \%$ & $20 \%$ & $25 \%$ & $30 \%$ & $35 \%$
\end{tabular}

\begin{tabular}{|lllllllll}
$40 \%$ & $45 \%$ & $50 \%$ & $55 \%$ & $60 \%$ & $65 \%$ & $70 \%$ & $75 \%$ & Average \\
\hline
\end{tabular}

\section{DEPARTMENT A}

Professor $(\mathrm{n}=3)$

Associate $(\mathrm{n}=6)$

Assistant $(n=2)$ 2

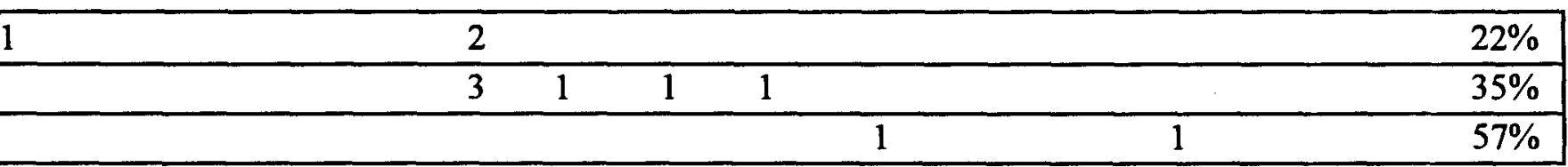

DEPARTMENT B

Professor $(\mathrm{n}=3)$

Associate $(\mathrm{n}=5)$

Assistant $(\mathrm{n}=2)$

DEPARTMENT C

Professor $(n=4)$

Associate $(n=4)$

Assistant ( $\mathrm{n}=3)$

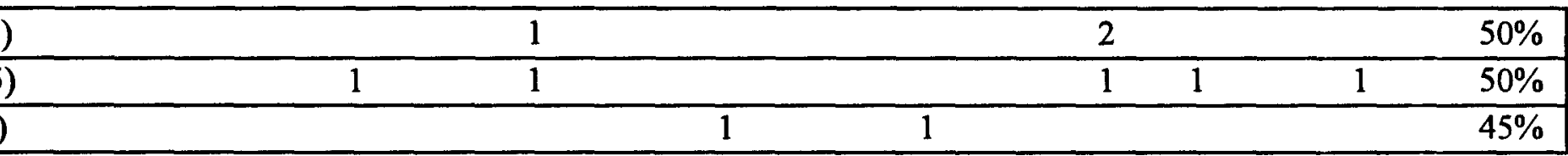

(1)

\begin{tabular}{|c|c|c|c|}
\hline & 1 & 2 & $50 \%$ \\
\hline 1 & 1 & & $42 \%$ \\
\hline & 1 & 2 & $57 \%$ \\
\hline
\end{tabular}


$42 \%$, and the full professors $50 \%$. As Table 12 shows, time spent teaching was inversely related to rank for Department A; relatively uniform for Department B; and mixed for Department C.

The survey also asked the faculty to separately rate the relative importance or value of the same academic tasks: teaching, research, department administration, university administration, and service.

\section{Table 13 shows the importance of teaching, by department and rank.}

In Department A, when asked to rate the relative importance of teaching, the assistant professors assigned values of $75 \%$ and $35 \%$ for teaching relative to the other tasks, associate professors averaged 29\%, and full professors averaged 33\%. In Department B, the assistant professors assigned an average value of $35 \%$ for teaching relative to the other tasks, associate professors averaged $45 \%$, and full professors averaged $43 \%$. In Department $\mathrm{C}$, the assistant professors assigned an average value of $42 \%$ for teaching relative to the other tasks, associate professors averaged $37 \%$, and full professors averaged $45 \%$.

As Table 13 shows, across the three departments, associate professor results show a close relationship between actual time spent teaching and the importance of teaching compared to other ranks. Assistant and full professors, in Departments B and C, spent more time teaching compared to their ranking of the importance of teaching, while assistant professors in Department A show the closest relationship between actual time and importance of teaching than any other group. In general, all ranks across departments spend more time teaching than the importance ascribed to it, with the exception of full professors in Department A who spend significantly less time teaching than the importance ascribed to it. 
Table 13.--IDEAL Percentage of Time TEACHING

\begin{tabular}{|c|c|c|c|c|c|c|c|c|c|c|c|c|c|c|c|c|}
\hline & $5 \%$ & $10 \%$ & $15 \%$ & $20 \%$ & $25 \%$ & $30 \%$ & $35 \%$ & $40 \%$ & $45 \%$ & $50 \%$ & $55 \%$ & $60 \%$ & $65 \%$ & $70 \%$ & $75 \%$ & Average \\
\hline DEPARTMENT A & & & & & & & & & & & & & & & & \\
\hline Professor $(n=3)$ & & & & & 2 & & & & & 1 & & & & & & $33 \%$ \\
\hline Associate $(n=6)$ & & & 1 & 1 & & 2 & 1 & & 1 & & & & & & & $29 \%$ \\
\hline Assistant $(n=2)$ & & & & & & & 1 & & & & & & & & 1 & $55 \%$ \\
\hline
\end{tabular}

DEPARTMENT B

\begin{tabular}{|c|c|c|c|c|}
\hline Professor $(n=3)$ & & 1 & 2 & $43 \%$ \\
\hline Associate $(n=5)$ & 1 & 1 & 2 & $45 \%$ \\
\hline Assistant $(n=2)$ & & 1 & 1 & $35 \%$ \\
\hline
\end{tabular}

DEPARTMENT C

\begin{tabular}{|c|c|c|c|c|}
\hline Professor $(n=4)$ & 1 & 1 & 1 & $45 \%$ \\
\hline Associate $(n=4)$ & & 1 & 2 & $37 \%$ \\
\hline Assistant $(n=3)$ & 1 & & 2 & $42 \%$ \\
\hline
\end{tabular}


Table 14 shows the \% of time spent on research, by department and rank.

As Table 14 shows, time spent on research was very consistent among rank for Department C; whereas for Department B, associate and full professors averaged about $22 \%$, compared to assistants averaging $35 \%$; and in Department $\mathrm{A}$ associates and full professors averaged about $29 \%$, compared to assistants averaging $20 \%$. In other words, assistant professors in Department B spent significantly more time researching than other rank in their department, whereas assistant professors in Department A spent significantly less.

Table 15 shows the importance of research, by department and rank.

In Department $\mathrm{A}$, when asked to rate the relative importance of research, the assistant professors assigned values of $10 \%$ and $40 \%$ for research relative to the other tasks, associate professors averaged $37 \%$, and full professors averaged $30 \%$. In Department B, the assistant professors assigned an average value of $35 \%$ for research relative to the other tasks, associate professors averaged 35\%, and full professors averaged 30\%. In Department $\mathrm{C}$, the assistant professors assigned an average value of $42 \%$ for research relative to the other tasks, associate professors averaged $42 \%$, and full professors averaged $32 \%$.

As Table 15 shows, across departments and all ranks there is not a single subgroup spending more time on research than the importance ascribed to it, except for the marginal differences of Department $\mathrm{C}$ full professors. Sub-groups with the biggest divergences are associate professors in Departments B and C, and assistant professors in Department C.

Table 16 shows the \% of time spent on department administration, by department and rank. 
Table 14.--ACTUAL Percentage of Time RESEARCH

\begin{tabular}{|c|c|c|c|c|c|c|c|c|c|c|c|c|c|c|c|c|}
\hline & $5 \%$ & $10 \%$ & $15 \%$ & $20 \%$ & $25 \%$ & $30 \%$ & $35 \%$ & $40 \%$ & $45 \%$ & $50 \%$ & $55 \%$ & $60 \%$ & $65 \%$ & $70 \%$ & $75 \%$ & Average \\
\hline DEPARTMENT A & & & & & & & & & & & & & & & & \\
\hline Professor $(n=3)$ & & & & 1 & & 2 & & & & & & & & & & $27 \%$ \\
\hline Associate $(n=6)$ & & & 1 & & 1 & 2 & & 2 & & & & & & & & $30 \%$ \\
\hline Assistant $(n=2)$ & & & 1 & & 1 & & & & & & & & & & & $20 \%$ \\
\hline
\end{tabular}

DEPARTMENT B

\begin{tabular}{lllllllll} 
Professor $(\mathrm{n}=3)$ & & 1 & & 1 & 1 & & & $23 \%$ \\
\hline Associate $(\mathrm{n}=5)$ & 1 & 1 & 1 & & 1 & 1 & & $22 \%$ \\
\hline Assistant $(\mathrm{n}=2)$ & & & & & 1 & & 1 & $35 \%$ \\
\hline
\end{tabular}

\section{DEPARTMENT C}

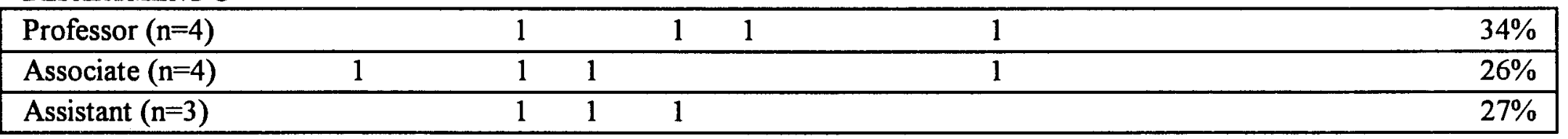


Table 15.--IDEAL Percentage of Time RESEARCH

\begin{tabular}{|c|c|c|c|c|c|c|c|c|c|c|c|c|c|c|c|c|}
\hline & $5 \%$ & $10 \%$ & $15 \%$ & $20 \%$ & $25 \%$ & $30 \%$ & $35 \%$ & $40 \%$ & $45 \%$ & $50 \%$ & $55 \%$ & $60 \%$ & $65 \%$ & $70 \%$ & $75 \%$ & Average \\
\hline \multicolumn{17}{|l|}{ DEPARTMENT A } \\
\hline Professor $(n=3)$ & & & & 2 & & & & & & 1 & & & & & & $30 \%$ \\
\hline Associate $(n=6)$ & & & & 1 & & 3 & & 1 & & & & & & 1 & & $37 \%$ \\
\hline Assistant $(n=2)$ & & 1 & & & & & & 1 & & & & & & & & $25 \%$ \\
\hline \multicolumn{17}{|l|}{ DEPARTMENT B } \\
\hline Professor $(n=3)$ & & & & 1 & & 1 & & 1 & & & & & & & & $30 \%$ \\
\hline Associate $(n=5)$ & & 1 & & & & 1 & & 1 & 1 & 1 & & & & & & $35 \%$ \\
\hline Assistant $(n=2)$ & & & & & & 1 & & 1 & & & & & & & & $35 \%$ \\
\hline \multicolumn{17}{|l|}{ DEPARTMENT C } \\
\hline Professor $(n=4)$ & & 1 & & & & 1 & & 1 & & 1 & & & & & & $32 \%$ \\
\hline Associate $(n=4)$ & & & & 1 & & & & 1 & & 1 & & 1 & & & & $42 \%$ \\
\hline Assistant $(n=3)$ & & & & & & & 1 & & 2 & & & & & & & $42 \%$ \\
\hline
\end{tabular}


Table 16.--ACTUAL Percentage of Time DEPARTMENT ADMINISTRATION

\begin{tabular}{|c|c|c|c|c|c|c|c|c|c|c|c|c|c|c|c|c|}
\hline & $5 \%$ & $10 \%$ & $15 \%$ & $20 \%$ & $25 \%$ & $30 \%$ & $35 \%$ & $40 \%$ & $45 \%$ & $50 \%$ & $55 \%$ & $60 \%$ & $65 \%$ & $70 \%$ & $75 \%$ & Average \\
\hline \multicolumn{17}{|l|}{ DEPARTMENT A } \\
\hline Professor $(n=3)$ & & & & & & 2 & & & & & & & & & & $20 \%$ \\
\hline Associate $(n=6)$ & & 1 & 2 & 2 & & & & 1 & & & & & & & & $20 \%$ \\
\hline Assistant $(n=2)$ & & 1 & & & 1 & & & & & & & & & & & $17.5 \%$ \\
\hline
\end{tabular}

\section{DEPARTMENT B}

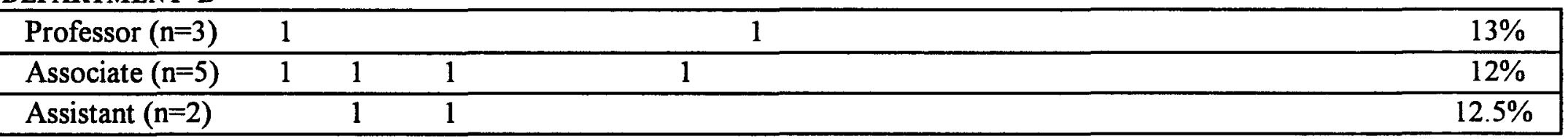

\section{DEPARTMENT C}

Professor $(n=4)$

Associate $(n=4)$

Assistant $(\mathrm{n}=3)$

1

$14 \%$

$12.5 \%$

$\begin{array}{ll}1 & 1 \\ 2 & 1\end{array}$

2

$7 \%$


In Department $A$, the responses showed that time spent on department administration was fairly consistent among rank: assistant professors averaged $17.5 \%$, associate professors averaged 20\%, and full professors averaged 20\%. In Department B, time spent on department administration was fairly consistent among all ranks (about 12.5\%). In Department $\mathrm{C}$, time spent on department administration for assistant professors averaged 7\%, associate professors averaged $12.5 \%$, and full professors averaged $14 \%$.

As Table 16 shows, time spent on department administration was similar among rank in Department A, similar among rank in Department B, and somewhat proportional to rank in Department $\mathrm{C}$.

Table 17 shows the importance of department administration, by department and rank.

In Department A, when asked to rate the relative importance of department administration, all three full professors did not respond; all six associate professors answered, averaging 16\%; and the two assistant professors averaged $12.5 \%$. In Department B, two of the three full professors did not respond, with the third responding $30 \%$; all five associate professors answered, averaging $9 \%$; and the two assistant professors averaged 15\%. In Department $\mathrm{C}$, all four full professors answered, averaging $16 \%$; associate professors averaged $10 \%$; and assistant professors averaged $5 \%$.

As Table 17 shows, in rating the relative importance of department administration, Department $\mathrm{C}$ was proportional to rank, while in Departments A and B, five out of six full professors did not respond, possibly implying a lack of importance despite greater actual time spent in department administration. Department $\mathrm{C}$ shows a closer relationship between importance of department administration and actual time spent than the other two departments. Regardless of rank, faculty in Department A spent more time on department 
Table 17.--IDEAL Percentage of Time DEPARTMENT ADMINISTRATION

\begin{tabular}{|c|c|c|c|c|c|c|c|c|c|c|c|c|c|c|c|c|}
\hline & $5 \%$ & $10 \%$ & $15 \%$ & $20 \%$ & $25 \%$ & $30 \%$ & $35 \%$ & $40 \%$ & $45 \%$ & $50 \%$ & $55 \%$ & $60 \%$ & $65 \%$ & $70 \%$ & $75 \%$ & Average \\
\hline \multicolumn{17}{|l|}{ DEPARTMENT A } \\
\hline Professor $(n=3)$ & & & & & & & & & & & & & & & & $0 \%$ \\
\hline Associate $(n=6)$ & 2 & & 1 & 2 & & 1 & & & & & & & & & & $16 \%$ \\
\hline Assistant $(n=2)$ & 1 & & & 1 & & & & & & & & & & & & $12.5 \%$ \\
\hline
\end{tabular}

\section{DEPARTMENT B}

Professor $(n=3)$

Associate $(n=5)$

1

Assistant $(\mathrm{n}=2)$

$2 \quad 2 \quad 1$

$10 \%$

$9 \%$

DEPARTMENT C

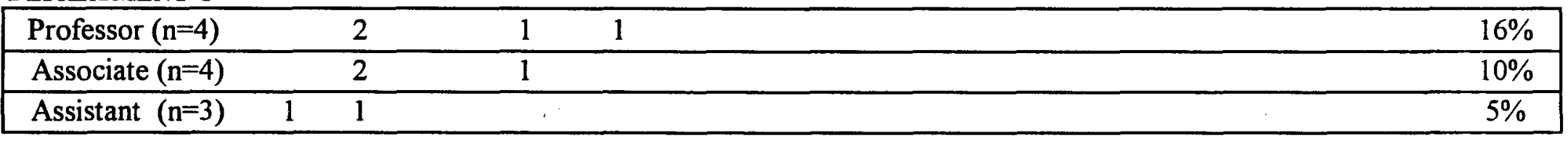


administration than faculty in the other two departments. The sub-group with the biggest divergence is that of full professors in Department A.

Table 18 shows the \% of time spent on university administration, by department and rank.

In Department $\mathrm{A}$, the responses showed that time spent on university administration was proportional to rank: assistant professors averaged $2.5 \%$, associate professors averaged $10 \%$, and full professors averaged $25 \%$, with one response of $55 \%$. In Department B, assistant professors averaged $5 \%$ for time spent on university administration; associate professors averaged $16 \%$, with one response of $65 \%$; and full professors averaged $10 \%$. In Department $\mathrm{C}$, two of the three assistant professors answered 5\%; the associate professors averaged $6 \%$, and the full professors averaged $11 \%$.

As Table 18 shows, time spent on university administration was proportional to rank in all three departments.

Table 19 shows the importance of university administration, by department and rank.

In Department A, when asked to rate the relative importance of university administration, of the three full professors, two said $50 \%$ and one did not respond; all six associate professors answered, averaging $12 \%$; and the two assistant professors averaged $5 \%$. In Department B, of the three full professors, two averaged $17.5 \%$ and one did not respond; only three of the five associate professors answered, two said 5\% and one said $40 \%$; and of the two assistant professors, only one responded, with $20 \%$. In Department $\mathrm{C}$, of the four full professors, three answered $10 \%$ and one did not respond; of the four associate professors, one answered $10 \%$ and three did not respond; and of the three 
Table 18.--ACTUAL Percentage of Time UNIVERSITY ADMINISTRATION

$$
\begin{array}{llllllllll}
\mathbf{5} \% & \mathbf{1 0} \% & \mathbf{1 5} \% & \mathbf{2 0} \% & \mathbf{2 5} \% & \mathbf{3 0} \% & \mathbf{3 5} \% & \mathbf{4 0} \% & \mathbf{4 5} \% & \mathbf{5 0} \%
\end{array}
$$

\section{DEPARTMENT A}

Professor $(n=3)$

Associate $(\mathrm{n}=6)$

Assistant $(n=2) \quad 1$

2

$25 \%$

$10 \%$

$2.5 \%$

\section{DEPARTMENT B}

Professor $(n=3)$

Associate $(\mathrm{n}=5)$

Assistant $(\mathrm{n}=2)$

\section{DEPARTMENT C}

Professor $(\mathrm{n}=4)$ 2

Associate $(\mathrm{n}=4)$ 1

Assistant $(\mathrm{n}=3) \quad 2$

\begin{tabular}{l}
$11 \%$ \\
\hline $6 \%$ \\
\hline $3 \%$ \\
\hline
\end{tabular}


Table 19.--IDEAL Percentage of Time UNIVERSITY ADMINISTRATION

\begin{tabular}{|c|c|c|c|c|c|c|c|c|c|c|c|c|c|c|c|c|}
\hline & $5 \%$ & $10 \%$ & $15 \%$ & $20 \%$ & $25 \%$ & $30 \%$ & $35 \%$ & $40 \%$ & $45 \%$ & $50 \%$ & $55 \%$ & $60 \%$ & $65 \%$ & $70 \%$ & $75 \%$ & Average \\
\hline DEPARTMENT A & & & & & & & & & & & & & & & & \\
\hline Professor $(n=3)$ & & & & & & & & & & 1 & & & & & & $33 \%$ \\
\hline Associate $(n=6)$ & 2 & 2 & & 2 & & & & & & & & & & & & $12 \%$ \\
\hline Assistant $(n=2)$ & 2 & & & & & & & & & & & & & & & $5 \%$ \\
\hline
\end{tabular}

DEPARTMENT B
\begin{tabular}{|lllll|}
\hline Professor $(\mathrm{n}=3)$ & 1 & 1 & 1 & $12 \%$ \\
\hline Associate $(\mathrm{n}=5)$ & 2 & & & $10 \%$ \\
\hline Assistant $(\mathrm{n}=2)$ & 1 & & $10 \%$ \\
\hline
\end{tabular}

\section{DEPARTMENT C}

\begin{tabular}{|c|c|c|}
\hline Professor $(n=4)$ & 3 & $7.5 \%$ \\
\hline Associate $(n=4)$ & 1 & $2.5 \%$ \\
\hline Assistant $(n=3)$ & 11 & $5 \%$ \\
\hline
\end{tabular}


assistant professors, one did not respond and the other two averaged 7.5\%. Department A is proportional (with two full professors stating 50\%), whereas Department $\mathrm{B}$ and $\mathrm{C}$ are mixed.

As Table 19 shows, there is a close relationship within departments, especially in Department $\mathrm{C}$; and rank, especially for assistants; for actual time spent on university administration and the importance ascribed to it. Full professors in Department A ascribed the most importance to university administration, and compared to all other sub-groups, spent the greatest actual time in this area.

Table 20 shows the \% of time spent on service, by department and rank.

In Department A, the responses showed that as for the time spent on service, no one spends more than 10\%: assistant professors averaged $2.5 \%$, associate professors averaged 5\%, and full professors chose not to respond. In Department B, only three of the ten faculty responded to the question of time spent on service -- one assistant professor said $5 \%$ and two full professors said $5 \%$. In Department $C$, only four (4) of eleven faculty responded to time spent on service -- with two assistant professors answering $10 \%$, associate professors averaging $10 \%$, and full professors chose not to respond.

\section{Table 21 shows the importance of service, by department and rank}

In Department $\mathrm{A}$, when asked to rate the relative importance of service no one stated more than $10 \%$ : one of the two assistant professors stated $5 \%$, associates averaged $7 \%$, and the two full professors responding averaged $5 \%$. In Department $\mathrm{B}$, again, only three faculty responded -- one associate said $5 \%$, and the full professors averaged $5 \%$. In Department $\mathrm{C}$, six of the eleven faculty responded when asked to rate the relative importance of service -- two assistant professors stated $10 \%$, associates averaged $7.5 \%$, and two of the four full professors stated $10 \%$. 
Table 20.--ACTUAL Percentage of Time SERVICE

\begin{tabular}{|c|c|c|c|c|c|c|c|c|c|c|c|c|c|c|c|c|}
\hline & $5 \%$ & $10 \%$ & $15 \%$ & $20 \%$ & $25 \%$ & $30 \%$ & $35 \%$ & $40 \%$ & $45 \%$ & $50 \%$ & $55 \%$ & $60 \%$ & $65 \%$ & $70 \%$ & $75 \%$ & Average \\
\hline \multicolumn{17}{|l|}{ DEPARTMENT A } \\
\hline Professor $(n=3)$ & & & & & & & & & & & & & & & & $0 \%$ \\
\hline Associate $(n=6)$ & 2 & 2 & & & & & & & & & & & & & & $5 \%$ \\
\hline Assistant $(n=2)$ & 1 & & & & & & & & & & & & & & & $2.5 \%$ \\
\hline
\end{tabular}

\section{DEPARTMENT B}

Professor $(\mathrm{n}=3)$

Associate $(\mathrm{n}=5)$

Assistant $(\mathrm{n}=2)$ $2.5 \%$

\section{DEPARTMENT C}

Professor $(n=4)$

Associate $(\mathrm{n}=4)$

Assistant $(n=3)$

2

1

\begin{tabular}{|c|c|c|}
\hline & & $0 \%$ \\
\hline 1 & 1 & $10 \%$ \\
\hline 2 & & $7 \%$ \\
\hline
\end{tabular}


Table 21.--IDEAL Percentage of Time SERVICE

\begin{tabular}{|lllllllllllllllll}
$5 \%$ & $10 \%$ & $15 \%$ & $20 \%$ & $25 \%$ & $30 \%$ & $35 \%$ & $40 \%$ & $45 \%$ & $50 \%$ & $55 \%$ & $60 \%$ & $65 \%$ & $70 \%$ & $75 \%$ & Average \\
\hline
\end{tabular}

\section{DEPARTMENT A}

\begin{tabular}{|llll|}
\hline Professor $(n=3)$ & 2 & & $5 \%$ \\
\hline Associate $(n=6)$ & 2 & 3 & $7 \%$ \\
\hline Assistant $(n=2)$ & 1 & & $2.5 \%$ \\
\hline
\end{tabular}

\section{DEPARTMENT B}

\begin{tabular}{|lllll|}
\hline Professor $(\mathrm{n}=3)$ & 1 & 1 & $5 \%$ \\
\hline Associate $(\mathrm{n}=5)$ & 1 & & $1 \%$ \\
\hline Assistant $(\mathrm{n}=2)$ & & & $0 \%$ \\
\hline
\end{tabular}

\section{DEPARTMENT C}

Professor $(n=4)$

Associate $(n=4)$

Assistant $(\mathrm{n}=3)$

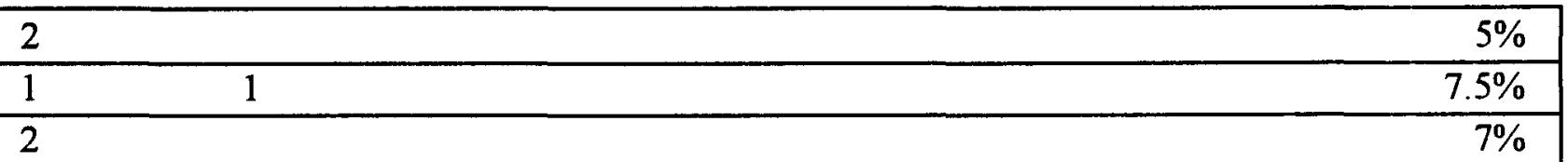


As Tables 20 and 21 show, when asked to rate the relative importance of service, only 17 of 32 faculty responded with no one stating more than $10 \%$,-- except for one associate professor in Department C who stated 20\%. Department B attached the least importance to service, while Department $\mathrm{C}$ attached slightly more importance to service than Department A. There is a close relationship in every sub-group between actual hours spent in service and importance attached to it, with no single sub-group averaging greater than $10 \%$.

Table 22 compares the actual percentage of time spent on each academic task and the relative importance ascribed to each task, by department and rank.

As depicted in Table 22, the percentage of time spent on academic tasks compared to the relative importance ascribed to the same tasks can be summarized as follows:

1. Teaching: Across the three departments, associate professors show a close relationship between actual time spent teaching and the importance of teaching compared to other ranks. Assistant and full professors, in Departments B and C, spent more time teaching, while Department A assistants show the closest relationship between actual time and importance of teaching than any other group. In general, all ranks across departments spend more time teaching than the importance ascribed to it, with the exception of Department A full professors who spend significantly less time teaching than the importance ascribed to it.

2. Research: Across departments and all ranks, there is not a single sub-group spending more time on research than the importance ascribed to it, except for the marginal difference with Department $\mathrm{C}$ full professors. With that exception and Department B assistant professors, all ranks spent less time on research than their ideal. Sub-groups with the biggest divergences are associate professors in Department B and C, and assistant professors in Department C. 
Table 22.--Comparison of Actual Time/Importance of All Tasks

\begin{tabular}{|llllll}
\hline \hline$\frac{\% \text { ACTUAL TIME }}{0_{\text {\% IDEAL }}}$ & TEACHING & RESEARCH & DEPT. ADMN & UNIV. ADMN. & SERVICE \\
\hline
\end{tabular}

DEPARTMENT A

\begin{tabular}{|ccccll|}
\hline Professors & 22 & 27 & 20 & 25 & 0 \\
& $\mathbf{3 3}$ & $\mathbf{3 0}$ & $\mathbf{0}$ & $\mathbf{3 3}$ & $\mathbf{3}$ \\
\hline Associates & 35 & 30 & 20 & 10 & 5 \\
& $\mathbf{2 9}$ & $\mathbf{3 7}$ & $\mathbf{1 6}$ & $\mathbf{1 2}$ & $\mathbf{7}$ \\
\hline Assistants & $\mathbf{5 7}$ & 20 & 17.5 & 2.5 & 2.5 \\
& $\mathbf{5 5}$ & $\mathbf{2 5}$ & $\mathbf{1 2 . 5}$ & $\mathbf{5}$ & $\mathbf{2 . 5}$ \\
\hline
\end{tabular}

DEPARTMENT B

\begin{tabular}{|llllll|}
\hline Professors & 50 & 23 & 13 & 10 & 3 \\
& $\mathbf{4 3}$ & $\mathbf{3 0}$ & $\mathbf{1 0}$ & $\mathbf{1 2}$ & $\mathbf{5}$ \\
\hline Associates & 50 & 22 & 12 & 16 & 0 \\
& $\mathbf{4 5}$ & $\mathbf{3 5}$ & $\mathbf{9}$ & $\mathbf{1 0}$ & $\mathbf{5}$ \\
\hline Assistants & 45 & 35 & 12.5 & 5 & 2.5 \\
& $\mathbf{3 5}$ & $\mathbf{3 5}$ & $\mathbf{1 5}$ & $\mathbf{1 0}$ & $\mathbf{0}$ \\
\hline
\end{tabular}

DEPARTMENT C

\begin{tabular}{|clllll|}
\hline Professors & 50 & 34 & 14 & 11 & 0 \\
& $\mathbf{4 5}$ & $\mathbf{3 2}$ & $\mathbf{1 6}$ & $\mathbf{7 . 5}$ & $\mathbf{5}$ \\
\hline Associates & 42 & 26 & 12.5 & 6 & 10 \\
& $\mathbf{3 7}$ & $\mathbf{4 2}$ & $\mathbf{1 0}$ & $\mathbf{2 . 5}$ & $\mathbf{7 . 5}$ \\
\hline Assistants & 57 & 27 & 7 & 3 & 7 \\
& $\mathbf{4 2}$ & $\mathbf{4 2}$ & $\mathbf{5}$ & $\mathbf{5}$ & 7 \\
\hline
\end{tabular}

3. Department Administration: Department $\mathrm{C}$ shows a closer relationship between importance of department administration and actual time spent than the other two departments, especially Department A. Regardless of rank, Department A faculty spent more time on department administration than faculty in the other two departments. The sub-group with the biggest divergences is that of full professors in Department A.

4. University Administration: There is a close relationship in Department $\mathrm{C}$ for actual time spent on university administration and the importance ascribed to it. Department A full professors ascribed the most importance to university administration, and compared to 
other sub-groups, spent the greatest actual time in this area.

5. Service: There is a close relationship in every sub-group between actual hours spent in service and the importance attached to it, with no single sub-group averaging greater than $10 \%$.

\section{Summary of Data Analysis}

In this chapter, the culture of the organization and the subcultures of the three participating departments are examined from the ideational (content) perspective of current culture bearers. To understand the culture of the institution, particular attention was devoted to issues of greatest consensus interpretation or perceptions of members. To understand the subculture of each department, particular attention was devoted to issues around which there was the greatest variation across departments.

While overall issues regarding the institution were complex and varied, within the range of issues expressed, patterns did emerge to permit further grouping of comments around single topics. Institutional culture was characterized in terms of four broad and interrelated themes: perceptions regarding the current transitory state of the institutional mission; perceptions regarding the diminishing Catholic nature of the institution; perceptions regarding shifting role expectations for faculty performance; and perceptions regarding the changing nature of the departments and disciplines. The assumptions, understandings, and meanings shared by current group members can be summarized as follows:

1. In one manner or another, all 65 coded transcript references related to institutional mission pointed to an institution in transition theme. Some respondents strongly supported the changing nature of the institution, some were less supportive of a shift in mission, and a few were openly resistant toward any perceived change in mission. Faculty generally expressed uncertainty regarding the eventual outcome of this transition. 
2. There was significant agreement that the institution was moving away from its founding teaching mission-- but, faculty were less certain of the full character and direction of the change. There was also agreement that, for the present time, the university was stressing a balance between research and teaching.

3. Faculty cited the religious nature of the institution as the primary force through which the tradition of learning had historically been reinforced. While most faculty described obvious indicators of a religious presence, or ways in which this presence had diminished over time, other faculty pointed to less obvious examples, e.g., that equity was an embedded value which permeated the organization-- a deep belief that everyone should be treated fairly.

4. While the nature of the religious tradition was seen as a continuing positive presence, faculty tended to make strong distinctions between this tradition and the diminishing importance of the Catholic nature of the institution.

5. Faculty perceived a shift in performance expectations away from teaching and increasingly toward research. Survey questions related to the issue showed that $(94 \%)$ of the faculty felt pressure to perform research; $(76 \%)$ reported pressure to increase involvement in research during the past 5 years; and, with the exception of associate professors in Department A, 85\% reported difficulty in balancing teaching and research.

6. Faculty in all three departments described the gradual shift towards specialization as departments became Ph.D. granting entities, increasingly divided relationships between older and newer faculty, and marked concerns regarding limited resources extended to support developmental changes. Despite these concerns, most faculty reported that the various changes in the institution and departments were somewhat positive.

The second section of the chapter was devoted to the three subcultures involved in the study. Survey and interview data were analyzed in relation to two dimensions: the 
overall environment and faculty morale, and the work climate or faculty attitudes toward work. Approximately 10 interview hours were conducted as a follow-up to the survey responses. A total of 82 coded transcript references were analyzed in relation to the two subcultural dimensions. Particular attention.was devoted to issues around which there were significant variation in interpretations or perceptions of members.

Survey responses related to the overall environment and to general faculty morale showed that the various changes in the institution and department work environments, as well as in faculty morale, were perceived as somewhat positive. This was especially true in the work environment, where both institution and department questions evoked a positive response from the majority of respondents. Departmentally, Department A was very positive in both the work environment and in faculty morale; compared to positive for work environment and mixed for faculty morale for Department B; and mixed for work environment and negative for faculty morale for Department $\mathrm{C}$. The interview data generally reflected these findings. Factors which were cited as contributing to positive morale included the overall quality of the academic program and the leadership style of the chairperson. For Department C, poor faculty morale was also attributed to these two factors.

In the survey, secondary subjects were also asked to rate the work climate of the department on eight bi-polar adjective dimensions. Generally, the data suggest that faculty in all three departments are more friendly than they are warm or accepting. Department A is rated as exhibiting the characteristics of friendliness, acceptance and warmth to a greater degree than the other two departments. Both the survey and interview data point to varying degrees of social isolation among faculty, regardless of the department.

The survey data also indicated that faculty in Departments A and B are generally more satisfied and enthusiastic about their work than those in Department C. The lowest characteristic ratings regarding attitudes toward work (interesting to boring) were 
attributed to the routine aspects of work. The difference in rating of productivity versus success were attributed to two factors: in rating productivity, faculty considered multiple aspects of the work role (teaching, research, administration, service) while ratings for success were predominately based on performance expectations for research. To further understand the subcultures of the three departments under study, the survey included questions concerning the role orientation of current members. The average number of hours spent per week on all tasks related to the academic profession, including teaching, research, administration and service, was approximately 55 hours regardless of department or rank.

The role orientation of faculty in each subculture can be summarized as follows:

Department A: Overall, the faculty do not spend as much time researching as they would like to, they spend more time in department administration than they would prefer, and they don't spend as much time in university administration as they would like. Full professors don't spend as much time in teaching or research as they would like given their responsibilities with department administration; associate professors would like to research more and teach less, and while the assistant professors are content with their teaching load, they still would like more time for research.

Department B: Full and associate professors reported that they would like to teach less and research more, while assistant professors seem to have reached a balance between the teaching and research roles.

Department $\mathrm{C}$ : Full professors reportedly have reached a balance between the teaching and research roles; for associate professors, there is a disparity between time spent on research and their much higher ideal; and assistant professors definitely prefer to teach less and research more.

In order to determine the extent to which the role orientation of new faculty varies in comparison to current faculty, these findings will be further discussed in Chapter V. 


\section{CHAPTER V}

\section{SOCIO-CULTURAL (PROCESS) DATA RESULTS}

\section{Introduction}

This chapter summarizes the results of the data analyses for primary subjects.

In order to describe the organizational entry process as new faculty became members of three separate academic departments within an institution of higher education, a conceptual model was drawn from theoretical constructs described in research on faculty development during organizational entry; from sociological studies on socialization and organization commitment; and from sociological, anthropological and higher education literature on organizational culture. The model suggests four sequential stages of organizational entry, including: (1) the pre-arrival stage, dealing primarily with an individual's predispositions prior to entering a new setting; (2) the encounter stage, dealing with an individual's preconceptions formed during recruitment and selection; (3) the adaptation stage, dealing with the external socialization processes and the initiate's identification with the organization; and (4) the commitment stage, dealing with the extent to which the norms and values of the local culture are assimilated by new organization members.

To describe the factors involved in each organizational entry stage, three newly hired faculty members (primary subjects), one from each department studied, were followed through the process. Qualitative methods were employed to capture their personal experiences. These methods included observation, structured and open-ended interviews, and a $\log$ format for primary subjects to record their affective and cognitive reactions to experiences encountered. Initial data collection corresponded to the time frame suggested by these four sequential stages: pre-arrival data were collected before the new faculty 
entered the setting and encounter data were collected a few days before faculty began their first week of work during the fall semester. To describe the adaptation and commitment stages, one interview per month was conducted with each primary subject beginning with the second week of the fall semester and continuing through the spring semester, a nine month period. During that time, primary subjects also maintained a log in which affective and cognitive reactions to important elements of their socialization were recorded. By analyzing data collected from the personal logs and interviews, factors involved throughout the stages of organizational entry became apparent and the explanatory power of the model was tested.

\section{Analysis of Socio-Cultural (Process) Data}

After all interviews were transcribed, data were categorized first into the appropriate stage of organizational entry: pre-arrival, encounter, adaptation, or commitment. In each stage, categorized data addressed the following questions:

Interview notations categorized as part of the pre-arrival stage addressed the question: what anticipatory socialization experiences does the newcomer bring into the new setting?

Prior to their first week in the department, new faculty were asked to complete a section of the survey administered to current faculty in the three participating departments. This survey section measured the relative importance of various academic tasks-- teaching, research, department administration, university administration, and service. This allowed current member responses of the relative importance of these academic tasks to be compared to the responses of primary subject. The data also allowed insight into what extent the role orientation of new faculty varied within and across disciplines?

Interview notations categorized as part of the encounter stage addressed the 
question: what preconceptions are formulated regarding the new setting?

Interview notations and log entries categorized as part of the adaptation stage addressed the question: in what manner were new faculty socialized and in what manner were cultural nuances transmitted?

Finally, interview notations categorized as part of the commitment stage addressed the question: to what degree are professional identity and role orientation adjusted as one is enculturated?

In this chapter, results are presented so as to address each question in relation to the four suggested sequential stages of organizational entry. To maintain confidentiality, pseudonyms have been assigned to each of the primary subjects and identifying characteristics have been changed.

\section{Stage One: Pre-Arrival}

\section{What professional identity and role orientation do newcomers bring into a new setting as a result of their anticipatory socialization experience?}

Prior to their arrival, the three primary subjects were at different points in their academic job search: In Department A, Tom was more seasoned having been in the job market for more than three years. During that period, he pursued his research and the year prior to accepting the position he served as an instructor at a liberal arts college on the east coast. Shortly before applying for the position, he had secured a book contract and was working on two short pieces for an encyclopedia in his discipline. During the first interview, he exuded confidence and enthusiasm which was to last well into the first term in his new position. In Department B, John was visibly uneasy during the first interview. His hesitancy was apparent given the number of questions he raised regarding the amount of time required to participate in the study. After learning more about the nature of the study and the requirements for participating, John quickly offered that his concern was solely 
with time factors involved. He was in the process of completing his dissertation when he accepted the position and indicated that finishing it would be his first priority. In subsequent sessions, John did not raise further concerns regarding time factors involved in the study. In Department C, Bill had graduated the spring prior to accepting the position. He seemed eager to participate in the study and he appeared to enjoy speculating about the new experiences which were about to unfold.

In the pre-arrival stage, three areas were considered to determine how candidates might later interpret experiences in the new setting: the primary subjects' graduate training experience, the values acquired during that period (professional identity), and the role orientation of primary subjects prior to entering the new setting. A few days before they began their first week of work during the fall semester, the primary subjects talked at length about graduate training. When asked to briefly describe their graduate program, and to indicate if anyone had been especially influential during that period of study, the following descriptions were offered:

Department AVTom: I did my graduate work, as well as my undergraduate, at (name of university) where I studied under (name of professor). I would describe my relationship with him as ideal. He always took the time out for questions and helped me with whatever problems I had. Because we had similar interests outside of class (cites research interests and sports), we became very good personal friends. His scholarship, his teaching, his modesty and general approach to research in the discipline will serve as my model for much of my career. Of course, there are some things we differ on-he tends to be more politically conservative than me, and he can be too defensive of institutions, even when they are wrong. These criticisms do not outweigh the many good things that came out of our relationship. Despite this good relationship, I found graduate training difficult and the institution failed to adequately support its students.

(When asked what he most admired about his mentor, he continued with...) It was his enthusiasm and love of the subject. It generated excitement and it evoked a passion about doing something scholarly in your daily living experience. I think most people live for their leisure, not their work. That's an aspect of life I wanted to avoid. 
In the description of his mentor, Tom did not use the word "scholarly" solely to mean research, but in terms of "blending research and teaching." He spoke about learning to think critically in the classroom and of the importance of "making judgments in written work." He also indicated that while graduate school had provided him formal training in this regard, learning to do things by himself was the basis of his socialization-- "essentially, you learn by yourself and you complete your dissertation by yourself-- people who get through that kind of experience have to have some passion for scholarly pursuits." $\mathrm{He}$ suggested that as a result of this training, scholars tended to be "more private...people who like to be independent."

Although a less flattering portrait of his mentor is provided, in Department B, John's comments reflect common sentiments regarding the motivational level required for successfully completing graduate studies--but, unlike Tom in Department A, he suggested that graduate training, and his mentor, had not fully prepared him for the work he was about to pursue.

Department B/John: I did my work at (name of university) in a very large program in which the graduate students were widely scattered and there was little sense of community. The M.A. program was huge and no one was guaranteed entrance into the Doctoral program. You had to prove yourself the first year in order to get into the Ph.D. program. The Ph.D. program had considerably fewer students than in the M.A. program. No one monitored student progress; the program required a great deal of self-reliance and selfmotivation. I had one mentor throughout most of my graduate years, as well as several other professors with whom I worked frequently.

(When asked if he had been influenced by his mentor, he continued with...) I think the most important thing I learned from this mentor was the importance of teaching, of placing the concerns of the students above all else in one's academic career. I don't think either my mentor or my graduate training gave me a thorough knowledge of the mechanics of the academic profession.

John concluded that what had kept him motivated was not his mentor or other faculty, but rather, his "love of the subject." 
Without pausing for a moment to reflect, in Department C, Bill indicated that graduate school had not been enjoyable and, unlike the other new faculty in the study, he had not had a faculty mentor within his program. He emphatically added the following:

Department C/Bill: I'd say mostly it was hell. I didn't have a mentor. It is perhaps becoming increasingly rare to have one these days. My advisors were helpful, but I had little affection for them and I saw them rarely except when I began work on my dissertation. I probably learned more about the profession from my aunt, who is a professor of religion at (name of university). She is a tireless researcher and networks very well. She is keen on success, but our visions of the profession and the good life in academia are somewhat different. I don't have the same ambitions. She wants an established reputation and she is constantly traveling, giving papers, and heavily involved in her professional association. She is also more interested in graduate studies than in teaching undergraduates.

(When asked what he most admired about his aunt, he continued with...) My aunt is great, she's amazing. Her overall enthusiasm in doing what she is passionate about is what I most admire. It's the philosophy that I differ on. You know...the more you teach, the less status you have. If you don't teach at all and are successful at pure research, you have the highest status. I think that's perverse.

A review of the responses from the first interview indicates the key values primary subjects had acquired during graduate training. In Department $\mathrm{A}$, Tom indicated that graduate school had taught him to be self-reliant, he admired his mentor's enthusiasm for and love of the subject, and his work ethic was extremely strong-- but, he had found that graduate school had failed to support these values; perhaps because of this, he mistrusted institutions. In Department B, John suggested that graduate school required self-reliance and self-motivation. Unlike the other two subjects, he felt that a person had to prove worthy to be admitted to graduate school. Perhaps because of that experience, he claimed he would place a concern for students above other aspects of his career. In Department C, Bill pronounced, almost defiantly, that in spite of his research-oriented graduate school, his identity was toward teaching. He exuded enthusiasm for teaching and took many 
opportunities to point out that he did not share the research ambitions others (he admired) seemed to have.

\section{To what extent does the role orientation of new faculty vary within and across disciplines?}

The traditional view of socialization in higher education is that the role orientation acquired in graduate school remains relatively stable over time, thus, it was important to identify primary subjects' role orientation prior to entering the new setting. Prior to their first week in the department, new faculty were asked to complete a section of the survey administered previously to current faculty in the three participating departments. In this section of the survey, primary subjects were asked to rate the relative importance or value of various academic tasks, including: teaching, research, department administration, university administration, and service. These data allow the role orientation of primary subjects to be compared to that of their home department, as well as, to the role orientation identified by primary subjects at the end of the entry period.

Table 23 depicts the relative importance primary subject $A$ ascribed to each task, in comparison to secondary subjects in his department.

Table 23.--Comparison of the Importance of All Tasks/Primary Subject A

\begin{tabular}{|c|c|c|c|c|c|}
\hline \% IDEAL & TEACHING & RESEARCH & 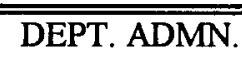 & UNIV. ADMN. & SERVICE \\
\hline
\end{tabular}

DEPARTMENT A

\begin{tabular}{|cccccc|}
\hline Professors & 33 & 30 & 0 & 33 & 3 \\
\hline Associates & 29 & 37 & 16 & 12 & 7 \\
\hline Assistants & 55 & 25 & 12.5 & 5 & 2.5 \\
\hline Primary Subject A & $\mathbf{4 0}$ & $\mathbf{4 0}$ & $\mathbf{1 0}$ & $\mathbf{0}$ & $\mathbf{1 0}$ \\
\hline
\end{tabular}

In Department A, the primary subject places less value (i.e., percentage of time) on teaching than do his peers (the other assistant professors), but more value on teaching than either the associate or full professors. He places more value (i.e., percentage of time) for research than the assistant professors. In fact, he places more weight on research than all 
faculty in his department.

Table 24 depicts the relative importance primary subject $B$ ascribed to each task, in comparison to secondary subjects in his department.

Table 24.--Comparison of the Importance of All Tasks/Primary Subject B

\begin{tabular}{|c|c|c|c|c|c|}
\hline \% IDEAL & TEACHING & RESEARCH & DEPT. ADMN. & UNIV. ADMN. & $\overline{\text { SERVICE }}$ \\
\hline
\end{tabular}

DEPARTMENT B

\begin{tabular}{|cccccc|}
\hline Professors & 43 & 30 & 10 & 12 & 5 \\
\hline Associates & 45 & 35 & 9 & 10 & 5 \\
\hline Assistants & 35 & 35 & 15 & 10 & 0 \\
\hline Primary Subject B & $\mathbf{4 5}$ & $\mathbf{4 5}$ & $\mathbf{0}$ & $\mathbf{0}$ & $\mathbf{1 0}$ \\
\hline
\end{tabular}

In Department B, the primary subject places more value on both teaching and research than do his peers (the other assistant professors). In fact, he places more value on research than the associate and full professors in his department, but the same value on teaching.

Table 25 depicts the relative importance primary subject $\mathbf{C}$ ascribed to each task, in comparison to secondary subjects in his department.

Table 25.--Comparison of the Importance of All Tasks/Primary Subject C

\begin{tabular}{|c|c|c|c|c|c|}
\hline \% IDEAL & TEACHING & RESEARCH & 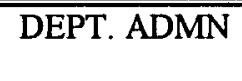 & UNIV. ADMN. & SERVICE \\
\hline
\end{tabular}

DEPARTMENT $C$

\begin{tabular}{|ccccll|}
\hline Professors & 45 & 32 & 16 & 7.5 & 5 \\
\hline Associates & 37 & 42 & 10 & 2.5 & 7.5 \\
\hline Assistants & 42 & 42 & 5 & 5 & 7 \\
\hline Primary Subject C & $\mathbf{6 5}$ & $\mathbf{3 5}$ & $\mathbf{0}$ & $\mathbf{0}$ & $\mathbf{0}$ \\
\hline
\end{tabular}

In Department C, the primary subject places far more value (i.e., percentage of time) on teaching than do his peers (the other assistant professors), and far more value on teaching than either the associate or full professors. He places less value (i.e., percentage of time) on research than the assistant and associate professors in his department, placing him at about the same level as full professors. 
To further delineate role orientation, in the second interview, each primary subject was asked to respond to the question: what are the beliefs (norms of the profession) to which you ascribe? The responses approximate the role orientation reported from the survey data.

Department AVTom: I think the discipline is too diffuse and complex to impose any single set of norms on those who study and practice the art of writing and teaching. For me, I prefer a balance between teaching and writing. I think a good teacher must be enthusiastic about his subject, and to maintain that enthusiasm one must continually raise new questions. At the same time, new discoveries must be put into language and forms that make knowledge accessible to a wider public. This is where teaching comes in. Teaching helps one to sift through many ideas and theories. If it doesn't fly in the classroom, something must be wrong. In sum, too much teaching leads to burnout; too much research and writing isolates the scholar from his or her public.

Department B/ John: I believe professors must pursue their own research to the best of their capabilities and make an attempt to teach as well as possible. I also believe that professors should always treat students fairly and professionally. What I value most about the profession is the opportunity it gives me to pursue my interest in (name of subfield) studies. I have found teaching both enjoyable and illuminating. I'm not certain, though, that I would have chosen an academic career if it had not allowed me the freedom to pursue my own research.

Department C/Bill: The profession is supposed to be fun. I believe that the tenure track, rat race is perverting the profession. It devalues teaching and forces people to generate rubbish in order to get published. I am opposed to the success, career mentality and will only stay in the profession as long as it is fun. What I most value is that I don't have to wear a suit. I can work at home if I want to. I'm glad I don't work for a profit-making organization. I get to do what I really like to do-- read, write, think and argue. I get the chance to convey to others how much fun thinking can be and that there is more to life than making money.

The primary subjects in Departments A and B placed greater value on research than current faculty in their home departments, and incidentally, across the three departments in this study. They spoke at length about their research interests and offered the following descriptions of their research methodology: 
Department AVTom: I'm not a number cruncher; it's boring. I like the detective aspect of research. Maybe that's the Irish cop in me. I like solving the mysteries. I don't approach things with specific questions that I try to prove or disprove. I look at the material, and by asking how, what, and where, a picture emerges. I immerse myself in the material and the problem is a lot of the work you do ends up being extraneous to the subject you're writing about. In a sense, some would accuse me of shoddy thinking; that I don't organize my research or questions from the start.

(When asked to compare his methods to other disciplines in the Humanities and Social Sciences, he continued with...) Other disciplines may try to come to some large theoretical conclusion using explanatory devices or models. I frown on that. The more research I do, the more confused I am about the past. That isn't a contradiction, it's an irony, a paradox. One studies to understand the world better and the more you study, the less you know. It happens in all disciplines. Unlike a political scientist or sociologist or economist, I take materials which were intended for other purposes and derive meaning from them. Other disciplines often create data. Sociologists do interviews, anthropologist hang out with the natives--I analyze documents and material which may have been written 100 years ago. This kind of research requires creativity. Political scientists talk about an "ordered sequence of facts" upon which one can theorize; we do not have such facts. When asked how he had formulated these views, he replied...) These are opinions I formulated in graduate school.

In Department B, John differentiated his research methods from the subject matter he would emphasize in teaching. He characterized his research as "traditional" and his subject matter, or teaching style, as progressive:

\section{Department B/John:}

My scholarly methods are fairly traditional, or conservative, but my training has been to emphasize cultures other than Western and voices other than males. I don't feel that the methods I have chosen are an important product of my graduate training. I suspect it is a product of my undergraduate experience. There are a couple of different issues that might be worth sorting out. Using conservative methodology is distinct from my approach to teaching. As far as what I think is important to teach, I'm anything but conservative. I strongly believe that the canons of what is considered important work needs to be changed; what once was excluded should be taught. So in that sense, I don't consider my teaching style as conservative, while I do consider my research methods as conservative. As to whether my methods will change, I expect that they will change somewhat over time.

Although Bill ascribed less importance to research than either assistant or associate 
professors in his home Department $\mathbf{C}$, he places approximately equal, or greater, value to research than current faculty across the three study departments. He described his research methodology as follows:

Department C/Bill: I guess my experience is colored by (his graduate school). In our department, there were strong clashes in "world views" among faculty. People were known to fight bitterly over how the program would be structured; which sub-fields would be emphasized. Central to the arguments were the sharp differences in approaches to research. Students were exposed to the arguments and they would adopt certain values on one side or the other. The subfield I pursued tends to be the smallest of four specialized areas in the discipline. My methods are interdisciplinary. I don't draw sharp boundaries and I'm not quantitative. I interpret text, which means that I don't approach research with the same set of questions used in other subfields. It is likely that others would not consider what I write as good scholarship.

The survey responses measuring role orientation, corresponding to the role orientations described in the interviews, can be summarized as follows. In Department A, Tom prefers a balance between teaching and research. His peers, the other assistant professors, reported greater importance for teaching than research. In fact, Tom placed greater importance on research than all of his colleagues. In Department B, John placed more value on both teaching and research than the assistant professors; and he placed more value on research than all of his colleagues. In fact, he claims he would not have chosen an academic career had it not allowed him to pursue research. In Department C, Bill placed more value on teaching than all colleagues in his department and less value on research than the assistant and associate professors, with approximately the same importance assigned to research as full professors in his department. However, his research response was greater than, or equal to, the responses across all three study departments. Overall, in Departments A and B, the primary subjects placed greater importance on research than faculty across all three departments. In Department C, the primary subject placed greater importance on teaching than faculty across all three 
departments. Analyses of both survey and interview data indicates primary subjects' role orientations respectively as: (a) Tom prefers a balance between teaching and research; (b) John prefers research; and (c) Bill prefers teaching.

In summary, the three areas considered during the pre-arrival stage included the primary subjects' graduate training experience, the values acquired during that period (professional identity), and their role orientation prior to entering the new setting. During organizational entry, these three areas are seen as predispositions-- a lens through which new faculty might later interpret experiences encountered in the new setting. It is through these lens that the next stages are viewed.

\section{Stage Two: Encounter}

Through what processes are newcomers able to detect, diagnose and interpret expectations of an institution and the work environment?

Data related to the encounter stage are organized in three sections. First, current faculty describe the hiring procedures in the three study departments. Then, primary subjects describe their perceptions of the job search and selection process, followed by perceptions as recalled from their on-campus interviews.

\section{Hiring Procedures Across The Three Departments}

The selection of faculty can be divided into a series of somewhat overlapping procedures reportedly common to higher education institutions (Kaplowitz, 1986). These procedures include: seeking administrative approval to fill a new or replacement position; organizing and appointing a search committee; advertising the position; selecting a pool of candidates; screening candidates; interviewing candidates; and selecting top candidates. First, it was necessary to determine the degree to which procedures for hiring new faculty were formalized in each department, and whether the procedures were uniform across departments. 
Table 26 depicts the degree to which procedures for hiring new faculty were formalized in each department.

Table 26.-- \% of Current Faculty Rating Formalized Hiring Procedures/By Department.

\begin{tabular}{llcccc}
\hline \hline & & YES & SOMEWHAT & NOT AT ALL & DON'T KNOW \\
\hline \hline Department A & $(\mathrm{n}=11)$ & $64 \%$ & $36 \%$ & & \\
& & & & & \\
Department B & $(\mathrm{n}=10)$ & $60 \%$ & $40 \%$ & & \\
& & & & & \\
Department C & $(\mathrm{n}=11)$ & $36 \%$ & $46 \%$ & $9 \%$ & $9 \%$ \\
\hline
\end{tabular}

When current faculty were asked to assess the degree to which procedures for hiring new faculty were formalized in each department, all responses were generally positive. In Departments A and B, all faculty responded yes or somewhat to the question; while $82 \%$ responded yes or somewhat in Department $\mathrm{C}$.

Interviews with a select sample of current faculty further supported these findings. Faculty in all three departments cited comparable hiring process components similar to the national norms described above, including: academic departments are not given new or replacement positions automatically; the recruitment process is seen as the responsibility of the department chairperson; the screening process is viewed as the role of the appointed search committee; and the interview process is seen as an essential role of all full-time department faculty. The recruitment and hiring process procedures described by current faculty were fairly uniform across the three departments. The chairperson of one of the search committees provided a synopsis of these procedures:

The search usually begins by advertising in our association's job newsletter. It lists all the jobs by state. They describe the job, any special requirements, and whether it is tenure track, or a temporary position. We automatically request a cover letter, the candidate's vitae and at least three letters of recommendation. After we've reviewed and verified the application materials, if we are further interested in an individual, we request a writing sample. After we've seen the writing sample and have gone over all recommendations, we select a pool of candidates. If they are still interested 
in us, then the next step is to arrange an interview. Normally, we try to arrange the initial interview schedule in conjunction with the association's convention. Based on this screening, we invite particular candidates to the campus for a second interview. The interview usually involves a presentation to the department; small group interviews; a seminar if time permits; and a social gathering, or dinner, with department representatives.

From these same interviews, another aspect of the hiring process was introduced. Although generally perceived as an open and competitive process, all six of the current faculty interviewed suggested that, in some cases, interviews were actually "preferential" and that "what a candidate may not realize is that one can be supported or torpedoed by individual faculty." When asked to describe further this preferential aspect, an assistant professor commented as follows:

On several occasions, when a senior faculty member wanted a particular candidate, questions were raised to challenge and embarrass the candidate. If there are turf battles or other hidden agendas, a candidate may not fully understand the hostile atmosphere or range of questioning. There are always human agendas in any department that reflect what's going on. All it takes is for one person in the department to undermine another person's candidate. All in all, the process is fluky. It's all very subjective. Standards change all of the time. A subject is in one year, but not the next. Issues of race, gender and ethnicity all figure in.

In summary, while survey responses indicate that recruitment and hiring procedures were fairly uniform across the three departments, the interviews introduced a caveat: hiring criteria changed, "based on department needs at particular points in time," and, occasionally, the process was perceived as preferential.

Within this context, primary subjects' perceptions of the job search and selection processes were explored.

\section{Perceptions of the Job Search and Selection Processes}

When asked why they applied for the position, and why they believed they had been hired; the three primary subjects commented on the length of their job search, what initially attracted them to the university, and why they believe they were hired: 
Department A/Tom: The university advertised an opening in my field (name of subfield). I also liked the fact that it was in a large city. I never really had a first choice; the job market is too tight to go into the application process with such a goal in mind. I applied to schools and universities all over the country, probably around 25 or 30 in number. I believe I was hired because I had a book contract, because I made a good presentation to the faculty, and because I had good teaching recommendations

(When asked if he believed the process was open and competitive, he replied...) I like to think that people found me likable. At the same time I think they saw me as someone who could add something to the department that they didn't have before. And, that they were getting an easily agreeable colleague who did work others were not doing-- they saw that as benefiting the department. So, I think both entered in; being likable and filling a particular need. Ultimately I think my credentials were of primary importance because of the detailed search I had to go through and because of the range of people involved in the interview. Being a seasoned interviewee also helped. The more you go through the process, the more relaxed you are and the more you look at factors other than your performance. The first interview I went on, I was overly concerned about the presentation. I was terrified. I talked so fast. There were 50 people in the audience and I wondered why they were all there to hear me. I didn't experience any of that in this interview.

(After further describing other interview experiences, he concluded by saying...) The interview and your credentials can have very little to do with why you are hired. One of my friends hadn't even finished his dissertation and I already had an article published. He got the job and I didn't. I thought what's going on here? I realized a lot of it had to do with the field. He was the right person at the right time and they took a chance with him. So, it's more than just credentials. It's being the right kind of fit. Another friend of mine wasn't considered here, probably because he was writing about gay culture... and that was too controversial for this university to hear about. His book is being published and he has more articles than I do. A lot has to do with the topic you pick.

Although on the job market for a shorter period of time, John indicated that his selection was the "fortunate" outcome of an anxiety-filled job search:

Department B/John: I applied for the position because, given its graduate program, I believed the university would have both motivated students and excellent research supports. I need to do my research, and adequate supports are very important to me. I also applied because the position which was 
advertised matched my area of specialization. The university was not my first choice for several reasons, the most important being that in taking the position my wife was forced to transfer out of her medical school. Moving to this city also meant leaving family and friends and coming to a place where we knew almost no one. The university was, however, high on the list of institutions I had applied to-- at least 25 , but I couldn't possibly name them all. I believe I was hired because of my versatility and because my initial interview went well. My background and area of specialization also allow me to teach particular courses that the department wanted to offer. I may have seemed a more useful addition to the department than other candidates whose qualifications may have been equal or better.

(When asked how long he had been searching for a position, he replied...) I got the position here my first year on the job market. I felt very fortunate especially because this was the only firm job offer I had after 25 applications. I also felt fortunate in getting the position because I was not the first candidate selected. I understand that he took a position elsewhere. I didn't feel coming out of the search...well, I didn't feel like I had been tremendously successful. I couldn't pick and choose where I wanted to go. And during the whole job search process, I kept asking, what am I going to do if I don't get a job? I associate the job search process as part of the whole graduate school experience. None of it was fun; it was psychologically debilitating.

In Department C, Bill indicated that although he had sent out numerous applications, the job search had been relatively quick and painless:

Department C/Bill: One applies to almost any tenure track opening when one is in (name of subfield). I really never heard of this university before I applied, but I was called rather quickly. Their job notice sounded right up my alley. I loved the place when I came for an interview. The Chair took good care of me and I was impressed by their commitment to teaching and research. I also liked the idea of available research supports. I had one previous call and interviewed at (name of university), but I disliked it intensely. The position sounded like naked exploitation; they were antiteaching, yet they had little money for research. I believe I was hired because I'm good, because I had good recommendations from big-wigs in the profession, I went to a top name school, and I gave a good presentation on my research. I do know, however, that I was not their first choice.

In summary, the three primary subjects claimed to know little about the institution before interviewing. All three were impressed by the thorough screening and interview process; which they perceived as fair. In Department A, Tom believed he had been 
selected because he was seen as congenial and because he perceived his credentials as superior. In Department B, John believed he had been selected because he was perceived to be a useful addition to the department. He felt fortunate to get the position because he was not the first candidate. In Department $\mathrm{C}$, Bill believed he had been hired because he had excellent recommendations, he came from a prestigious graduate school, and he gave a good presentation on his research. He also indicated that he knew he had not been the department's first candidate. During organizational entry, perceptions about individual selection criteria are likely to be incorporated within a set of preconceptions candidates formulate about the institution. These data show that positive perceptions of selection reinforced positive aspects of choice; new faculty were satisfied with their decision to join the university, and despite the difficulties encountered during the overall job search, they believed their decisions were positive career choices.

\section{Perceptions Following the On-Campus Interviews}

During the encounter stage, candidates are seen as selecting or attending to information in the form of norms, expectations, or general impressions of the institution. The primary subjects' on-campus interviews were the primary occasions for gathering such information. When the new faculty were asked what impressions they had formed about the university as a result of the interview process, they responded as follows:

Department A/Tom: I was favorably impressed with the university during the interview. After studying at (his graduate school) and teaching for a year at (name of college), as well as growing up in the East, I probably had a little educational elitism. And after being raised as a Catholic and going to parochial school for 12 years, I was always suspicious of what type of academic freedom existed at Catholic universities. My interview dispelled many of these misconceptions. The university seems to be trying to upgrade its standing by recruiting a more research-oriented faculty. Of course, this has both good and bad points. Overall, I think the good points will ultimately make the university a more intellectually alive institution and improve its reputation nationwide. I was also impressed with the quality of the current faculty, both in terms of their scholarship and in the thoughtful and fair way 
they treated me during my visit. The fact that the department is located in this new building is also an example of how the university is promoting the humanities. I think all of these things are a good sign of a positive future for the institution. It's unlike either (his graduate school) or the liberal arts college I taught at last year. It is interested in both teaching and research, which means it's the kind of institution where I can thrive.

Department B/John: I got the impression that the department strongly supported research and cared about its students. I also got the impression that the institution as a whole was dedicated to improving itself, and that the members of my department felt that their conditions at work were improving and would continue to improve. Almost everyone I met during the process was friendly; the only exception were people who were indifferent. Actually, I saw the downtown campus first and they put me in a hotel near the campus. The location was nice, but I got the impression that the department was in a very cramped place. When I came to this campus, I was especially impressed with this building because it's new. That's very rare for the humanities to be in one of the newer buildings on campus. The humanities are usually located in the oldest, most beaten down building. I guess that's the way it was here. I think that may be a reflection of the institution's Jesuit tradition of interest in humanities. Also, to do your research you need a good library. The university does not have a great research library, but the Newberry Library is downtown and our library belongs to a good network for interlibrary loans.

Department C/Bill: The faculty seemed upbeat about the students; they were friendly and were interested in making a good impression on me. I knew I wanted this job. I think the training that I was getting in graduate school was too far removed from teaching. My graduate advisor didn't like to hear that kind of talk. She told me at one point that people from (his graduate school) shouldn't think that way; that schools of lesser stature produce teachers. They would say that my values are really screwed up. Because I got through my dissertation quickly and I wrote a fairly good one, they envisioned me to be on the career fast-track. But, I didn't want to be someone who just does research. I guess I left them with the impression that I hadn't been socialized to the important values of the profession. (laughing) So they probably think they failed with me. I'm really upbeat about being in an institution that doesn't buy into that rat race.

In summary, during the encounter stage, primary subjects formulated the following general impressions of the university or department: in Department A, Tom believed that the university was trying to upgrade its national reputation, but that equal value was placed on teaching and research; in Department B, John got the impression that the department 
strongly supported research and cared about its students; and in Department C, Bill thought his training in graduate school was too far removed from teaching and he looked forward to working in an environment that supported teaching. The data showed that preconceptions formulated following the on-campus interviews were as follows: (a) Tom felt the institution was a place where he could thrive; (b) John believed that the entire university was dedicated to improving itself; and (c) Bill strongly believed that the institution did not "buy into the research rat race."

\section{Perceptions Regarding Performance Expectations}

During the encounter stage, perceptions regarding performance are expected to be formulated. These expectations are important because they are likely to be incorporated within the overall preconceptions faculty formulate about the new setting. Thus, when the new faculty were asked to describe their department's expectations for performance, they responded as follows:

Department A/Tom: Judging from what I was told during my interview, my tenure and promotion will be based fifty percent on research and publishing and fifty percent on teaching. I have to be rated good in both of those areas and be excellent in at least one. In addition, some service work will be considered, but it will not be primary. In tangible terms, this means publishing my book, continuing to do research in the next six years, and maintaining a good teaching record. For other faculty members, I think there are similar expectations.

(When asked if he had formulated goals for the first few months, he responded with...) I have my work cut out for me. I will need to publish my book within the year, complete and publish an article I plan to give at a conference in spring, and complete and publish two short essays for two different disciplinary encyclopedias. My immediate and most important concern is to improve my teaching.

Department B/John: I think the department expects faculty, and especially new, young faculty, to publish a significant quantity of work and to teach effectively. Research is more easily quantified than proficiency in teaching. Therefore, I think the publishing requirement may at least seem more important. Given the nature of the university, I think the department also 
expects faculty to serve on committees and hold positions of responsibility. I think that this requirement, or demand, is less during the first year.

When asked if he had formulated goals for the first few months, he responded with...) At this point in my career I feel that I need to finish my dissertation as quickly as possible in order to fulfill both the department's requirements of me and my own expectations. I will need to work steadfastly this year to develop new teaching skills. I particularly need to learn how to teach graduate students in a way that is both challenging and respectful to them.

Department C/Bill: They say one thing, but who knows what the reality is? I will have to teach well-- getting good evaluations from the students and the chairperson-- and I need to publish at least one article per year. It would also be good to present a paper, each year, at a conference. If I do this consistently, they say I will get tenure. This seems fair to me.

(When asked if he had formulated goals for the first few months, he responded with...) I need to concentrate on, and experience, teaching. During the first year I will experiment. I hope to have the opportunity to learn from others who have been doing this awhile. The profession is not very good about transmitting such knowledge. One is forced to rely on memories of good teachers one had in the past. I also need free time to pursue my own research. This will not be possible this term given my courseload, but I will have more time next term. I need to get integrated into the larger profession through conferences and meetings.

Based on these general responses, primary subjects translated their perceptions into tangible goals, or performance expectations, for their first year. These goals reflect differing emphasis on teaching and research, but all emphasize teaching: (a) Tom planned an ambitious research schedule for publishing his book and various articles, and his most important goal was to improve his teaching; (b) John indicated that he needed to complete his dissertation as quickly as possible and to work steadfastly in developing new teaching skills; and (c) Bill planned to concentrate on teaching.

During the encounter stage, impressions of the new setting are seen to intermingle with personal predispositions. As impressions and expectations are processed using past experiences and values as a frame of reference, preconceptions about the new setting are formed. During the adaptation stage, preconceptions of the institution, and of performance 
expectations, may either support or confuse faculty as they assimilate to their new work roles.

The next section addresses the adaptation process and primary subjects' responses to the socializing efforts of the organization.

\section{Stage Three: Adaptation}

\section{In what manner are cultural nuances transmitted to new members and to what extent are they adopted?}

After newcomers have formulated a set of individual preconceptions regarding the reality in which they expect to function, the adaptation process is seen to begin. Given that the department provides the milieu in which new faculty are socialized, it was important to determine initially if formal procedures for orienting new faculty were perceived, by current faculty, as common practice. Thus, current faculty perceptions regarding the socialization process were measured first, followed by analyses of primary subject data on socialization experiences.

\section{Current Faculty Perceptions of Socialization}

First, it was necessary to determine the degree to which procedures for orienting new faculty were formalized in each department, and whether these procedures were seen as uniform across the study departments.

\section{Table $\mathbf{2 7}$ depicts the degree to which procedures for orienting new faculty were formalized in each department.}

When asked the degree to which procedures for orienting new faculty were formalized in each department, the responses were slightly negative for Department $A$, slightly positive for Department B, and very negative for Department C. Overall, more faculty across departments responded "somewhat" or "not at all", than did faculty who indicated formal procedures existed. 
Table 27.-- \% of Faculty Rating Formalized Orientation Procedures/By Department.

\begin{tabular}{llllll}
\hline \hline & & YES & SOMEWHAT & NOT AT ALL & DON'T KNOW \\
\hline Department A & $(\mathrm{n}=11)$ & $36 \%$ & $55 \%$ & $9 \%$ & $9 \%$ \\
Department B & $(\mathrm{n}=10)$ & $40 \%$ & $60 \%$ & & \\
& & & & & \\
Department C & $(\mathrm{n}=11)$ & $18 \%$ & $55 \%$ & $27 \%$ & \\
\hline
\end{tabular}

Interview data support the survey results. In the interviews, current faculty cited five examples of orientation or learning opportunities provided for new faculty: an alluniversity convocation, sponsored by the institution, officially opened the academic year -and four departmental opportunities including; initiation to the departmental structure or operations, via committee work and participation in formal faculty meetings; a formal assessment of teaching conducted by the chairperson during the first semester; an opportunity to present one's research in a department's faculty lecture series; and a midyear performance evaluation, conducted by the chairperson during the second semester. Differences in the extent to which these opportunities were extended uniformly across departments were found in two of the examples cited: new assistant professors were not automatically assigned committee work, nor were opportunities to present research uniformly extended in each department. Formal faculty meetings, the assessment of teaching performance, and the mid-year performance evaluation were perceived as common across the study departments.

Despite the common socialization opportunities cited in the interviews, it is interesting that the majority of faculty, across departments, responded "somewhat" or "not at all" on the survey when asked if there were formal procedures for orienting new faculty. The interview data provided two possible explanations. First, orientation of new faculty was seen by current faculty as a primary responsibility of the chairperson. Yet, most faculty interviewed perceived fluctuations in the extent to which each chairperson carried out that 
responsibility, particularly in Department C. Second, in reflecting on their own entry period, faculty tended to cite "the greater potency of informal opportunities" (compared to formal opportunities) as a means of socialization to the department. In current faculty recollections, these opportunities were described either as "positively influencing my socialization" or as "making the assimilation to the department more difficult." Positive socialization was attributed to the quality of initial relationships with colleagues, to the level and frequency of support in learning new work roles, and to the intellectual climate of the department. Key phrases used by current faculty to describe their positive entry experiences included: "acceptance and inclusion in formal department activities" or "in informal social gatherings," "guidance provided in learning appropriate teaching methods," opportunities for "sharing research interests with interested colleagues," and "a positive work climate." Difficult assimilation experiences were attributed to "being isolated from others," to the "limited direction provided in trying to meet performance expectations," and to a "stressful work climate."

Within the context of current faculty experiences, primary subject data collected during the adaptation stage were classified into four areas: formal learning opportunities; perceptions of acceptance and inclusion; efforts to learn appropriate teaching methods; and perceptions of the subcultures and work climate.

\section{Formal Learning Opportunities}

Given that few studies have examined the entry experiences of new faculty, from an intensely personal point of view, a log was employed to provide written structure for primary subjects to record their affective and cognitive reactions to these experiences. The primary subjects tended to record events daily, while extended comments regarding cognitive and affective reactions appeared sporadically. Each month, the interviews provided further opportunity to discuss log entries.

Over a period of six months, the primary subjects made almost daily entries in their 
logs. Often the entry was no more than one or two sentences reflecting the routine cycle of the semester: "prepared my lecture for tomorrow's class", "read some research on microfilm in the library," "graded papers today," or "ran into a colleague in the hallway who asked how things were going."

Of the five opportunities cited by current faculty as a formal means for orienting new faculty, three were briefly acknowledged: an all-university convocation, the formal assessment of teaching performance, and opportunities to present one's research to colleagues; while the remaining two: departmental meetings and the mid-year performance evaluation, elicited extensive comments spilling over into interview time. The three brief $\log$ entries, dealing with learning opportunities provided in the first semester, are reviewed in this section. The longer entries, which deal with learning opportunities provided during the second semester, have been interwoven with interview data in later sections. The first entry in the log dealt with the dean's convocation:

\section{Department AVTom}

(log entry) Convocation at Flanner Hall. New faculty were introduced and reception was held afterward. Discussed possibility of getting a Mellon grant to fund a biking field trip for my students. Met several more department members. Discussed core curriculum and the possibility of going to a White Sox game with two other members of the department.

\section{Department B/John}

(log entry) Attended the dean's convocation. During the introduction of new members of the faculty and staff they skipped my name (thinking I wasn't there). So, it was a little embarrassing because at the end they asked, did we miss anybody? So I had to stand up and say yes. When people in the department realized they had skipped over me, they were apologetic. It was nothing, I didn't feel slighted -- simply embarrassed. The chairperson apologized at the reception afterwards, during which I met his wife and found out that this will be his last year as chair of the department.

\section{Department C/Bill}

(log entry) Faculty Convocation. Both the dean and the chairman urged me to attend so that I could be introduced to the faculty. Heard uninformative speeches about the Jesuit mission and identity of the school. I was impressed 
by the emphasis on teaching in the dean's address. He said what I believe: this is not just a profession, it is a calling. With each week I am more upbeat. I share the institution's values. Had an interesting chat with a colleague who said that it was normal to feel guilty about not being able to do my own research during the first term. She claimed the department knows it takes time to get into writing. I hope so. By and large I felt like a graduate student at a faculty cocktail party.

Aside from the comments referring to social plans, discussions with colleagues, and the affective remarks aroused by other incidents occurring during the event, the primary subjects indicated that the all-university convocation had provided little new information about the university.

Another formal learning opportunity cited by current faculty, the assessment of new faculty's teaching, occurred also during the first semester. In Department $A$, where the candidate was seen to have more teaching experience, no formal assessment was scheduled. In the log entries related to the assessment, the primary subjects in Departments B and C indicated only relief -- and disappointment:

\section{Department B/John}

(log entry) The chairperson observed my undergraduate class today, and although I was very nervous at first, the class seemed to go well with many students contributing to the discussion. Later in the day I found his report, or write-up, in my mailbox. I was surprised that it read so much like a summary of the class. His only suggestions for improvement were that I have the students speak more loudly and that I call on students more often. $\mathrm{He}$ seemed to be satisfied with my performance, and I guess it's a relief to be done with the evaluation. I would have appreciated a more direct exchange of information and ideas.

\section{Department C/Bill}

(log entry) The chairperson sat in on one of my courses today. No feedback yet (groan). It is curious to be under surveillance. Hopefully, there will be feedback. Thus far the department is unaware of what I'm teaching, or how well or poorly I'm doing. (The following was added to this entry...) At the end of the day, a brief positive note arrived. But no pointers!

Finally, only one of the three primary subjects was asked to present his research as part of a faculty seminar series. Given that he was in the midst of completing his 
dissertation, the thought of "getting up in front of the faculty" and time spent preparing the presentation caused undue pressure weeks before the actual seminar. He did not perceive this as a learning opportunity, but as a way to make his work known to others:

\section{Department B/John}

Today I gave my talk in the lecture series and it's quite a relief to be done with it. I had been nervous about it all semester, but my nerves intensified over the last few weeks. I thought it went over well and there were many questions at the end, which indicated that the audience had been at least somewhat interested. None of the questions were at all hostile, and several people made interesting suggestions for further work related to my topic. I was glad that it went fairly well, and that it's no longer hanging over my head. I think it is better to have new people give lectures sometime after the first or second semester-- although it does provide a way of making one's work known to colleagues.

Of the first three formal socialization opportunities, the all-university convocation and the opportunity to present research were not perceived by the primary subjects as learning opportunities. In the instance of the teaching assessment, where a formal occasion had the potential of leading to a more fruitful learning dialogue, the opportunity fell short of its potential.

The next section considers the ways in which new faculty related to their department colleagues. By forming direct relationships, or in observing colleagues' relationship patterns, it was expected that new faculty would interpret their status in relation to others, and their acceptance or inclusion in the department's social network.

\section{Perceptions of Acceptance and Inclusion}

By the fifth week of the term, the primary subjects had the opportunity to attend their first department meeting. Generally, this first meeting was perfunctory and new faculty gleaned little information about the department. In Department A, Tom had nothing to add during the interview regarding his log entry for the first meeting: "an uneventful meeting, rather brief and cordial, hopefully setting the tone for the academic 
year."

In Department B, John was struck with the formality of the meeting and was not certain how he should behave. John's reference to the formality of the meeting (the chairperson referring to faculty as doctor) caused him to feel that he was being set apart from current faculty since he was in the process of completing his dissertation for a $\mathrm{Ph} . \mathrm{D}$.

\section{Department B/John}

There has only been one departmental meeting since I've been here and new faculty were introduced. We discussed people's backgrounds and what they're doing, what they've done. It was nice to be introduced to people-but, there wasn't much interaction between faculty members. I felt somewhat uncomfortable with the meeting dynamics. The chairperson refers to everyone as doctor, and everything is handled formally, very polite. The meetings are more formal than I expected them to be and people do not express their attitudes. When he is chairing the meeting, he likes to keep people focused. He does not advocate general discussion. He is a strict parliamentarian. If there were changes in the curriculum, those would be voted upon by the faculty. Because I was uncertain of my status, and because I wasn't allowed to vote, my position on a particular issue wasn't voiced. I wasn't sure when I could speak, so I didn't.

In Department C, Bill also indicated some feelings of being an outsider. In this case, the feeling of being an outsider developed from his assigned office -- a space outside department office quarters, near the building's escalator. He referred to this space as "my reconverted closet."

\section{Department C/Bill}

It was strange to be sitting there. I had attended departmental meetings as a graduate student at (name of university), but it was unusual to be sitting there as a faculty member. I got the impression that junior faculty were nominally equal...you know...be seen, but not heard. I objected to an issue and afterward I distinctly felt that the senior types liked obedience. (In his log entry he continued with...) One must prove oneself to be accepted. Is that why my office is away from everyone in the department...low man on the totem pole? After the meeting, I had a chat with an associate professor. I discovered factions in the department and learned more about the mindset of faculty. Junior faculty are supposed to be committed to research and to building the reputation of the department. Is this the role I'm supposed to 
adopt?

During the first eight weeks of the semester, while the primary subject in Department A often commented on relationships he had developed with colleagues, in Departments B and C, the primary subjects frequently hinted at feelings of isolation. The log entries essentially confirm differences in social opportunities provided. In Department A, Tom had begun to develop what would become fairly close and regular contacts. He averaged one dinner and one lunch per week with various faculty members, he began to meet weekly at the gym with two associate professors, he talked regularly about research interests with an associate professor whose office was next to his, and he had frequent contact with the chairperson whose office was also next to his. In Department B, John's $\log$ entries indicate that no social opportunities had been extended, nor had he developed close contact with other faculty. He was invited to one dinner at a faculty member's home and had lunch twice with an associate professor during the entire eight week span. When asked if he had formed any particular relationships with his colleagues, he replied:

\section{Department B/John}

Generally, it seems like people just come in on the days they teach and they don't stay around too long after classes. The general perception I have is that faculty are friendly but indifferent. I'm not rushing to form relationships. I don't want to accept any one person's perceptions about things as necessarily accurate without waiting to see what my own experiences confirm. It's not that I'm not concerned about relationships, I'm simply cautious and a bit reserved.

In Department C, the office situation, for Bill, became a running joke with feelings alternating between "being in a closet" and "not minding that I'm removed from the gossip circle." He began to perceive that the main course of business for the department was complaining and he continued to feel "the outsider" at informal social gatherings:

\section{Department C/Bill}

(log entry) Had lunch with a group of junior faculty today. They are cynical and complain about everything. Is that how one becomes an insider? People don't talk about intellectual things, rather, they complain about the institution 
and its bureaucracy. To be a good citizen one ought to have lunch with them. But, I'm not interested in department gossip. Where are the intellectual discussionș?

(He continued this line of thinking in a log entry following a dinner party at the chairperson's home.) Dinner for new faculty at the chairperson's house. They all knew one another and I was not treated seriously, in part because I'm so young. Partly it may be me being intimidated by all of these middle age people. Also, the other new faculty members had taught here or had previous connections with the university. I heard that they don't usually hire someone straight out of graduate school, they normally try to hire people who have a few years of teaching experience. Now it's more difficult to draw people here if they've been somewhere else. What struck me, though, is that ideas cease to matter once they've left the office. It's almost a danger to be an intellectual. They want intellectual discussions in moderate doses. Philistines.

In summary, the data described perceptions regarding status, acceptance, or inclusion as (a) Tom perceived no difference in his status from other members of the department, and he frequently associated with colleagues of various ranks during and after work hours; (b) John kept to himself, in part because no one reached out to him, and, in part, because he did not yet have status in terms of having earned a Ph.D.; and (c) Bill was disappointed with the social network, and the limited contact he had with colleagues tended to further confuse him about performance expectations.

Efforts to Learn Appropriate Teaching Methods

The subtle differences perceived by newcomers in the move from graduate school to the rank of assistant professor are important considerations during the adaptation period. As the primary subjects faced the new demands and responsibilities of their positions, especially in teaching, they began to question whether the skills and abilities learned in graduate school would be sufficient for meeting the requirements of the new position:

\section{Department AVTom}

When I was in graduate school I recognized that I wasn't going to be that well prepared for my orals by the kind of training I was getting. I needed to talk, to verbally express a lot of the ideas, concepts, and theories that I was reading about. In a sense, I needed to be forced to come to grips with how I felt about some of these ideas and concepts. So, I volunteered to teach a 
course at a Catholic high school for two years. Four days a week, I would go up to this school and I would teach for an hour. This is how I prepared for orals. In the past two months, I've realized graduate school did not fully prepare me for the realities I'm facing in this position. So, I've had to immerse myself in a similar manner. I've been juggling both teaching and research and I'm beginning to feel that I will be able to do what the job requires of me. I'm feeling more satisfied with my level of competence, although I've been experimenting a bit with teaching and that's not always been successful. I think learning to teach is something that you constantly do, it's something you perfect. So, I've been working on it, trying to improve it. I'm still occasionally anxious, but I'm not being overwhelmed by the experience. I feel I am competent in doing what I am doing.

\section{Department B/John}

I think things are going fairly well. I'm pretty satisfied with my students in general. I'm teaching both an undergraduate class and a graduate class. I've never taught a graduate course before, so it's hard to know exactly how much to expect of the students, how much I can expect them to be able to do and what level of expertise they're going to have in the subject. Those are the kinds of things I've been learning about. Graduate school did not prepare me for the realities of different course levels. I ' $m$ still uncomfortable with the idea of teaching the graduate course before I finish my Ph.D. That's sort of a psychological thing. It hasn't come up or been an issue in the class in any kind of way at all. That's a relief.

\section{Department C/Bill}

If I was running a graduate program somewhere some day, I would try to incorporate opportunities for teaching. I would get graduate students into the classroom an hour a day. You don't really learn until you are forced to come to grips with various interpretations, to answer questions, to look at the controversies. Graduate school does not teach you to do that. You are supposed to do it on your own, to be responsible. I don't know what they prepare you for sometimes. In the beginning you take course work. And to do well in courses is different from what is required for you to pass your oral examinations, which is much different than writing a dissertation, which is then much different than trying to write a readable book. And none of those experiences prepare you for teaching.

Tom expressed the most confidence of the three primary subjects when talking about his teaching experiences. He experimented with multiple teaching methods to try appealing to "as many constituencies" as he could. He also believed that his enthusiasm and eagerness for teaching was being recognized in the department: 
Department A/Tom

I've been throwing everything at them. I show slides, give them maps, lecture, I show them movies. Some of it is entertainment, but it's designed to be provocative. Teaching is somewhat like a presidential debate. You're up there trying to appeal to as many constituencies as you can. You try to reach out to different groups all at the same time. That is a very, very hard thing to do. That requires talking to one group at one time in one way, and then to another group another time in another way. That's why I try field trips, I use videos, I use slides, that's why I have handouts. I have discussion of the assigned books. That's one thing I never did before, because the students here don't usually read the books I've assigned. It's frustrating, but what can I do? You've got to find the connection that will make it relevant to them. That's why my class is always different.

When I complimented him on his openness for experimentation, he continued with...) I was also amazed that most of the students were not familiar with landmarks in the city. Can you believe that they've grown up here and they've never gone to some of the spots we are talking about? Because of that, I talked to the chairperson and he encouraged proceeding with something I used before. I'm organizing a midnight biking tour of the city. That's one of the things I like about this place, they view such things as field trips as a form of teaching. They are enthusiastic about students. They recognize teaching as a standard for promotion.

In the interview, one month later, Tom's initial perceptions were challenged.

His disappointment with reactions to the bike tour, and his tenacity in proceeding are evident:

\section{Department AVTom}

Two weeks before my midnight bike ride, I got the impression that there was a significant change in the department's attitude toward the whole idea, perhaps because of liability issues. I just got the impression that the reaction was suddenly more of, isn't that a little dangerous? Are you crazy? The feedback I got related to common fears: the city, night time, bikes, danger...I didn't know what to make of it. At (name of university) I did the bike tour with another professor and we had 130 students involved. At (name of university) it was, "what a cool idea!" Here the faculty seemed to think there was this whacko in the department that wanted to teach (name of subject) at midnight on a bike. I went ahead because the students wanted to do it. I also did a trial run beforehand. I ended up having a good turnout, and no flat tires! Everyone seemed to enjoy it.

In Department B, John was reflective in his remarks about performance. He used his 
mentor's style as a starting point and contrasted those methods with his own developing style:

\section{Department B/John}

His teaching style was intentionally difficult for students. That is not to say he's mean, but that he liked a Socratic method of teaching. Sometimes being perplexed, because it makes you struggle and think; his style was successful. At other times it was simply frustrating. Sometimes very frustrating and at other times very rewarding. He forced you to learn a lot on your own. People provoke critical thinking in many different ways. He would ask questions that would be very difficult to answer. That was mostly what he did, he asked difficult questions. And he was never quick to provide the answers. I do not like leaving the students perplexed.

(When asked how he hoped to develop his own teaching style, he continued with..) I'm still working this out. Definitely, it is based on some of the graduate courses I had taken. I'm trying to keep my approach on how to teach each particular class session a little flexible. I have had some graduate professors where the class session was pretty much unfocused discussion, and others where it was very focused discussion, and still others where the professor did $95 \%$ of the talking. I've found that I've had days like almost all of those styles. I've tried to achieve some sort of a balance between me talking and an open discussion. I guess on the average I try to talk about $40 \%$, maybe $50 \%$ of the class, and then the rest of the class is a discussion of particular topics. I think that the best way to get discussions going in class is by asking questions that are challenging. Maybe I hadn't really thought about the fact that was what I was using my mentor's style, but now it's fairly clear to me that I do. It's hard because sometimes, especially in the undergraduate class, which is an introductory level class, the danger is you'll ask questions where you get no response. So, you sort of scramble when that happens-should you just wait and give people a chance to think, or should you push them to respond. I usually don't push them to respond, I usually come up with an easier question. That's different than the way he would do things. Many times when you're teaching you have no idea whether you are really making a difference. Either people are learning or they're not.

In Department C, when asked how things were going, Bill was direct and pointed in his comments about his teaching experiences. He talked about specific problems:

\section{Department C/Bill}

Generally, I'm enjoying teaching. I'm getting pretty proficient with class preparations, I now have preparation time under control. What I'm having difficulty with is the amount of time it takes to grade all of the papers. In one 
of my classes, it's especially hard. They had an overload in enrollment and I'm teaching a god-awful number of students. In a sense, it's like teaching four courses instead of three. I'm just glad that Thanksgiving break is coming, I'll have an extra day to catch up. Part of it's my own fault. I've been assigning papers because I believed that would be the most worthwhile learning approach. But it means my grading burden is probably higher than anyone in the department. I've heard that other faculty tend not to assign papers, they tend to do in-class examinations. Here and there, there are a few exceptions, but it seems people go with what is easiest to grade. So, that's why I'm swamped with grading. I'm concerned that maybe my expectations are too high. The in-class discussions are as good as any at (name of graduate school). But then, when you see how they write, it's troubling. For a few, there are fundamental problems in knowing just how the English language works. But, that's not my problem. I've been referring them to the writing program. For the majority, it's mostly laziness, not lack of ability. I'll continue to assign papers until I get so fed up or burnt out that I'll resort to easier methods. It's just that I believe so strongly that students ought to write; they need to practice.

As the primary subjects became fully engaged in the challenges of teaching, they reported that few supports were provided. In attempting to meet their teaching responsibilities, the primary subjects' adjustment techniques or concerns can be summarized as (a) Tom experimented extensively with his teaching style and methods with the belief that these efforts were recognized by the department; (b) John reflected on his mentor's teaching style in graduate school to develop his own teaching style and methods, he also reported being uncomfortable teaching a graduate course; (c) Bill reported being comfortable with his teaching style, he also reported struggling with related teaching concerns including testing methods and variations in students' learning needs.

\section{Perceptions of Subcultures and the Work Climate}

Just as dimensions of work, and the network of social relationships surrounding work can affect the individual who is adapting, when newcomers are adjusting to the new setting, they are also assimilating the assumptions and values of the work unit. In effect, newcomers are learning the culture as they attempt to understand the environment in which their work is performed. In this section, primary subject interview and log data were 
categorized in relation to two factors: how new faculty were able to detect features of the institutional culture and subcultures, and how close their perceptions came to the assumptions and understandings of culture reported by current faculty in Chapter IV.

In an interview following the first department meeting of the second term, the new faculty were asked to comment on the culture of their department:

\section{Department AVTim}

I get the impression the central administration is trying to enhance the reputation of the department through its younger ranks, rather than recruiting someone with an established reputation. That approach pits departments and fields against one another. In part, there is a cultural divide here, a generational division. The younger faculty have been acculturated differently than the older faculty. The younger faculty were socialized to believe that the only way to advance was to publish, and moreover, they were socialized to the enjoyment of writing, as opposed to those who are teachers. The older group are dinosaurs. I don't think the tension is as strong here though as it might be in other places.

\section{Department B/John}

Older members of the faculty tend to be more blase about new people. I get the sense from people who are recent members, faculty who are especially research oriented, that there is some level of antagonism between older members of the faculty who are more interested in teaching. I think there are a number of people who have been here a while who are very active in scholarship. It's not a cut and dry thing. There are probably exceptions either way. I think there is more than one or two exceptions. I hesitate to make a generalization of that kind, but I would say that faculty are somewhat torn between teaching and research. I don't think they've determined which area should be emphasized.

\section{Department C/Bill}

I believe you could characterize the department, in part, by the divisional differences between the senior faculty, who are teachers, and the "young Turks," who perceive research to be their mission in life. (Where does that impression come from?) Everywhere. From my interview, from departmental meetings, the faculty orientation, in discussion with librarians, ...everywhere. The only people who don't talk about it are students. I get the impression that everyone in the faculty and administration sees this as a major change, as something real that is taking place.

In all three cases, the perceptions parallel two elements of institutional culture previously 
cited by current faculty: a shift in performance expectations away from teaching and increasingly towards research, and increasingly divided relationships between older and newer faculty.

The discussion of cultural conflicts continued in the same interviews. When asked to further describe the conflict between faculty, they commented as follows:

Department AVTom There is a debate going on in the department about how disciplines are defined. For example, the traditionalists tend to argue that interdisciplinary approaches, like (name of particular sub-fields) are not disciplines in and of themselves because they are based on subject matter and not on abstract intellectual concepts. Some of the newer trained academics reject that because they argue that boundaries in history, or political science, or sociology are artificially created. Disciplines are defined by the way they approach modes of intellectual inquiry. In many disciplines there has been a debate the last 20 years between quantifiers and non-quantifiers. Research, regardless of our differences, remains a matter of unraveling complexities.

\section{Department B/John}

I'm a little new to know exactly what everyone is doing here but there are people who practice older forms of scholarship as opposed to younger or newer faculty members who may be more interested in theoretical questions. As far as I can tell, that's the biggest basis for a split. On the other hand, everyone still teaches courses within particular periods. There are specialties based on periods, but, then there are also particular orientations or methods of scholarship. Especially in the past 10 to 15 years there has been an explosion of interest in theory so although they have some level of particular specialization in a period, their work is more theoretically based than other people's work. This is just a general impression based on what several people within the department have told me-- there is a perceivable distinction between people and what they are interested in.

The cultural conflicts detected in Departments A and B reflect an element of institutional culture previously cited by current faculty: with an increasingly specialized faculty, changes in disciplinary styles of inquiry had become more pronounced.

In Department C, Bill mentioned divisions among faculty, though he did not identify the nature of these differences. 


\section{Department C/Bill}

I would say that the institutional culture is very strong. Many people seem to believe that they have a particular kind of purpose here and that they are trying to do what they can to fulfill it. I'm not sure that transcends into the department. I've so rarely seen people together as a whole. There are a good number of practices that people carry out without questioning, the same way they would in any department. But, I think there are divisions in the department, areas of disagreement. This is not a cohesive department.

The primary subjects also talked at length about conflicts they perceived as unique to their departments. In Department A, Tom gained further insight on conflicts within his department from an "off-the-cuff" conversation he had with a number of colleagues following a department meeting:

\section{Department A/Tom}

There is some controversy in the department about irregularities in hiring. Someone was hired for an interim appointment and then, after one year, the chairman turned that position into a tenure track line without going through a regular search. That's not the way you build the reputation of the department. There are different expectations now. People currently up for promotion feel that the standards are unfair. It's a question of status. Should a person who has not published be promoted? I guess if I spent a lot of time working on a book and then saw someone else get promoted who didn't do that kind of work, I'd resent it. In part, it reflects the way the culture is changing-moving away from informality in the hiring and promotional review processes.

The second conflict Tom indicated having heard more about after the meeting was related to a particular program in the department:

Department AVTom: There is a division in the department that is not generational. In some quarters, the (name of sub-field) is frowned upon because the students are trained in a methodology that is not seen as very rigorous, or scholarly, in the traditional sense. Recently, some of the faculty have recognized that this specialty is something good for the department. The program attracts a lot of students. In fact, students enroll, at least at the graduate level, in greater numbers than any other field. It is a more professional, or applied degree, as opposed to one that is more theoretical or scholarly. As a consequence there is a market there. There is a certain sense of elitism that says if you are making money, or if you are playing to the market, you are not being intellectually sound. That is what the tension is about. 
In Department B, where the current chairperson was completing his term, a conflict was detected in the selection process. John indicated that junior faculty believed they were being excluded from the decision process:

\section{Department B/John}

I didn't actually know that this was the chairperson's last year, until that dean's convocation. The process for selecting a new chairperson clearly reflects, or is an obvious indicator of where the power is in the department. I am not sure whether I even get to vote. Thus far, only tenured faculty have been involved in the decision. I'm interested in finding out more about the process. The chairperson is someone who will directly affect my future here because he/she will be influential in my overall evaluation and in deciding whether I get tenure or not. Yes, I'm definitely eager to find out who is likely to become the chairperson.

(In a log entry one week later, John indicated that...) I was extremely surprised with the process for selection of the chair. Divisions in the department became real to me when a vote was taken for scheduling candidate interview sessions. The vote was divided with the junior faculty requesting an interview session and senior faculty seeing no reason for one. One faculty member said he knew who he was going to vote for. I wasn't even aware of who the candidates were! His comment showed a complete lack of interest in what the newer faculty might feel.

In Department C, Bill mentioned a conflict which he perceived to be unique to the department; the quality of the graduate program was being debated within the faculty ranks:

\section{Department C/Bill}

This is a very secure department in terms of undergraduates. The graduate program is not as secure. It seems that the administration is not happy with the way things are going at the graduate level and a review process will be held the Spring after next. There are differences of opinion regarding what should be done to strengthen the program before the review. It really is a problematic program and people have different opinions on what should be changed. They've only had 4 students complete their dissertations out of perhaps 80 total students. With only four defending, it's a waste of money. It's almost as if graduate students are the serfs because they're used as cheap labor for teaching introductory courses. Year after year they teach without making any progress in the program. Recently, there has been some movement to make the graduate program more structured. I think a lot of the faculty feel that the Ph.D. program could be wiped out. It's only ten years 
old. I personally feel that much of that thinking is based on rumor and paranoia.

A number of observations can be made by examining the above cultural conflicts. First, the conflict in Department A, described by Tom as a "hiring controversy," in a broader context, is an example of the effect of shifting performance expectations. This conflict parallels an element of institutional culture cited by current faculty: a shift in performance expectations was seen as effecting a shift in promotion standards. Second, two conflicts reported above, in Departments B and C, were perceived by John and Bill as "unique" to their department. Yet, these conflicts parallel the work climate characteristics previously cited by current faculty. That is, when asked to cite factors contributing to positive faculty morale and those factors contributing to poor morale, two factors were mentioned: the overall quality of the academic program and the leadership style of the chairperson. Viewing the new faculty's perceptions of conflict in this context, the selection of a chairperson and questions related to academic program quality would evoke strong debate among faculty. Thus, new faculty perceptions parallel elements of the subcultures previously cited by current faculty. It is interesting that new faculty perceived these conflicts as unique to their departments, and it is likely that current faculty would perceive these as unique. Finally, new faculty detected cultural features of the work environment through conflicts they observed or heard faculty discuss in informal and formal meetings.

During the adaptation period, the reports of new faculty focused on responsibilities connected to their new role; on establishing their niche, or place in the department; and on establishing relationships with colleagues in their department. As the new faculty continued to assimilate, the study considered if they would begin to question the preconceptions they had formulated about the institution. That issue, and the new faculty's response to the adaptation period, will be considered in the next stage of organizational entry. 


\title{
Stage Four: Commitment
}

To what degree are professional identity and role orientation adjusted as one is enculturated?

In the commitment stage, two factors were considered to measure the effect adaptation experiences had on primary subjects: those experiences new faculty had not expected to encounter, and their affective response to those experiences. Over the course of the last three months of the study, interviews were structured to address these factors. During the first of the three final interviews, in Department A, Tom became engrossed in discussing his, and the department's, reaction to an incident involving the Women's Center. This response arose when he was asked to describe experiences he had not expected to encounter in the new setting.

\begin{abstract}
Department A/Tom
When I got home one night from class, I had a message from a friend in New York who is a producer for Ted Koppel. She said; "I think your institution is back in the Middle Ages. What are you going to do about it? Give me a call." I found her remark and the whole situation troubling. It smacked of the old Bernard Shawism, that a Catholic university is a contradiction in terms. My initial reaction was that the university was stifling discussion. I knew they weren't specifically violating academic freedom, but a university is a lot more than what goes on in the classroom. I think it sent a bad signal through the university. It drew attention to the problem that Catholic institutions in general are facing with these gender and sexual issues. I really think that by stifling discussion, the university will lose my generation. Now I think, if I write a letter to the newspaper, I might lose tenure. You have to think about these self-preservationist things.
\end{abstract}

In Department B, although John cited the Women's Center incident as an example of a controversy he had not expected to encounter, he spent the bulk of the interview talking about "more important news:"

\section{Department B/John}

The Women's Center issue became controversial because an openly dissident view of the church's position on abortion and birth control was being taken.. This had a two-fold interest for me. One was my own personal beliefs and 
the second was more professional. The professional side has an obvious implication, if students can't speak on these issues, what right does a faculty member have? Some people make a distinction that what goes on in the classroom is different than what goes on outside. I don't think there is such a distinction; if they can disband a group for giving a public statement that disagrees with official church teaching, they can also fire somebody, or deny somebody tenure. There is a line in the faculty handbook that says a person can be dismissed for teaching on issues contrary to church policy. Faculty talked about it the incident in those terms. But the whole thing died down after awhile.

(Following his synopsis of the incident, John indicated that what he had least expected was how different he would feel after completing his dissertation...) Well, I sent the dissertation in, so for the first time in months, it's off my mind. When I have a date for the defense it will be back on my mind. Columbia has a reputation for having difficult defenses and requiring revisions. It's possible that I'm going to have to open it all back up and do a lot more work. But, for the moment, I feel a great sense of relief. Being this close now has made a difference in how comfortable I feel. I feel better about my status. I'll feel even better when I have the degree. It's like having your feet in two places. There is this sensation of being viewed as a graduate student, and yet occasionally being treated as an equal. But it's a feeling you have more within yourself. The transition from one role to the other is not yet complete. It took so much of my time, and I was so eager to get it done, that I didn't really want to get into discussions with people. I needed to focus on taking care of what my advisors wanted me to do. I didn't want to get confused by other people's comments, however valid they might be. Now, I'm eager to find out what people think and to satisfy the department. I want to do that as quickly as possible.

In Department C, Bill was even less inclined to talk about the Women's Center, although he introduced the topic without being prompted.

\section{Department C/Bill}

Since I never had any experience before coming here with either Jesuit education or Catholic education, I didn't know quite what to expect when the incident occurred. People in the department were talking about academic freedom and Catholic doctrine, those kind of things. So, I was a little apprehensive about how it was being handled. With the outcome, I think there is very little to be concerned about on that level. I think generally people, both the administration and the faculty, are concerned for the welfare of the students. It ended fine. 
had least expected to encounter...) The graduate program director asked me be chairperson for the Master's Exam Committee. The prospect of chairing a graduate committee is unnerving. I'm scarcely out of graduate school and I'm expected to test graduate students? Don't you think it's strange that .I've never taught these students, and I've been asked to coordinate the committee? Basically I don't want to even teach at the graduate level, but I found out that will be a key part of my role here. You see...I fudged a bit during my interview. I told them that graduate teaching would be fine, but that just being out of graduate school the concept was foreign to me. When I met the associate dean of the graduate school, I told her research was great and that teaching at the graduate level was fine. I'm not thrilled at all with teaching graduate students! I'm concerned, because if you don't share their values you're in trouble. I've been told that at the mid-year review, they harass people if they haven't produced. Not really harass, but the evaluation could affect your salary and the overall assessment goes in your file. I'll be here a couple of years, presuming they don't get rid of me. I'm not sure I'll be here beyond that. I'm thinking of some people who were here and went elsewhere. I might do that. Yeah, I might do that.

In examining the above responses, in Department $\mathrm{A}$, Tom was the most alarmed by the Women's Center incident. It is interesting to note that, of the three primary subjects, he expressed the most concern about how academic freedom would be treated in a Catholic university. Although Tom claimed that "his misconceptions" about academic freedom had been dispelled during his on-campus interview, he reported that his suspicion and mistrust of institutions were aroused. In Departments B and C, the incident was detected and interpreted, but it did not arouse a response as intense. Rather, when asked to describe experiences he had not expected to encounter, John reported being surprised with how secure he felt after completing his dissertation. Bill, on the other hand, was challenged with new responsibilities that directly contrasted with the preconceptions he had formulated about performance expectations.

New faculty were asked to talk about the major adjustments they perceived as having made during the first six months of their entry period. In Department A, Tom perceived that his major adjustment had been, and still was, the amount of time he was spending overall in teaching. In addition to his teaching load, his log entries indicated that 
he had also maintained a consistent research schedule; on average, two days per week had been set aside for writing. Normally, a sizable portion of the weekend was devoted to academic work in general. This constant production schedule, and the results of his midyear evaluation, caused him to lament:

\section{Department_AVTom}

Yesterday I was doing all sorts of things during the day unrelated to what I had to teach that night. Because of that, I really wasn't prepared for the second part of my lecture. Ideally, if I had time, I would have completely memorized the lectures in order to speak extemporaneously. I did not expect my research and teaching time to be quite so disjunctive. I want more of a balance. I was hoping to integrate more of my research into my teaching. I haven't been able to do that because my teaching and research schedules are not in sync; and because I've been working hard to produce equally in both areas. For example, I just finished a chapter for my book and I would have liked to use it as a lecture in my (name of) class. I just never got around to incorporating it. Ideally, you want to integrate your teaching with your research, or vice versus. Teaching takes away from research time, and the reverse is equally true. To a large degree it depends upon what courses you teach. For instance, they want me to teach (name of course) and that's a lot of time. It's going to require a whole new preparation for me and I expect that it will take away from my writing schedule. I would normally prepare and put a lot of time into it. I think I will need to adjust my priorities.

(After commenting on his obvious level of frustration, Tom further described the root of his frustration...) I'm not thrilled about teaching the course, but I've been told that I have to. While I believe faculty should teach in the core program, I want to teach what I've been trained to teach and what I'm interested in. Now, I'm stuck learning material in an area I was not trained in. The bottom line is I don't think I'll get rewarded for spending all this time on it. It's just expected. This is the kind of experience that takes you away from research.

In Department B, John indicated that while he had expected the adjustment to be personally difficult, he was surprised that "few faculty made an effort to reach out".

\section{Department B/John}

The department fosters inquiry and professionalism. It is not an especially warm department. It wasn't until this month that I was invited to several social occasions. I was too preoccupied with finishing the dissertation for it to really have mattered. I felt self conscious about my status as it was, and I suppose that 
being isolated reinforced those feelings. Even now, I've noticed that there are few spontaneous get togethers. I also did not expect the experience of teaching the (name of) class to be such a difficult adjustment. I was concerned that I wasn't providing, or I should say, I was frustrated that the students were not responding as I would have liked. I've learned that much of that could not be tied to my performance; it was a matter of their level coming into the course and of the amount of work they were willing to do.

(When asked if he had a better idea of what was expected of him, he replied...) With teaching, that's a difficult question to answer. I was really surprised with the assessment of teaching format. It was a summary of my class. I expected it to be more of an evaluation, not a narrative discussion. In general, I have a better idea of what is expected just having observed people over the course of a semester. The mid-year evaluation which took place last week provided more concrete information for what is expected. It was fairly helpful. I'm considerably more at ease now.

In Department C, Bill reported that his major adjustments had been dealing with the isolation he had experienced during the first six months, and with his confusion about performance expectations. He reported that his attitude had significantly improved since our last interview. When asked what had happened to raise his outlook on things, he replied:

\section{Department C/Bill}

I actually think that the appointment to the Master's Committee has had a positive effect on me. I now feel more fully integrated into the department. Initially I joked about how I had been assigned to this office, but a part of me thought maybe you had to prove yourself to get assigned to the other end of the hall. Lately, people have apologized that I'm down here and there's talk of moving my office next year. I also feel considerably reassured now that the mid-year evaluation is over. It was actually a positive experience; very upbeat.

When asked if he had a better idea of what was expected of him, he continued)

I've been thinking a lot about that lately. I thought about my graduate experiences and how many of the best teaching assistants never finished the doctoral program. They ended up being totally involved in teaching, and the system eventually weeded them out. Possibly the best educators were eliminated. For a long time, I thought that the profession should have been shaped to accommodate them. I guess it doesn't work that way. Perhaps there needs to be reasonable expectations for research. While I had thought 
we were expected to publish an article every year, during the review I was told that one article over the next two years would be fine. When I think about it, I was never actually pressured to do research in the first semester. Only one junior colleague teasingly asked me how many articles I had written. I jokingly told him five or six. He was on leave last term and hadn't got anything done. I think I can beat that track record.

These reports show that as the new faculty settled into the routine aspects of work, and as questions of status in relation to others were answered, they reported conflicts between preconceptions and the reality encountered in the new setting. These data show that the source of the cognitive or emotional response may differ dramatically from individual to individual, and the timing, and intensity of the response will vary also. The responses were (a) Tom's preconceptions had been that the institution was where he would thrive, and one which recognized exceptional teaching-- but, as a result of the mid-year evaluation, he no longer believed that the institution valued teaching and research equally; (b) John indicated that being isolated from other faculty may have reinforced selfconscious feelings-- but, when these feelings were eliminated by having earned a Ph.D., his earlier perceptions were confirmed: the department was professional, not social or accepting (generally, though, he found the mid-year evaluation helpful and he reported being ready to continue his assimilation efforts); and (c) Bill's appointment to a Master's Committee had, over time, made him feel more fully integrated into the department. $\mathrm{He}$ was reassured by the mid-year evaluation, and he was relieved that performance expectations were not as high as he had feared.

In the final two interviews, new faculty were asked to reflect upon the entire socialization period, to talk again about their professional identity, and to summarize how they felt about the university currently. Following these interviews, their reports were analyzed to determine if role orientations had been adjusted, or if new value commitments had been made, since the first week of the Fall semester. In Department A, when asked if he perceived changes in his professional identity given his experiences, Tom responded as 
follows:

\section{Department A Tom}

I gained my professional identity in graduate school. Not much has changed since I've come to the university. I'm in this field because I like what I do. I will continue to try to balance teaching and research, and I expect that I will perform well in both areas. I guess that means that I may never be fairly compensated and I may need to look elsewhere for job satisfaction. You have to do the things you like even if it changes your priorities down the road. I now question whether it's loyalty to the institution that keeps people in one place. I guess I'm a bit skeptical of institutions. All institutions have self-interests that they have to protect. The university's interests aren't necessarily going to jive with your self-interests. I think they can take advantage of you. It's just the nature of the academic world. So, would it be easy for me to leave in the next few years? Sure it would be, because I've already left (one state) to go to (another), and I left (that state) after 14 years to come here.

When asked if he had made a decision to leave after a period of time, he replied...) No, I haven't made that kind of decision. What I'm saying is...well...I now recall that when I interviewed they asked me what my salary expectations were and I told them I hoped to make at least as much as I was currently making. When the chairman called me he made this very serious formal offer, "I wish to inform you that I have been authorized by the VicePresident for Academic Affairs that you have been nominated for appointment in the (department name) at a beginning salary of (dollar amount)! I could tell this was a big deal for him-- but I expected that this would be the starting range. I thought it was a big university that was definitely marketing itself as an up and coming research institution and that they were trying to build up their faculty. I guess I thought if I proved my worth the compensation would quickly reflect my efforts.

(When asked how he felt currently, he continued with...) I was completely surprised by the evaluation-- but, I found something out after my evaluation that gave me a broader perspective on things. I was telling another associate professor about my disappointment and he told me what he was making. He's a highly published member of the department. My astonishment is based on what was published in the Chronicle on median faculty salaries. On that scale, he's $\$ 10,000$ below the mean. They want greater publication and faculty to become more respected, but the other side of the equation is the rewards for this emphasis. It goes back to what shocked me...that I was told I would be paid the same as someone not publishing. That's a real message. But my colleague told me "Tom, they'll take care of you because you are young and 
they don't want to lose you --they don't care about senior faculty." That was a revealing thing for me to hear. I'm now asking, am I going to be resentful if I put in a lot of time and effort over the next few years? I hope not.

(When asked how he visualized things five years from now, he quipped...) I tend to believe the core of any good university is the arts and science. I think things will get better for the department in time. If they don't...well...I'm not sure how the chairperson gets selected. If I lobbied for it, who knows?

In Department B, when asked to reflect upon his experiences of the past year, to talk again about his professional identity, and to summarize how he felt currently, John commented as follows:

\section{Department B/John}

I'm still a little unclear about the ways in which the department works. There seems to be some decisions made by committees that I only become aware of after decisions have been made. There have only been three department meetings since I've been here. So, the operation is still mysterious to me. Most of the time, I don't even know what issues are being deliberated. I have not been encouraged or pushed into belonging to any committees. I probably will be on something in the beginning of next year. It's not something I'm either burning with anticipation about or dreading. It will be interesting to see what goes on first-hand.

(When asked how he felt currently about the department, he continued with...) People have been a bit more responsive to me lately, inquiring about the dissertation and congratulating me on finishing it, and more friendly in a general way. There has been a bit more willingness shown to cooperate. I'm not at the point where I'm included in any distinct group, but I've been invited to do things with various people.

When asked how he would characterize the socialization period, he replied...) My socialization has been a period in which I've continued forming my professional identity. Graduate school provided particular skills and helped me to select my particular research emphasis. I have learned more about what it means to be a professor in the past eight months than I did through training in graduate school. I do not even think these experiences could be transferred to graduate school. Until you've actually taken on the responsibilities that are expected of you, teaching classes on a daily basis, adjusting to being a member of an academic community--those experiences cannot be simulated in graduate school. In graduate school we were protected. Everything was in certain stages of development. You didn't get to the next stage until you successfully passed through the prior stage. Part 
of the difference is being immersed in it all at once. Starting out, you don't know if you'll make it through the entire graduate school process and you don't know if you are going to get a job when you get out. It feels good to be settled.

In Department $\mathrm{C}$, when asked to reflect upon the experiences of the past year, to talk again about his professional identity, and to summarize how he felt currently, Bill commented as follows:

\section{Department C/Bill}

In the first semester, it was hard for me to think of myself as a researcher when all I could think about was the teaching experience at hand. The realities of the work load make a person really tense. But, you know all along that your graduate training does not prepare you to be a teacher; it prepares you to be a scholar. And even then, I have to admit thinking about this after my experience this year, it doesn't do a very good job of that. In graduate school, I was known as "the machine." I'm good at self-discipline and writing. What graduate school did not provide is an understanding of how you get things published. Now, I think I'd be concerned if, over time, I weren't able to do research. I wouldn't know if I'd want to stay. I don't want to become soft and flabby. If I didn't do original research, I'd become a moosehead-- you know, dead from the neck up. But I'm still not careeroriented. So, there's got to be a balance. But if teaching doesn't count towards tenure, I'm not sure what the balance is.

These comments demonstrate that varying responses had occurred in terms of adjustments both in role orientation and in new value commitments. The responses, accordingly, were (a) Tom vowed to maintain his role orientation, to continue to balance teaching and research (he did not appear to make new value commitments-- rather, his response to the socialization period seemed to be aimed at questioning the organization's attempt to alter his self-image); (b) Given John's preoccupation with completing his dissertation, and the isolation he reported experiencing, he concluded that his professional identity was still developing; and (c) Bill's response to the socialization period seemed to be focused on acquiring new values and in broadening his identity: his role orientation was expanded to include research in a more significant way than he had previously reported possible. 
A summary and a discussion of the major findings of the study are presented in Chapter VI. Recommendations for further study are also addressed. 


\section{CHAPTER VI}

\section{SUMMARY AND CONCLUSIONS}

\section{Context of the Study}

The traditional view of faculty socialization in higher education has been that professional identity is acquired through extensive and intensive formal education during graduate school and that role orientation remains relatively stable over time. This normative view fails to address the first professional transition in an academic career -- the move from being a graduate student to that of a professor. The present study was undertaken to extend recent research on faculty development during organizational entry by analyzing the ways in which different academic disciplinary subcultures select and socialize new faculty; the manner in which institutional culture is expressed to new faculty; and the degree to which professional identity and role orientation are carried over, or adjusted, by new faculty during this entry period.

This study developed a four stage model of organizational entry to examine the processes by which new faculty became members of three separate academic departments within an institution of higher education. The model was drawn from theoretical constructs described in research on faculty development during organizational entry; from sociological studies on socialization and organizational commitment; and from sociological, anthropological and higher education literature on organizational culture. Four sequential stages of organizational entry were depicted: (1) the pre-arrival stage, dealing primarily with an individual's predispositions prior to entering a new setting; (2) the encounter stage, dealing with an individual's preconceptions formed during recruitment and selection; (3) the adaptation stage, dealing with the external socialization processes 
and the initiate's identification with the organization; and (4) the commitment stage, dealing with the extent to which the norms and values of the local culture are assimilated by new organization members. An inductive research approach was chosen to test the explanatory power of the model. The study traced the entry of three new faculty into one institution as a test of the model's applicability to the organizational entry period for new faculty.

\section{Research Design}

Two sets of subjects participated in the study: culture-bearers/current faculty, those termed secondary subjects; and new faculty initiates, those termed primary subjects. Three academic departments, out of seven involved in the process of recruiting and selecting new faculty, were invited to participate. All secondary subjects were either institutional administrators or current faculty within the three participating departments. Three newly hired faculty members, one from each department, agreed to serve as primary subjects. The research design utilized both quantitative and qualitative techniques. A questionnaire was administered to current faculty to describe their perceptions regarding the institutional culture, the degree of similarity or differences of institutional ideology between subcultures, and the role orientation of current group members in each subculture. Qualitative methods included observation, structured and open-ended interviews, and a log format for new faculty to record their affective and cognitive reactions during the entry period. The log format, and the corresponding new faculty interviews, were of primary importance to the study because these qualitative techniques captured new members' personal points of view about the experiences encountered. In order to describe the enculturation processes as the new faculty became members of the three academic departments, a holistic-inductive research design was selected. Using the constant comparative method of naturalistic inquiry, simultaneous data collection and 
analysis permitted the enculturation model to be inductively generated, to be tested as data were collected, and to be refined accordingly.

\section{Data Collection}

Prior to the first, new faculty interviews, the questionnaire was distributed to all current faculty in the three study departments. The results of the survey were later compared to interview data collected from a subset of the current faculty. Prior to their first week in the department, new faculty were asked also to complete a section of the same survey. This section related to the relative importance of various academic tasks-teaching, research, department administration, university administration, and service. Current faculty survey responses related to the relative importance of these academic tasks were compared to new faculty responses.

The collection of new faculty interview data corresponded to the time frame suggested by the four proposed sequential stages of organizational entry: pre-arrival data were collected before the new faculty entered the setting and encounter data were collected a few days before faculty began their first week of work during the Fall semester. To collect data related to the adaptation and commitment stages, one interview per month was conducted with each primary subject, beginning with the second week of the Fall semester and continuing through the Spring semester; a nine month period. During that time, primary subjects maintained a log in which affective and cognitive reactions to important elements of their socialization were recorded. By analyzing data collected from the personal logs and interviews, the factors involved throughout the stages of organizational entry became apparent and the explanatory power of the model was tested.

\section{Data Analysis}

Data were categorized initially into either content or process dimensions of the enculturation model. Content dimensions related to the institutional culture; the work 
environment, or department subcultures; and the role orientation of current members. Process dimensions identified the manner in which the three academic disciplinary subcultures selected and socialized new faculty, and the manner in which institutional culture was expressed to new faculty.

First, current faculty survey and interview data were coded as relating to the institutional culture; to perceptions regarding the subcultures; or to the work climate in the three study departments. These data addressed the question: what are the assumptions, understandings and meanings shared by current group members? In a similar manner, survey data coded as relating to the relative importance of various academic tasks, and to the amount of time spent working on the same academic tasks, addressed the question: what is the role orientation of current organization members?

Process data from the new faculty interviews were then classified into the appropriate stage of organizational entry: pre-arrival, encounter, adaptation, or commitment. In each stage, data were organized around a set of questions: (a) interview notations related to the pre-arrival_stage addressed two questions; what anticipatory socialization experiences does the newcomer bring into the new setting, and to what extent does the role orientation of new faculty vary within and across disciplines; (b) interview notations related to the encounter stage addressed the question, what preconceptions are formulated regarding the new setting; (c) interview notations and log entries related to the adaptation stage addressed the question, in what manner are cultural nuances transmitted to new members; and (d) interview notations related to the commitment stage addressed the question, to what degree are professional identity and role orientation adjusted as one is enculturated? 


\section{Major Findings: Ideational (Content) Data}

To understand the culture of the institution, and of the three participating academic departments, current faculty reported their perceptions of the institutional culture, and their ratings of the relative importance of various academic tasks.

In describing the institutional culture, particular attention was devoted to issues of greatest consensus in the perceptions of current faculty within the institution, and across disciplines. The assumptions, understandings, and meanings shared by current group members within the institution include the following:

In one manner or another, all current faculty spoke of the changing nature of the institution's mission; they generally expressed uncertainty about the eventual outcome of this transition. At the same time, survey questions related to performance expectations found that $(94 \%)$ of the current faculty felt pressure to engage in research, and (76\%) reported pressure to increase involvement in research during the past 5 years. Yet, while there was significant agreement that the institution was perceived to be moving away from its founding teaching mission, during this transition period, the university was perceived as stressing a balance between research and teaching. However, with the exception of associate professors in Department A, the majority of faculty reported that they did not balance these two roles.

Faculty cited the religious nature of the institution as a continuing positive presence within the university, but made strong distinctions between this tradition and the diminishing importance of the Catholic nature of the institution.

Faculty in all three departments described a gradual shift towards disciplinary specialization as departments became Ph.D. granting entities; increasingly divided relationships between older and newer faculty; and marked concerns regarding limited resources to support change. Despite these concerns, most faculty reported that the 
various changes in the institution and departments were somewhat positive.

To understand the subculture of each department, particular attention was devoted to issues around which there was significant consensus within departments, but variation across disciplines. Major findings related to the overall environment and faculty morale, and to the work climate or faculty attitudes toward work, include the following:

․ Department A rated itself as very positive in both work environment and faculty morale; compared to positive work environment ratings, but mixed faculty morale ratings in Department B. Department C reported mixed ratings for work environment and negative faculty morale ratings. Factors cited as contributing to positive morale in Departments A and B pointed to the quality of the academic programs and the leadership style of the chairpersons. In Department C, poor faculty morale was also attributed to these two factors.

Current faculty in all three departments rated their work climate as more friendly than warm or accepting. Department A rated the characteristics of friendliness, acceptance and warmth more positively than either of the other two departments. Yet, regardless of the department, both survey and interview data point to social isolation among faculty. In spite of these ratings, faculty in Departments A and B reported being more satisfied and enthusiastic about their work than those in Department C.

To understand further the subcultures of the three departments under study, the survey included questions which asked current faculty to rate the relative importance of various academic roles-- including teaching, research, department administration, university administration, and service. Major findings related to the role orientation of current faculty suggest differences across subcultures and academic rank: 
Overall, current faculty in Department A reported that they did not spend as much time in research as they would like, they spent more time in department administration than they preferred, and they did not spend as much time in university administration as they would like. Looked at as a function of rank, full professors did not spend as much time in teaching or research as they would like; associate professors wanted to research more and teach less; and, while the assistant professors were content with their teaching load, they still wanted more time for research.

Full and associate professors in Department B reported that they would like to teach less and research more, while assistant professors reported reaching a balance between the teaching and research roles.

Full professors in Department $\mathrm{C}$ reportedly reached a balance between their teaching and research roles; for associate professors, there was a disparity between time spent on research and their much higher ideal; and assistant professors reported preferring to teach less and research more.

\section{Major Findings: Socio-Cultural (Process) Data}

To analyze the factors involved in the organizational entry process, qualitative methods were employed to capture the personal experiences of three newly hired faculty members, one from each department of the study. Analyses of logs and personal interviews yielded a look at the factors involved in each stage of organizational entry. Major findings are presented according to the questions raised in each of the four sequential stages of organizational entry-- pre-arrival, encounter, adaptation, and commitment:

What anticipatory socialization experiences did the newcomers bring into the new setting? As expected, pre-arrival responses pointed to the key values primary subjects had acquired during graduate training. In Department A, Tom indicated that graduate school 
had taught him to be self-reliant, he admired his mentor's enthusiasm for and love of the subject, and his work ethic was extremely strong-- but, he found that graduate school had failed to support his values; perhaps because of this, he mistrusted institutions. In Department B, John suggested that graduate school required self-reliance and selfmotivation. Unlike the other two new faculty, he felt that a person had to prove worthy to be admitted to graduate school. Perhaps because of that experience, he claimed he would place a concern for students above other aspects of his career. In Department C, Bill pronounced, almost defiantly, that in spite of his research-oriented graduate school, his identity was toward teaching. He exuded enthusiasm for teaching and took many opportunities to point out that he did not share the research ambitions others (he admired) seemed to have.

To what extent did the role orientation of new faculty vary within and across disciplines? New faculty reported their role orientation both in responding to the survey, and in response to questions in the first interview. In Department A, Tom reported a preference for a balance between teaching and research in contrast to his peers, the other assistant professors, who reported greater importance for teaching than research. In fact, in the survey ratings Tom placed greater value on research than the average of all of his colleagues in Department A. In Department B, John placed more value on both teaching and research than the assistant professors in his department; and he placed more value on research than all of his colleagues in his home department. In fact, he claimed he would not have chosen an academic career had it not allowed him to pursue research. In Department $\mathrm{C}$, Bill placed more value on teaching than all colleagues in his department and less value on research than either the assistant or associate professors, with approximately the same value assigned to research as full professors in his department. 
Overall, in Departments A and B, the new faculty placed greater value on research than faculty across all three study departments. In Department $\mathrm{C}$, the primary subject placed greater value on teaching than faculty across all three departments. Analyses of both survey and interview data indicate that new faculty role orientations were respectively: (a) Tom preferred a balance between teaching and research; (b) John preferred research; and (c) Bill preferred teaching.

What preconceptions were formulated regarding the new setting? The data support the notion that positive perceptions of selection reinforced new faculty's satisfaction of institutional choice. These positive impressions of the selection process were incorporated into the overall preconceptions the new faculty formulated about the institution. Though preconceptions were all positive, the meaning attached to these preconceptions were quite different: (a) Tom felt the institution was a place where he could thrive; (b) John believed that the entire university was dedicated to improving itself; and (c) Bill strongly believed that the institution did not "buy into the research rat race."

Based on these general perceptions, primary subjects also translated their impressions into tangible goals or performance expectations for the first year. These goals reflect differing emphasis on teaching and research, but all emphasize teaching: (a) Tom planned an ambitious research schedule for publishing his book and various articles, and his most important goal was to improve his teaching; (b) John indicated that he needed to complete his dissertation as quickly as possible and to work steadfastly in developing new teaching skills; and (c) Bill planned to concentrate on teaching.

In what manner were new faculty socialized to their work roles and in what manner were cultural nuances transmitted? As the new faculty became fully engaged in the challenges of teaching, they reported few supports were provided. In attempting to meet their teaching responsibilities, the primary subjects' adjustment techniques and concerns 
varied: (a) Tom experimented extensively with his teaching style and methods, and he believed these efforts would be recognized by the department; (b) John reflected on his mentor's teaching style in graduate school to develop his own teaching style and methods; and (c) Bill struggled with related teaching concerns including testing methods and variations in students' learning needs.

The data demonstrated that informal, or accidental, opportunities were the most frequent means of socialization to the department and that formal socialization opportunities were not perceived to be structured to address the learning needs of new faculty. Department meetings, and conversations following the meetings, were the occasions through which new faculty learned about the inner workings of the department. From the data reported, it appeared that new faculty were able to detect cultural features of their departments through the conflicts they observed or heard current faculty discuss in informal and formal meetings. Finally, the perceptions new faculty formulated about their respective department parallel elements of the three subcultures, previously cited by current faculty.

To what degree were professional identity and role orientation adjusted as new faculty were enculturated? These data indicate that varying responses to socialization had occurred: (a) Tom vowed to maintain his role orientation to teaching and research (he did not appear to make new value commitments-- rather, his response to the socialization period seemed to be aimed at questioning the organization's attempt to alter his selfimage); (b) Given John's preoccupation with completing his dissertation, and as a result of the isolation he reported experiencing, he concluded that his professional identity was still developing; and (c) Bill's response to the socialization period seemed to be focused on acquiring new values and in broadening his identity (his role orientation was expanded to include research in a more significant way than he had felt previously possible at the 
beginning of the entry period).

\section{Discussion and Interpretation of Findings}

This study developed a four stage model of organizational entry to examine the processes by which new faculty became members of three separate academic departments within an institution of higher education. The conceptual framework was drawn from theoretical constructs described in research on socialization and organizational commitment; from research on new faculty development during organizational entry; and from the higher education literature on organizational culture. By tracing the processes by which new faculty became members of three separate academic departments, the explanatory power of the enculturation model was tested and the framework was refined accordingly. Primary theoretical propositions and process dimensions delineated, in the present study, are presented in Figure 3. In this section, within the context of this illustrative framework, the theoretical constructs and process dimensions determined are presented within the four sequential stages of organizational entry-- pre-arrival, encounter, adaptation and commitment. The discussion and interpretation of major findings are interwoven in each section to explain the manner in which theoretical propositions were tested or determined, and to illustrate process dimensions of each stage.

\section{Stage One: Pre-arrival}

In the pre-arrival stage, the study investigated whether or not faculty formulated expectations about the institution, based on anticipatory socialization experiences, prior to entering the new setting. Expectations were formulated regarding the new setting based on three interacting factors: the values acquired during graduate training; the role disposition formulated in graduate training; and the differences in the training experiences of each candidate. 
STAGE:

Theoretical

Propositions:

The values acquired during graduate training

provide a perspective for interpreting

experiences in the new setting

\section{Encounter}

Existing predisposition

are questioned. Preconceptions

and performance scripts are formed.
Adaptation

As prior experience

are recalled \& contrasts

generated, a cultural

leaming process begins.

\section{Commitment}

The dynamic

(enculturation)

response occurs.

$\begin{array}{lll}\begin{array}{l}\text { Process } \\ \text { Dimensions }\end{array} & \begin{array}{l}\text { Graduate students formulate role } \\ \text { orientation based on an internal response } \\ \text { weighing personal beliefs against the role } \\ \text { orientations espoused in their graduate } \\ \text { school. }\end{array} & \begin{array}{l}\text { Candidates select or attend to } \\ \text { information during the hiring } \\ \text { process, process this information, } \\ \text { using predispositions as a frame of } \\ \text { reference, and preconceptions } \\ \text { regarding the setting are formed. }\end{array} \\ \begin{array}{ll}\text { The values and role disposition formulated } \\ \text { during graduate training serve as } \\ \text { predispositions in the new setting. }\end{array} & \begin{array}{l}\text { If information encountered during } \\ \text { the selection process is not congruen } \\ \text { with personal predispostions, the } \\ \text { information is unconsciously } \\ \text { underwritten to affirm personal } \\ \text { satisfaction of job choice; and }\end{array} \\ & \begin{array}{l}\text { performance scripts are formulated } \\ \text { to reduce uncertainty. }\end{array} \\ & \begin{array}{l}\text { An individual's preconceptions } \\ \text { either support or cause confusion } \\ \text { during the adaptation stage. }\end{array}\end{array}$

Development

Tasks

identified:
Forming general impressions of the

new setting; defining institutional

expectations; and developing per-

formance goals for the first academic

appointment year (based on perceived

performance expectations).
Socialization includes

formal, informal, and

accidental learning

opportunities.

Adaptation is encouraged

or inhibited through three

dimensions: the work itself

the climate in which work is

performed, and the network of

social relations surrounding

the work.

New members detect cultural

features of the new setting

through informal commun

ications and observed

conflicts in the work setting

Defining work role expectations,

balancing multiple role demands

prioritizing time; and developing

teaching styles and methods.
As new members encounter realities of the new setting. preconceptions are challenged, and a cognitive or emotional response occurs.

If an individual's response is aimed at questioning the organization's attempt to alter self-image, individuation occurs.

If an individual's response is aimed at acquiring new

self-images, or roles, attachment occurs.

Re-defining or

adopting the role

orientation learned

in graduate school.

Figure 3: Theoretical and Process Dimensions of the Enculturation Model 
The professional values acquired, and the role orientation formulated during graduate training, were equally influential throughout the organizational entry period: both were seen as predispositions faculty initiates carried into the new setting. In the present study, the professional values acquired by the three new faculty members, during graduate training, were similar despite disciplinary affiliation differences. Common values reported during interviews with the new faculty included: self-motivation and self-reliance; individual autonomy and academic freedom; a profound interest in scholarly activities (in both producing knowledge and in disseminating knowledge); and an appreciation of the intellectual climate surrounding professional work.

The literature describing anticipatory socialization uses the terms professional identity and role orientation interchangeably to describe the values transmitted to students during this graduate training period. Rather than being conceived as a transmission process, the present study suggests that a more complex process occurs: while professional values are acquired during graduate training, role orientation appears to be tentatively formulated. In the present study, while the values adopted during graduate training were characteristically similar, the role orientations adopted by the new faculty were dissimilar. So, too, the new faculty reported that they had not automatically adopted the role orientation espoused in graduate school. Rather, role orientations were formulated as each individual weighed the role orientation espoused in graduate school against personal values. In this manner, the role orientations adopted were distinct (a) Tom preferred a balance between teaching and research that was consistent with the role orientation of his graduate school mentor; (b) John preferred a research orientation that was consistent with his graduate training; and (c) Bill preferred a teaching orientation that was not consistent with his graduate training. The distinction between acquired professional identity (or values) and tentatively formulated role orientation is an important one because the traditional view of graduate training is that professional identity and role 
orientation remain relatively stable over time. In the present study, while professional values remained relatively constant, role orientation shifted slightly as faculty assimilated to the new setting.

\section{Stage Two: Encounter}

According to the enculturation model, faculty candidates select or attend to information during the hiring period, process this information, and formulate preconceptions regarding the new setting using predispositions (professional values and role disposition) as a frame of reference. To test this proposition, the study explored the manner in which new faculty formulated preconceptions during the encounter stage. First, from limited information described in the job notice, and from information sent by each department as individuals became job candidates, general impressions of the institution were formed. Then, each candidate focused on information in the form of norms, performance expectations, and descriptions of institutional mission presented by administrators and current faculty during the on-campus interviews. Salient features of the institution emerged differently for each candidate. Which features were attended to, or selected, depended, in part, on the graduate school experiences and predisposition of each candidate. Finally, as this information was processed, the study confirmed that primary subjects established a preconception framework complementing past experiences and individual values-- a framework also consistent with each candidate's role orientation. The preconception framework reported for each candidate was (a) Tom believed that the university was trying to upgrade its national reputation, but that equal value was placed on teaching and research; (b) John got the impression that the university supported strongly research and cared about students; and (c) Bill thought his training in graduate school was too far removed from teaching and he looked forward to working in an environment that supported teaching.

In comparing individual preconceptions, the uniqueness, or dissimilarity of each 
framework is evident. Yet, the preconceptions are relatively congruent with the predisposition reported for each individual. This suggests that individual preconceptions were unconsciously formulated to reflect the professional values and role disposition of each candidate. This suggests, also, that if cognitive distortions occurred during the interview and selection process-- i.e., if information encountered was not congruent with personal predispositions-- this information may have been unconsciously underwritten to affirm personal satisfaction of job choice and to facilitate individual assimilation. This proposition seems likely given that only positive perceptions of the institution were reported, and the new faculty formulated tangible performance goals, prior to entering the new setting, to reduce uncertainty about performance expectations. The goals formulated were congruent with each individual's predisposition-preconception framework, and their goal statements were consistent with their varying role orientations. Finally, the tangible performance scripts formulated for the first academic appointment year were not necessarily consistent with the actual performance expectations of the three study departments.

In summary, during the encounter stage the study found that new faculty were preoccupied with three developmental tasks: forming general impressions of the work setting, defining institutional expectations, and developing goals for what (they believed) performance expectations would be during the first academic appointment year.

\section{Stage Three: Adaptation}

According to the enculturation model, unrealistic impressions, expectations or goals may be formulated about the new setting as a result of the inter-mixing of personal predispositions with preconceptions during the encounter stage. During the adaptation stage, these anticipated expectations and experiences, and the performance scripts new faculty had formulated, were compared to the actual experiences they reported as formal socialization began. 
In the present study, the usefulness of the formal opportunities departments employed to socialize new members were suspect in addressing new faculty learning needs. Although these opportunities were perceived as occasions where additional information on departmental operations could be accumulated, the new faculty reported few deliberate supports were provided to assist them. By analyzing the informal processes by which new faculty were able to detect, diagnose and interpret the expectations of the institution and the work environment, three primary socialization dimensions arose: the work itself; the relationship network surrounding the work; and the climate in which work was performed.

\section{Socialization Dimensions of Work}

While the orientation of new faculty was perceived to be the primary responsibility of the chairperson, across the three departments, the chairpersons' styles were relatively uniform-- new faculty were allowed a great deal of autonomy in adopting to the environment. Thus, direction provided in trying to meet performance expectations was an extremely limited portion of the socialization experience for the three new faculty. Given such limited direction, new faculty drew from their student experiences as they became immersed in the realities of teaching: imitating, or modeling, the teaching styles of their graduate school mentors, or other graduate faculty; extracting, and experimenting with, teaching methods that had best met their learning needs in their undergraduate and graduate studies; and adopting attitudes, values, or performance characteristics they most admired and hoped to impart (e.g., a "love of learning," "enthusiasm for the subject matter," "placing student concerns above all else").

In addition to developing teaching style and methods, other work-related tasks with which the new faculty had to contend, included: defining work role expectations, balancing multiple role demands, and prioritizing time for multiple task performance. Coping with contrasts between personal performance expectations (personal goals and 
standards), and the reality encountered in performing actual work roles, also occupied a considerable portion of the new faculty's time.

Socialization Dimensions of the Social Network

The level of assistance provided in meeting work role requirements, and the level of encouragement provided as work roles were performed, varied considerably among the three study departments. This finding is supported by the perceptions new faculty reported regarding feelings of isolation, acceptance, and inclusion in their home departments. Supportive relationships with colleagues in Department A contributed to Tom's positive assimilation experiences. It may be that the positive level of acceptance and inclusion Tom experienced immediately were related, in part, to the fact that he was the department's first choice (as compared to the other two primary subjects). This is not meant to imply that the other two new faculty members automatically had difficult assimilation experiences; it suggests that the top candidate was a better known commodity, and that may have fostered more rapid association and relationships at the outset. Given that the nature of the hiring process was focused on finding the best match to particular department needs, when other than the top candidate was selected, attention might have been devoted to the following: introducing the new member to current faculty who had similar research interests, or those who shared similar research methodology; and introducing them to those who had an interest in the subject matter the new faculty member had been assigned to teach. In this sense, socialization would have fostered support networks for new faculty as they learned their work roles, responsibilities, and performance expectations.

\section{Socialization Dimensions of Department Climate}

In the study institution, the overarching values-- a respect for individuals; a concern with equity, or fairness in policies and practices; and the historic tradition and concern for teaching-- helped to build a strong and convergent institutional culture. Regardless of the strength of these values, current faculty generally indicated that the 
future mission of the university was unclear. Given such uncertainty, the study departments found it difficult to manage and to integrate diverse perceptions of the mission-- and to tolerate uncertainty in how various dimensions of faculty work could be appropriately supported, evaluated, and rewarded.

Debate over these issues extracted real costs in the functioning of departments, and new faculty socialization was often hindered by these conflicting aspects of the culture. Where conflicts were the strongest, the potential for sharing, supporting, and stimulating an intellectual environment within the department were reduced, and, the chances of sending mixed messages about performance expectations to new faculty were increased. This was especially true for Department $\mathrm{C}$, where Bill believed the institution implied, in certain instances, that the university had retained its priority for teaching, yet at other times, (to him) the message seemed reversed.

An unexpected finding of the study was the substantial variability in work climate among the three study departments, and the impact of department climate differences on new faculty. The data suggest that, in Department $C$, where work environment, faculty morale, and general climate were rated lowest across the three departments, the primary subject's assimilation experience was the most difficult. Similarly, in Department A, where the work environment, faculty morale and climate were generally rated the highest, the primary subject experienced the least difficulty in adapting to the new setting. Tom's disenchantment with the work environment in Department A came much later, and it was based on a specific equity issue emanating from his mid-year performance assessment.

In summary, during the adaptation stage, the study found that the assimilation of new faculty was encouraged, or inhibited, by three dimensions of the departmental environment: the work itself, the support network surrounding the work, and the climate in which work was performed. During this period, the new faculty were preoccupied with developmental tasks including: defining work role expectations, balancing multiple role 
demands, prioritizing time, and developing teaching styles and methods. The developmental tasks identified, in this study, are consistent with the findings of previous studies of new faculty development during the first academic appointment year (Boice, 1991; Feldman, 1984).

\section{Stage Four: Commitment}

In the enculturation model, as newcomers settle into the routine aspects of work, they begin to focus on establishing their niche, or place in the department; and as a result of this, a cultural learning process begins. How new faculty were able to detect features of the departmental subcultures, and how close their interpretations came to the assumptions and understandings of culture reported by current faculty were considered to test this proposition.

First, as the new faculty settled into the second semester, and as they questioned their status in relation to others, conflicts between their preconceptions and the reality encountered in the new setting arose. These cognitive conflicts (ideational influences) heightened the new faculty's sensitivities for exploring, diagnosing and interpreting cultural aspects of their home department.

Second, as they reflected upon experiences they did not expect to encounter in the new setting, they learned about the assumptions, beliefs, and practices of the academic community they had joined. The new faculty reported learning about the culture of their departments through conflicts they observed or heard faculty discuss in informal and formal meetings (socio-cultural influences).

Third, in all three cases, the perceptions of new faculty clearly reflected elements of culture cited previously by current faculty. New faculty detected these cultural features through informal communication, and by observing current faculty as sensitive issues were debated.

Finally, as they began to question preconceptions formulated about the institution, 
a cognitive or emotional response was triggered in two of the three new faculty in Departments $\mathrm{A}$ and $\mathrm{C}$. The responses demonstrated that the source of these conflicts differed dramatically, and the timing and intensity of the response varied, from individual to individual. Ultimately, though, the experiences of these new faculty supports the conclusion that dissatisfaction with the work setting does not automatically lead to decreased performance, and satisfaction with the work setting does not necessarily lead to increased performance.

This point can be better understood by examining the enculturation response of the two new faculty. By the end of the socialization period, Tom began to view his place in the department more carefully. When he first entered the new setting, performance standards were internalized already; he took pride in his efforts and achievements, and he set performance goals based on those standards. He believed the institution was one in which he would thrive, i.e., he perceived the institution as one in which he would be recognized and rewarded for his efforts. In this regard, and with his natural mistrust of institutions having been aroused with the Women's Center incident, he was critical of, or more sensitive to, his mid-year assessment. He perceived inequities in his evaluation in comparison to other, less productive, faculty and he speculated about how such evaluations might later impact on his advancement. Although he was clearly dissatisfied with these aspects of the work environment, he vowed to maintain his role orientation and productivity level; and he did not appear to make new value commitments. Rather, his response to the enculturation process seemed to be aimed at questioning the organization's attempt to alter his self-image. In the enculturation model, this type response is characterized as individuation.

In Department $\mathrm{C}$, Bill's role orientation was not congruent with the predominant role orientations of his department. Given his concern for affiliation, and for an acceptable performance assessment, he began to focus his efforts on acquiring new values, and in 
broadening his identity. While his role orientation was expanded to include research in a more significant way than he had anticipated, it is interesting to note that this change was accommodated by two factors: his dissertation experience had reinforced soundly his research potential-- and, he also came to realize that the department supported a lesser standard of productivity than he anticipated previously. In the enculturation model, this response is characterized as attachment.

In comparing Tom's and Bill's responses, in Department A, Tom was more successfully anchored in his position when he began his new faculty role and he defined his progress in terms of recognition. In Department C, Bill was not yet anchored in his position. He cared less about recognition and more about meeting expectations and living up to group standards-- even if this meant shifting his role orientation. In contrast to these two responses, in Department B, because John was preoccupied with completing his dissertation, his adaptation to the department was not yet complete-- at the time of the final interviews he was still unclear about the ways in which the department worked and he was only now beginning to form relationships with department colleagues. Most importantly, he concluded that while graduate school had helped him to develop particular skills, and to select his particular research emphasis, the experiences encountered during the organizational period had fostered the development of his professional identity.

\section{Conclusions: The Enculturation Model}

The present study was inspired by Tierney's work on institutional culture; by Van Maanen's general research on socialization; and by higher education studies that shed light on new faculty work role orientations, and the unique experiences of the first academic appointment year (Boice, 1991; Braskamp, Fowler \& Ory, 1984; Fink, 1984; Olsen, 1993). In contrast to these works, this study tested the explanatory power of a conceptual model of the enculturation of new faculty. This approach was taken for several reasons. First, the conceptual framework integrates theoretical constructs from disparate research 
into a more coherent view of the organizational entry process. Second, while organizational theory has separated the complex entry period into three stages-- prearrival, encounter, and adaptation-- an intensive review of the literature did not produce research delineating process factors involved in each stage. Finally, studies focused on socialization (the overt or deliberate, formal or informal structure) often overlook the reciprocal cultural learning process (the internal cognitive and affective enculturation response) which occurs as new faculty assimilate to the work setting. In the enculturation model, a fourth stage of organizational entry was proposed-- the commitment stage-- in which the dynamic enculturation response to socialization occurs. As the model was tested, refinements were made in the commitment stage of the model to descriptively approximate two process dimensions actualized in the study: role development and organization identification (Figure 4). Role development (re-defining, or adopting, the role orientation formulated in graduate school) drew the new faculty's attention in the first half of the adaptation period; and the commitment stage culminated with organizational identification (the level of integration of organization goals and personal goals). Other than these two refinements, the enculturation model accurately predicted the developmental stages and process components reported in the present study.

While the present study supports the explanatory power of the model, the findings indicate also that new faculty did not adapt at the same pace. The rate of assimilation was predicted on two factors: the level of experience primary subjects accumulated prior to entering the new setting, and the congruence of their role orientation to the predominant role orientation of the department. Thus, different levels of experience account for variations in the assimilation and in the timing of the enculturation response. Because of this, the enculturation response cannot be confined to the first academic appointment year.

In addition, a cautionary point should be made: the conceptual framework is a cognitive model of organizational entry. In this sense, the enculturation process cannot be 


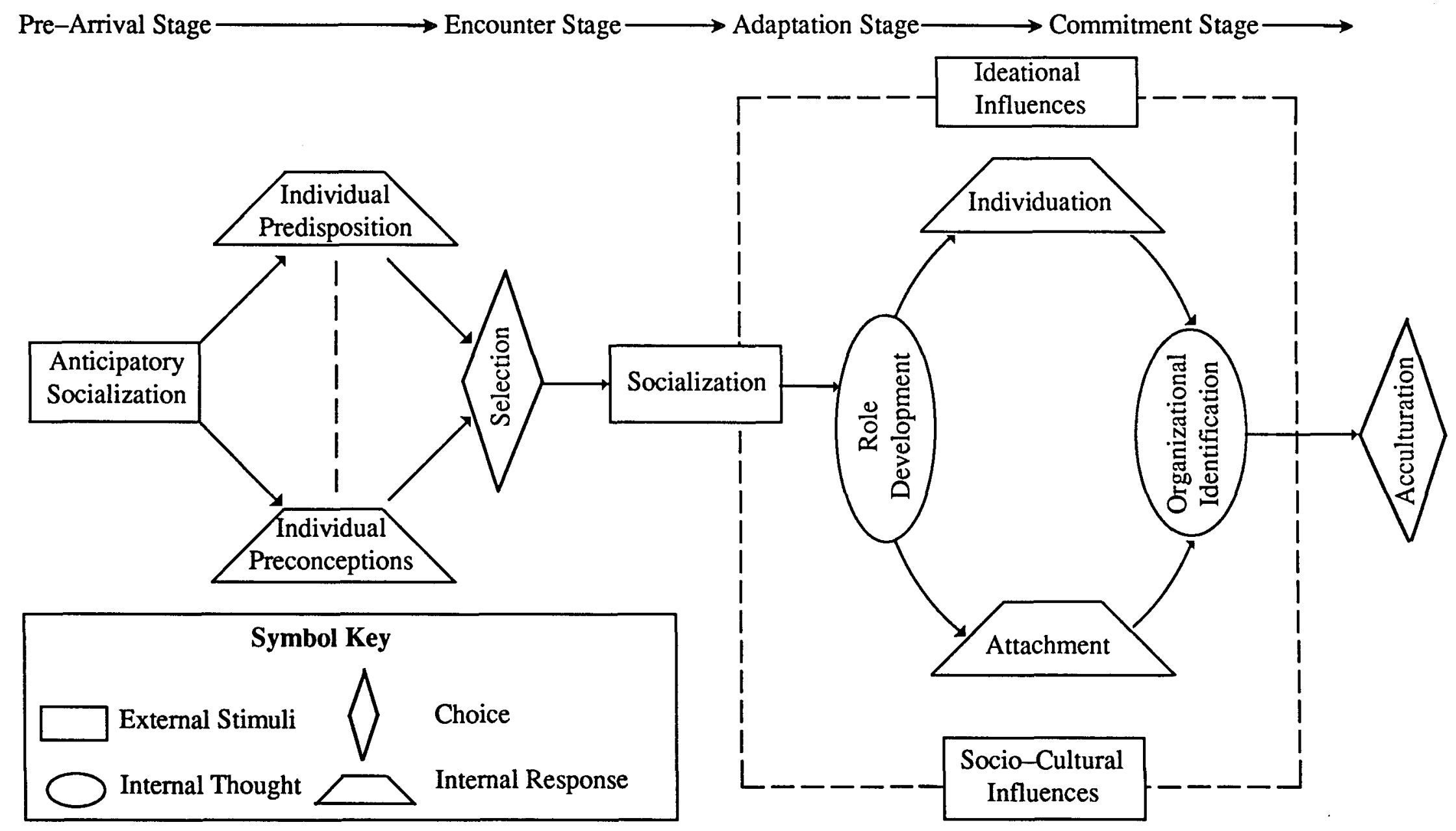

Figure 4: Enculturation Model (Refined) 
fully understood, and new faculty responses or development cannot be predicted, without examining the internal thought process of newcomers. The model stresses also the relationship between external stimuli and individual response. Thus, newcomers make unconscious, and conscious, choices about their behavior which may not be evident unless examined through the eyes of the newcomer.

Finally, the model suggests, additionally, that as new faculty continue beyond the first academic appointment year, acculturation will occur. The present study did not trace new faculty development through to this level of assimilation. For studies tracing acculturation beyond the first year, according to the enculturation model, inter-cultural borrowing will occur. This suggests that where the enculturation response was attachment, the faculty member will assimilate and support the norms and values of the local culture; where individuation occurs, the faculty member will assimilate, also, and introduce new norms and values-- resulting in new or blended cultural patterns.

\section{Limitations of the Study}

1. It is important to emphasize the exploratory nature of the model and the general findings of the study. Given that the study traced the experience of only three new faculty, in one institution, results may not be generalizable without additional replication and extension.

2. Qualitative methods measuring self-reported perceptions, and changes in attitudes, may not be as objective as quantitative methods, but the variety of methods, and the mix of quantitative/qualitative measures used in the study guarded against the weakness of any one criterion.

3. Although the disciplines studied differed significantly in their knowledge base and subject matter, these contextual differences were not examined in order to preserve the anonymity of the three primary subjects. 
4. Greater differences may have been found in socialization practices if the study had involved departments beyond the social sciences or humanities. Consequently, the organizational entry model, and the process experiences of new faculty, may differ dramatically in scientific or applied fields.

5. Certain sections of the survey would be improved by substituting interval scales for Likert scales. For instance, where response categories asked respondents to indicate if the environment had "greatly improved," "improved," "remained unchanged," "worsened" or "greatly worsened," an interval scale would have provided a more valid measurement. Also, the averages for this small population sample were occasionally skewed by one respondent. The survey can be improved by incorporating mechanisms to explain and treat aberrations. Finally, in measuring climate and faculty morale, each index should have included multiple statements for respondents to answer to yield a better description of climate and morale.

6. By having new faculty maintain a $\log$ of their entry experiences, the socialization process became something upon which they reflected regularly. This qualitative approach, coupled with monthly interviews, likely increased meta-cognitive awareness of the entry experience. This may have assisted new faculty, in turn, to take conscious control of their own learning processes by seeking specific information and support for particular needs. 7. Finally, emotional support may have been a direct by-product of the monthly interviews. The simple act of listening to the needs and concerns of new faculty may have made their adjustment different from the usual experience.

\section{Implications for Practice}

The findings of the study have a broad array of implications for practice:

1. The study suggests a cumulative learning period: individuals build upon, and draw from their graduate training experiences in assuming the role of assistant professor. Thus, 
graduate training can be improved by examining carefully the needs of new faculty during organizational entry; and new faculty socialization can be improved by paying attention to the next stage of development, or particular learning needs, of individual faculty. In the first case, graduate schools should consider shifting from a nearly exclusive content-based training program to a more balanced process-based socialization program.

2. Given that informal communication encounters were the primary means by which new faculty learned, or misinterpreted performance expectations, departments should frequently and clearly disseminate information about performance standards. In the study, performance standards were vague. To reduce uncertainty and misinterpretation of expectations, and to support new faculty as teaching approaches are developed, whenever possible, informal communication opportunities and information exchange should be encouraged; and occasions for observing, being observed, and collaborating in teaching should be promoted, at least during the first semester of teaching.

3. The chairperson, in particular, needs to take an active role in providing the communication and teaching support opportunities cited above. An active support role is significantly different than the passive role chairpersons exercised in this study. In all three departments, the chairpersons assumed that being available, accessible, or open to requests for support from new faculty was a sufficient, unobtrusive support strategy. The paradox is that new faculty may be reluctant to make their needs known, fearing they would be judged as incompetent, and in certain cases, new faculty may not be able to articulate their needs without being prompted to share their adjustment experiences.

4. Given that the chairperson can play an important part in reducing role uncertainty or role ambiguity, and promote general assimilation of newcomers to the work environment and performance requirements, more consideration should be given to delineating formally a chairperson's responsibilities in this regard. 
5. New faculty work experiences may be so dissimilar in content that individuals must learn new behaviors in the context of self-identified needs. Thus, varied types of support, based on needs arising during the adaptation period, are more desirable than standardized approaches.

6. Effective mechanisms to improve social networking for emotional support; strategies to increase instrumental aid, and information, in designing courses and tests; and assistance in developing or experimenting with teaching methods, should be designed.

7. Given that factors related to climate affect the overall functioning of an academic department, which in turn may affect the assimilation experiences of new faculty, current faculty might be enlisted to define ways in which the collegial and intellectual climate of their department can be improved. Such a dialogue may lead to identifying consensual norms for performance, and collegial expectations for assisting in the socialization of new faculty. These norms could become important in clarifying performance standards for the first academic appointment year, and in providing newcomers a realistic job preview.

8. The most important implication may be for the new faculty themselves, and for those who help prepare graduate students. It would be beneficial for new faculty to enter an organization with an understanding of the organizational entry period and what they may encounter.

\section{Implications for Further Research}

The present study was not intended to cover a broad sample of faculty, nor was it intended solely to test differences in the socialization experiences of new faculty. Rather, the study tested a range of theoretical concepts, and delineated process factors involved in the organizational entry period, to provide a conceptual framework for continued research in this area.

Using the conceptual framework as a basis for continued studies, there are a number of directions in which future research might proceed. The first arises from the fact 
that contextual differences of the three disciplines, in this study, were not examined to preserve the anonymity of the three primary subjects. Investigating the organizational entry process in the same discipline, across several institutions, would support a more detailed investigation of subcultural variations in each discipline.

Second, the present study investigated the organizational entry process in three departments within the humanities and social sciences. Attention should be given to comparing the process experiences of new faculty in scientific and applied fields.

Third, to account for possible contributions to the positive assimilation the qualitative methods in this study may have caused, a control group can be incorporated in the research design. Comparing beginning and end of the year control group data may help account for personal tracking effects.

Fourth, a longitudinal study of continued assimilation experiences would be needed to explain the outcomes of the enculturation response differences reported in this study. For instance, the cosmopolitan-local dimensions frequently reported in the literature on faculty in higher education, was not a useful typology by which new faculty role orientations could be described. It may be that such orientations develop over time, and that these orientations will approximate the enculturation responses. Where an attachment response is noted, an individual may eventually adopt a local orientation; and, where the individuation response occurs, a cosmopolitan orientation may develop.

Finally, the findings of the study support the notion that organizational subcultures, within the same institution, can produce variable influences in new faculty development. Future studies might focus on the academic departmental climate as a unit of analysis to determine how different climates are associated with differences in the assimilation of new faculty. 
APPENDIX 1

DEFINITION OF TERMS 


\section{APPENDIX 1 DEFENITION OF TERMS}

Acculturation -- the extent to which the norms and values of the local culture are either assimilated or exchanged by new organization members; resulting in either new or blended cultural patterns.

Anticipatory Socialization -- the developmental period in which professional values and norms are acquired and role disposition is formulated.

Enculturation -- the reciprocal learning process that occurs during organizational entry, by which new members diagnose the culture's normative-value system, and respond dynamically to this reciprocal learning process.

Individuation and Attachment -- affective and developmental responses to the goals and values of an organization, and to one's role in relation to these goals and values. When individuation occurs, an individual's response is aimed at questioning the organization's attempt to alter self-image, or work role orientation. When attachment occurs, an individual's efforts are focused on acquiring new self-images, or work role orientation.

Institutional Culture -- norms, values, practices, beliefs and assumptions rooted partially in history, which guide the behavior of individuals and groups and which are continually reshaped as organizational members learn to cope with problems of external adaptation or the internal integration of collective understandings.

Organizational Climate -- perceptions or conditions related to morale and general work environment satisfaction.

Organizational Commitment -- the affective attachment to the goals and values of an organization, to one's role in relation to these goals and values, and to the relative strength of an individual's identification with and involvement in the organization (Mowady, Porter, \& Steers, 1982).

Organizational Identification -- an understanding of organizational goals coupled with the level of integration of organization goals with personal goals and values (Hall \& Schneider, 1972)

Preconceptions -- perceptions of a new setting formulated during the hiring process, using predispositions as a frame of reference.

Predispositions -- the values acquired, and the role disposition formulated, during graduate training. 
Socialization -- the overt or deliberate, formal or informal, structure by which an individual comes to understand the values, abilities, expected behavior, and social knowledge essential for assuming an organizational role and for appropriate participation as an organizational member.

Subculture -- a subset of an organization's members who interact regularly with one another, identify themselves as a distinct group within the organization, share a set of problems commonly defined to be the problems of all, and routinely take action on the basis of collective understandings unique to the group (Van Maanen \& Barley, 1985). 
APPENDIX 2

CONSENT FORM FOR PARTICIPANTS 


\section{APPENDIX 2 \\ CONSENT FORM FOR PARTICIPANTS}

\section{Description of Purpose}

The overall purpose of this study is to analyze the enculturation processes by which new faculty adjust and respond to the socializing efforts of a particular academic institution and to various disciplinary subcultures within this university setting.

Two sets of subjects will participate: those termed secondary subjects (current faculty) and those termed primary subjects (new faculty initiates).

The methods used in the study will include an initial survey for current faculty, administrative interviews, observation, and document analysis. In addition, to gather ongoing personal perceptions of primary subjects both a log format and interviews will be used. Interviews will include both a structured and open-ended format. Interviews will be taped with prior permission.

\section{Safeguarding Procedures}

Neither the institution, nor the names of faculty participants, will be identified in any reports of this study. Uncoded transcript material will not be shared with the department or institution.

\section{Consent Procedures}

Faculty members in each discipline will be invited to participate. No penalty is associated with refusal to participate. Individuals will be free to withdraw their participation at any point during the study.

I freely and voluntarily consent to participate in the research project: 
APPENDIX 3

\section{CURRENT FACULTY QUESTIONNAIRE}




\section{APPENDIX 3 \\ CURRENT FACULTY QUESTIONNAIRE}

Dear Faculty Member:

The attached questionnaire is being distributed in connection with a study currently being conducted in a number of academic departments in your institution.

The general purpose of this study is to examine the socialization of new faculty within the context of institutional culture and academic subcultures.

The study will explore the shared assumptions or collective understandings which underlie the institutional culture, and the variations or patterns of academic subcultures within a number of academic departments.

I am writing to ask your cooperation and assistance. I would appreciate your taking the time to complete the enclosed questionnaire.

All information will remain confidential. Neither the institution, nor the department, will be identified in any reports of this study.

If you have any questions regarding the study, please do not hesitate to contact me at

Thank you for your cooperation.

Sincerely,

Teryl ann Rosch 


\section{Current Faculty Questionnaire}

1. Department:

2. Number of Years with this institution/department

3. Academic Rank (please check one):

Professor
Associate Professor
Assistant Professor
Instructor

4. What is the average number of hours per week that you spend on tasks related to your profession? Include in your estimate the time spent on all tasks: research, teaching, administration, and service. Include reading related to this work.

hours

5. Of the total amount of time you spend working on tasks related to your profession, what percentage of time do you actually spend, during the school year, on the tasks listed below? (Estimate to the nearest 5\%. After finishing, please check to determine if the total of percentages $=100 \%$ ).

\section{TASK}

A. Teaching and training (e.g., lecture preparation; office hours for students; advising; contacts with teaching assistants).

B. Research, scholarly activity or technical activity

(e.g., performing an experiment; writing an article, etc.).

C. Departmental administrative work (e.g., managing academic/nonacademic staff; serving on departmental committees).

D. University administrative work outside the department (e.g., university committees).

E. Service Tasks (e.g., consulting; communicating with outside groups; journal editing).

\section{$\%$ Actual Time}
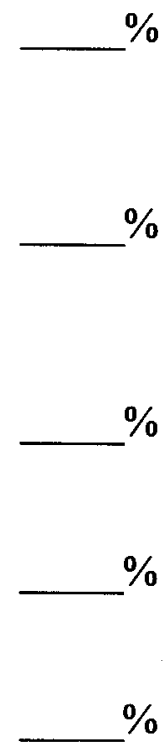
F. Other Tasks (Please specify):

Total for all tasks $=100 \%$

6. Do you anticipate the total distribution of time, as noted above, to remain constant for this academic year?

Yes No

IF NO, why not? (Please comment):

7. In your department are faculty "under pressure" to participate in research?

Yes No

IF YES, what is the source of this pressure and how do you perceive it to be communicated? (please explain)

8. In the last five years have you perceived any pressure to increase involvement in research?

Yes

No

If yes, how would you describe this added pressure?

There is a great deal more pressure

There is some added pressure 
9. Please rate the relative importance or value which the various tasks listed below have to you. Do this by distributing 100 percentage points among the tasks so that the larger the number of points alloted to a task represent the ideal \% of time you would devote to this task. (Estimate to the nearest 5\%. After finishing, please check to determine if the total of percentages $=100 \%$ )

\section{TASK}

\section{\% Ideal Time}
A. Teaching and Training

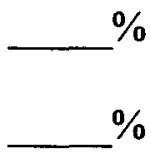
B. Research or technical work
C. Administrative work in department

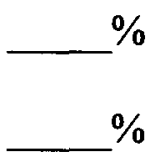
D. Administrative work outside department

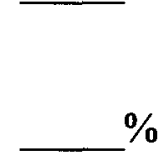 organizations)

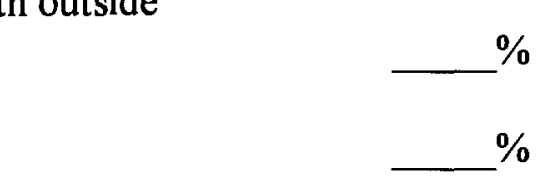
F. Other (please specify)

Total for all tasks $=100 \%$

10. Please indicate, by marking the appropriate response, the changes you have noticed in your institution in the last five years.

$\begin{array}{clccc}\begin{array}{c}\text { Greatly } \\ \text { Improved }\end{array} & \text { Improved } & \begin{array}{c}\text { Remained } \\ \text { unchanged }\end{array} & \text { Worsened } & \begin{array}{l}\text { Greatly } \\ \text { worsened }\end{array}\end{array}$

a. The work environment has

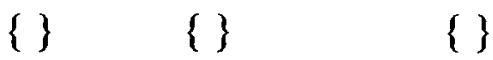

\{\}

b. The faculty morale has

11. Please indicate, by marking the appropriate response, the changes you have noticed in your department in the last five years.

$\begin{array}{lllll}\begin{array}{l}\text { Greatly } \\ \text { Improved }\end{array} & \text { Improved } & \begin{array}{l}\text { Remained } \\ \text { unchanged }\end{array} & \text { Worsened } & \begin{array}{l}\text { Greatly } \\ \text { worsened }\end{array}\end{array}$

a. The work environment has 
b. The faculty morale has
\{\}
\{\}
\{\}

\{\}

12. Please indicate the degree to which procedures are formalized in your department i.e., the extent to which there exists relatively fixed and explicit rules concerning the various activites listed below.

\section{Procedures for:}

a. hiring academic staff

b. orienting new faculty

c. allocation of teaching

d. assessment of teaching

e. assessment of students

\section{YES / SOMEWHAT / NOT AT ALL/ ?}

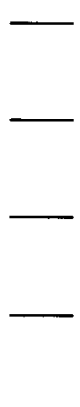

13. Describe the atmosphere or climate of your department by checking the following items ( $8=$ high, $1=$ low):

a. friendly $\frac{}{8}-\frac{1}{7} \frac{1}{6} \frac{1}{5} \frac{1}{4} \frac{1}{3} \frac{1}{2} \frac{1}{1}$ unfriendly

b. rejecting $/ \frac{1}{1} \frac{1}{2} \frac{1}{3} \frac{1}{4} \frac{1}{5} \frac{1}{6} \frac{1}{7} \frac{1}{8}$ accepting

c. cold $\quad / \frac{1}{1} \frac{1}{2} \frac{1}{3} \frac{1}{4} \frac{1}{5} \frac{1}{6} \frac{1}{7} \frac{1}{8}$ warm

d. satisfying $/ \frac{l}{8} \frac{l}{7} \frac{1}{6} \frac{l}{5} \frac{l}{4} \frac{l}{3} \frac{/}{2} \frac{l}{1}$ frustrating

e. unenthusiastic $/ \frac{1}{1} \frac{1}{3} \frac{1}{4} \frac{1}{5} \frac{1}{6} \frac{1}{7} \frac{1}{8}$ enthusiastic

f. $\quad$ interesting $\frac{1}{8} \frac{l}{7}-\frac{1}{6} \frac{1}{5} \frac{1}{4} \frac{1}{3} \frac{1}{2} \frac{1}{1}$ boring

e. nonproductive $/ \frac{1}{1} \frac{1}{3} \frac{1}{4} \frac{1}{5} \frac{1}{6} \frac{1}{7} \frac{1}{8}$ productive 
g. $\quad$ successful $/ \frac{1}{8} \frac{1}{7} \frac{1}{6} \frac{1}{5} \frac{1}{4} \frac{1}{3} \frac{1}{2} \frac{1}{1}$ unsuccessful

14. According to your own experience, and in your own words, what is the university really like? What is the department really like? (Use the reverse side if necessary.)

Thank you for taking the time to complete this questionnaire.

PLEASE NOTE: RETURN THE QUESTIONNAIRE TO YOUR DEPARTMENT SECRETARY IN THE ENVELOPE PROVIDED BY

To insure confidentiality, please seal the envelope. 
APPENDIX 4

NEW FACULTY LOG FORMAT 


\section{APPENDIX 4 \\ NEW FACULTY LOG FORMAT}

The purpose of the log is to provide structure for written comments regarding what you encounter within the university, or department, in the normal course of your entry period during the fall semester.

The log is not intended to be a complete recording of your daily schedule. In fact, many things can happen in the course of a week that are not of interest to the study. The purpose of the log is to gather information regarding what you perceive as important elements of your socialization.

What is of particular interest are your affective and cognitive reactions to what you encounter. The following questions may assist you in determining the kinds of entry statements to be recorded:

What have you experienced or encountered in the department, or university, which has met your general expectations regarding your role, or regarding the way the department (or institution) operates?

$\square$ What have you experienced or encountered in the department, or university, which you did not expect to encounter?

W Who are the people you see on a regular basis?

What are the meetings you attend (informal or formal) over the course of a week?

PLEASE NOTE: For the last two questions, you may choose to record such information on a daily basis. For example:

9/13/ Attended Departmental Meeting

Comment:

If you have no comment regarding the meeting, please write no comment.

The first two questions are more reflective and may require that you consider each at the end of the day. You can choose to write a short paragraph, or a longer statement. 


\section{REFERENCES}

Abelson, P.H. (1967). Justifying acacdemic research. Science, 4, 157-167.

Arnold, D.O. (Ed.). (1970). The sociology of subcultures. New York: The Glendessary Press.

Baldwin, R.G., \& Blackburn, R.T. (1981). The academic career as a development process: Implications for higher education. Journal of Higher Education, 52, 598614.

Becher,T. (1987). The disciplinary shaping of the profession. In B. Clark, ed., The academic profession. Berkley: University of California Press.

Becker, H.S. (1964). Personal changes in adult life. Sociometry, 27, 40-53.

Bess, J. (1978). Anticipatory socialization of graduate students. Research in Higher Education, 8 , 289-317.

Bess, J. (1982). University organization: A matrix analysis of the academic professions. New York: Human Services Press.

Berger, P.L., \& Luckmann, T. (1966). The social construction of reality. Garden City, NY: Doubleday.

Biglan, A. (1973). The characteristics of subject matter in different academic disciplines. Journal of Applied Psychology, 57, 195-203.

Boice, R., \& Thomas, C.T. (1989). Diagnosing academic culture. Journal of Staff, Program and Organizational Development, 7, 165-171.

Boice, R. (1991). New faculty as colleagues. International Journal of Qualitative Studies in Education, 4, 29-44.

Boice, R. (1992). The new faculty member. California: Jossey-Bass, Inc.

Bowen, H.R., \& Schuster, J.H. (1986). American professors: A national resource imperiled. New York: Oxford University Press. 
Bragg, A.K. (1976). The socialization process in higher education. NIE: Department of Health, Education and Welfare (\#132909).

Braskamp, L.A., Fowler, D.L., \& Ory, J.C. (1984). Faculty development and achievement : A faculty's view. Review of Higher Education, 1, 205-222.

Brim, O.G. (1966). Socialization through the life cycle. In O.G. Brim, \& S. Wheeler (Eds.), Socialization after childhood: Two essays New York: Wiley, 1-49.

Brown, J.S., Collins, A., \& Duguid, P. (1989, January/February). Situated cognition and the culture of learning. Educational Researcher, 8, 32-42.

Clark, B. (1963). Faculty Culture. In T.F. Lunsford, (Ed.). The study of campus culture. Colorado: Western Interstate Commission for Higher Education.

Clark, B. (1975). The organizational saga in higher education. In J.V. Baldridge, \& T. Deal (Eds.), Managing change in educational organizations. Berkeley:McCutcheon, 98-108.

Clark, B. (1980, March)). Academic culture. Working paper, 42, Yale University: Higher Education Research Group.

Corcoran, M, \& Clark, S.M. (1984). Professional socialization and contemporary career attitudes of three faculty generations. Research in Higher Education, 20, 131-153.

Cornwall, J.R, \& Grimes, A.J. (1987, May). Cosmopolitan-local: A class-lagged correlation analysis of the relationship between professional role orientation and behaviors in academic organizations. Journal of Human Relations, 40, 281-297.

DeVries, D.L. (1970). The relationship of departmental and personal role expectations to the role behaviors of university faculty members. University of Illinois: Ph.D. dissertation.

Enz, L.D. (1986). The moderating effects of value similarity and company philosophy on the climate-commitment relationship. Journal of Applied Psychology, 68, 193 200.

Feldman, D.C. (1981). The multiple socialization of organization members. Academy of Management Review, 6, 309-318.

Fink, L.D. (1984). The first year of college teaching. New Directions for Teaching and Learning, 17, San Francisco: Jossey-Bass, Inc. 
Finkelstein, M.J. (1984). The American academic profession: A synthesis of social inquiry since World War II. Columbus: Ohio State University Press.

Freedman, M.B. (1979). Academic culture and faculty development. Berkeley, California: Montaigne.

Gamst, F.C., \& Norbeck, E., eds., (1976). Ideas of culture: Sources and uses. New York: Holt, Rinehart, and Winston.

Glauser, B.G., \& Strauss, A.L. (1967). The discovery of grounded theory: Strategies for qualitative research. Chicago: Aldine.

Glauser, B.G., \& Strauss, A.L. (1971). Status passage. Chicago: Aldine.

Geertz, C. (1973). The interpretation of cultures. New York: Basic Books.

Goodenough, W.H. (1971). Culture, language, and society. Reading Mass: AddisonWesley.

Gotlieb, D.J. (1961, December). Processes of socialization in American graduate schools. Social Forces, 40, 127-140.

Hall, D.T., and Schneider, B. (1972). Correlates of organizational identification as a function of career patterns and organizational types. Administrative Science Quarterly, 15, 176-189.

Honey, P., \& Mumsford, A. (1989). Incremental opportunities for learning. The manual of learning opportunities. Berkshire: Maidenhead.

Hossler, D. (1988). An investigation of knowledge claims supporting goal based planning and organizational culture as keys to excellence in educational organizations. Indiana University: Paper funded by the Proffit Foundation

Hughes, E.C. (1958). Men and their work. Glencoe, IL: Free Press.

Kuh, G.D., \& Whitt, E.J. (1988). The invisible tapestry: Culture in American colleges and universities. ASHE-ERIC Higher Education Report.

Lawler, E.E. (1973). Motivation in work organizations. Belmont, CA : Brooks/Cole.

Light, D. (1974, Winter). Introduction: The structure of academic professions. Sociology of Education, 47, 2-27. 
Lincoln, Y.S. (1986, Spring). The ladder and the leap. Education Horizons, 113-116.

Lincoln, Y.S., \& Guba, E.G. (1985). Naturalistic inquiry. Beverly Hills, CA: Sage Publications.

Louis, M.R. (1980). Surprise and sensemaking: What newcomers experience in entering unfamiliar settings. Administrative Science Quarterly, 25: 226-250.

Masland, A. (1985). Organizational culture in the study of higher education. The Review of Higher Education, 8, 157-168.

Mix, M.C. (1971). Toward a theory of socialization into the academic profession. State University of New York at Buffalo: Ph.D. dissertation.

Moore, W.E. (1969). Occupational socialization. In D. Goslin (Ed.). Handbook of socialization theory and research. Chicago: Rand McNally, 861-883.

Mowday, R., Porter, L., \& Steers, R. (1982). Organizational linkages: The psychology of commitment, absenteeism, and turnover. New York: Academic Press.

Olsen, D. (1993, July/August). Work satisfaction and stress in the first and third academic year of academic appointment. Journal of Higher Education, 64, 453-471.

Ruscio, K.P. (1987). Many sectors, many professions. In B. Clark (Ed.). The academic profession. Berkley: University of California Press.

Satow, R.L. (1975). Value-rational authority on professional organizations: Weber's missing type. Administrative Science Quarterly, 20, 526-531.

Schein, E.H. (1985). Organizational culture and leadership. San Francisco: JosseyBass, Inc.

Shibutani, T. (1961). Society and personality. Englewood Cliffs: Prentice-Hall.

Simpkins, T.J. (1977). Non-formal education and development: Some critical issues, $\underline{8}$, Manchester: Department of Adult and Higher Education.

Smart, G.R. (1978). Career roles of research university faculty. Toronto: Paper presented at the meeting of the American Educational Research Association.

Sorcinelli, M.D. (1985). Faculty careers: Satisfactions and discontents. To Improve the Academy, 4, 44-62. 
Tierney, W.G. (1987). Facts and constructs: Defining reality in education organizations. The Review of Higher Education, II, (1), 61-73.

Tierney, W.G. (1988). Organizational culture in higher education: Defining the essentials. Journal of Higher Education, 59, (1), 2-21.

Van Maanen, J. (1976). Breaking in: Socialization to work. In R. Dubin (Ed.). Handbook of work, organization, and society. Chicago: Rand McNally, 67-130.

Van Maanen, J. (1978, Summer). People processing: Strategies of organizational socialization. Organizational Dynamics, 19-36.

Van Maanen, J., \& Barley, S.R. (1985). Cultural organizations: Fragments of a theory. In P.J. Frost, eds., Organizational Culture California: Sage Publications.

Vroom, V.H. (1964). Organizational choice: A study of Pre- and post-decision processes. Organizational Behavior and Human Performance, 1, 212-225.

Wanous, J.P. (1977). Organizational entry: Newcomers moving from outside to inside. Psychological Bulletin, 84, 601-618.

Weiner, Y. (1982). Commitment in organizations: A normative view. Academy of Management Review, Z, 418-428.

Wilkins, A. (1983, Autumn). The culture audit: A tool for understanding organizations. Organizational Dynamics, 24-38. 


\section{VITA}

The author grew up in Chicago, Illinois, and attended DePaul University where she received the Bachelor of Arts degree in 1972, and the Master of Arts degree in human services and counseling, in 1982. During a twelve year period, she served also in various administrative capacities at DePaul University, including Associate Dean of Students for two campuses.

In 1985, she joined Roosevelt University (Chicago, Illinois) as Assistant to the Vice President for Student Services and was admitted to doctoral candidacy in the department of Educational Leadership and Policy Studies at Loyola University of Chicago. During this period, she also served as intern to the Dean of the Graduate School and as graduate instructor in the Institute for Industrial Relations at Loyola University.

In 1991, she was appointed Executive Assistant to the President of Roosevelt University and Assistant Secretary to the Board of Trustees. She was promoted to her current position at Roosevelt University in 1993. As Executive Director of the Educational Partnership, she develops and supervises college preparation programs for high school students and educational leadership programs for Chicago high school principals, teachers, and local school councils. 


\section{DISSERTATION APPROVAL SHEET}

The dissertation submitted by Teryl ann Rosch has been read and approved by the following committee:

Dr. Jill Reich

Professor \& Chairperson, Psychology

Loyola University of Chicago

Dr. Francis J. Catania

Dean of the Graduate School

Loyola University of Chicago

Dr. Terry E. Williams

Associate Professor, Educational Leadership and Policy Studies

Loyola University of Chicago

The final copies have been examined by the directors of the dissertation and the signature which appears below verifies the fact that any necessary changes have been incorporated and that the dissertation is now given final approval by the Committee with reference to content and form.

This dissertation is, therefore, accepted in partial fulfillment of the requirements for the degree of Doctor of Philosophy.
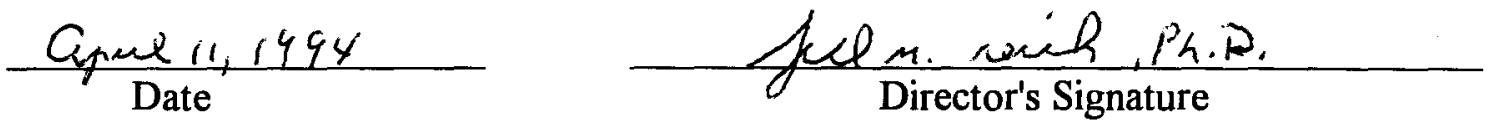